1285.23939

NASA CR 83098

\title{
CAPTURE OF \\ LIQUID HYDROGEN BOILOFF \\ WITH \\ METAL HYDRIDE ABSORBERS
}

FINAL REPORT

PREPARED FOR

NATIONAL AERONAUTICS AND SPACE ADMINISTRATION

JOHN P. KENNEDY SPACE CENTER

CONTRACT NAS10-10625

WORK PERFORYED BY:

ERGENICS, INC

WYCKOFF, NEW JERSEY 
Page No.

LIST OF FIGURES

LIST OF TABLES ii

ABSTRACT iii

I. EXECUTIVE SUMMARY 1

II. INTRODUCTION T

A. Background 7

B. Hydride Applications at KSC 8

C. Capture Demonstrations 11

III. APPROACH 12

A. Task 1-System Performance Requirements 14

B. Task 2 - Hydride Alloy Selection 17

C. Task 3 - Hydride Container Design 31

D. Task 4 - Alloy/Container Design Verification Test 34

E. Task 5 - Hydride Alloy Manufacture 36

F. Task 6 - Container Construction and System Assembly 38

G. Task 7-System Test 42

H. Task 8 - Report Preparation 45

I. Task 9 - Proof of Concept Demonstration \& Project 45 Review

IV. FOLL SCALE SYSTEM 46

V. FINAL COMMENTS AND RECOMMENDATIONS 52

ACKNOWLEDGEMENTS

REPERENCES $\quad 54$

APPENDIX A-1 


\section{LST OF FIGURES}

FIGURE NOMBER

PAGE NO.

1

2

3

4

5

6

7

8

9

10

11

12

13

14

15

16

17

18

19
Cumulative Annual Boiloff at KSC

9

Off-loading Boiloff Rate Profile

Hydride and Boiloff Profile Comparison

16

Comparative Kineties for Three Hydrides

18

Temperature Dependence of Kineties for LaNi

19

Absorption Kineties for LaNi3.8Fe1.2

19

Absorption Kineties for LaNi $47 \mathrm{SnO}_{0.3}$

20

Absorption Kineties for $\mathrm{LaNi}_{3} \mathrm{Co}_{2}$

20

Reduced Pressure Kineties of LaNi4.9Al0.1

21

Dynamie and Statie Isotherms for LaNi4.6 $\mathrm{Al}_{0.4}$

22

Statie Isotherm for LaNi3.8Pe1.2

23

Statie Isotherm for LaNi4. $15 n 0.3$

23

Dynamie Isotherm for CaNi4.9Al0.1

25

Dynamie Isotherm for LaNi3. $\mathrm{Co}_{2}$

26

Dynamie Isotherm for $\mathrm{LaNi}_{4.7} \mathrm{Al}_{0.3}$

27

Statie Isotherm for LaNi 4.9 I $_{0.1}$

27

Dynamie isotherm for LaNis

28

Statie Isotherm for LaNi . $_{.6} \mathrm{Al}_{0.4} \mathrm{~T}-88855-2$

Dynamie Van't Hoff Diagrams for Five Alloys 29

Boiloff Capture Device Engineering Drawing 33

Small Coil Absorption Performance Curve 36

Isotherms for LaNi4.6 $\mathrm{Al}_{0.4} \mathrm{~T}-88860-2$

37

Static and Dynamie Van't Hoff Diagram for T-88860-2 37

Schematie of Demonstration Test Set-up 40

Hydrogen Boiloff Capture System 


\section{LIST OF FIGURES (CONTINUED)}

FIGURE NOMBER

Remote Control Panel for KSC Demonstration

Balloon Poisoning Effect on Small Test Coil
Large Coil Absorption Performance

Boiloff Capture System Pietorial

LH $_{2}$ Dewar Piping Diagram W/Capture Hook-up

Detail of Figure 31 Showing Hook-up Point
Capture System Integration Sehematie
PAGE NO.

41

41

44

48

49

50

51 
PAGE NO.

1 Computer Run for $10 \mathrm{ft}$. dia., $10 \mathrm{ft}$. stack, $1 \%$ Hydride

2 Computer Run for $10 \mathrm{ft}$., dia., $10 \mathrm{ft}$. stack $1.2 \%$ Hydride

Computer Run for $12 \mathrm{ft}$., dia., $15 \mathrm{ft}$. stack $1.4 \%$ Hydride 


\begin{abstract}
Standard operating procedure at the Kennedy Space Center (KSC) for the Space Shuttle Program requires the storage and transfer of substantial quantities of liquid hydrogen $\left(\mathrm{LH}_{2}\right.$.). Vaporized liquid, routinely lost during these transfer operations, is vented to the atmosphere or burned in the burn pond, and represents a significant fraction of the total hydrogen-fuel used for each launch. This report describes a procedure which uses metal hydrides to capture some of this low pressure ( $<1$ psig) hydrogen for subsequent reliquefaction. Of the five normally occurring sources of boil-off vapor the stream associated with the off-loading of liquid tankers during dewar refill was identified as the most cost effective and readily recoverable. The design, fabrication and testing of a proof-of-concept capture device, operating at a rate that is commensurate with the evolution of vapor by the target stream, is described. Liberation of the captured hydrogen gas at pressures $>15$ psig at normal temperatures (typical liquefier compressor suction pressure) are also demonstrated. A payback time of less than three years is projected.
\end{abstract}




\section{EXECUTIVE SUMMARY}

\section{A. Purpose}

The volume of liquid hydrogen which will be used during the late 1980's by the Space Shuttle program at the Kennedy Space Center is expected to exceed 10 million gallons per year. Of this 10 million gallons only about 7 million will actually be used as propellant. The balance, over 3 million gallons per year, will be lost as boil of $f$ in various transfer and storage operations at launch pads $39 \mathrm{~A}$ and $\mathrm{B}$.

The highest valued use for hydrogen boiloff identified during the preparation of the unsolicited proposal which led to this work was as feed stock for reliquefiers. Unfortunately, the boiloff rates during the intermittent loss periods are too high for economically sized equipment to reliquefy in "real time". The loss rates are also too high for conventional gas compressors and storage equipment to capture the boiloff vapor.

Metal hydride hydrogen absorbers are fast enough to capture the boiloff hydrogen during many of the loss episodes at LC-39. Hydrides are fairly expensive however, so the only losses which may be economically captured are those which are large and occur frequently. This leads to many cycles of use for the hydride and a large credit for hydrogen capture.

The most attractive use for hydrides identified in this program is for capturing the losses which occur during the transfer of liquid hydrogen from truck and rail cars. These "off-loading" operations will occur about 170 times per year(1). Other opportunities to capture boiloff are apparent which bring the total annual cycle number to about 200. Approximately 1.5 million gallons can be recovered from this source which will result in an annual savings $>\$ 2$ million (assuming $\$ 1.50 /$ gallon). At this rate of use, a metal hydride absorber will pay for itself in a few years of use (2-3 years depending on reliquefaction costs).

\section{B. Approach}

In the course of this program a "proof-of-concept" unit utilizing the unique characteristics of metal hydrides was designed, fabricated and tested. The 
device was used with low pressure (atmospheric) hydrogen gas to demonstrate the technical feasibility of recovering hydrogen normally vented at the KSC.

\section{Results}

The test results indicate that a metal hydride capture/storage system:

- Can absorb low pressure ( $<2.5$ psig) hydrogen at a rate that is commensurate with the rapid boiloff of hydrogen vapor experienced during the $\mathrm{LH}_{2}$ tanker "off-loading" operation.

- Will interface with existing equipment at LC-39 with minimum impact on present operating procedures and be compatible with KSC safety practices.

- Can release the stored hydrogen at normal temperatures and at pressured $>2$ atma for reliquefaction at a rate that is synchronized with the $\mathrm{LH}_{2}$ delivery schedule.

- Provides sufficient economic incentive to warrant consideration for further development of the concept at the KSC.

The tests confirmed the validity of the initial design configuration. A full-scale storage system (to absorb one-hour boiloff) will require 290,000 Ibs of metal hydride. The hydride will be contained in 1-1/8 IN O.D. copper tubes with a flexible filter (gas distributor) on the axial center line for the full length of the coil. The tubes are spirally coiled with a minimum diameter of 2 feet and a maximum diameter of 10 feet. 73 coil layers are stacked in each of the five $10 \mathrm{ft}$. high vessels. See Tables 1-3 for three of the size options considered. Table 4 is a listing of the program that was used to generate the weight and size requirements of the full-scale system, and Table 5 is a compilation of thirty-six computer runs that represent the range of reasonable sizes. 


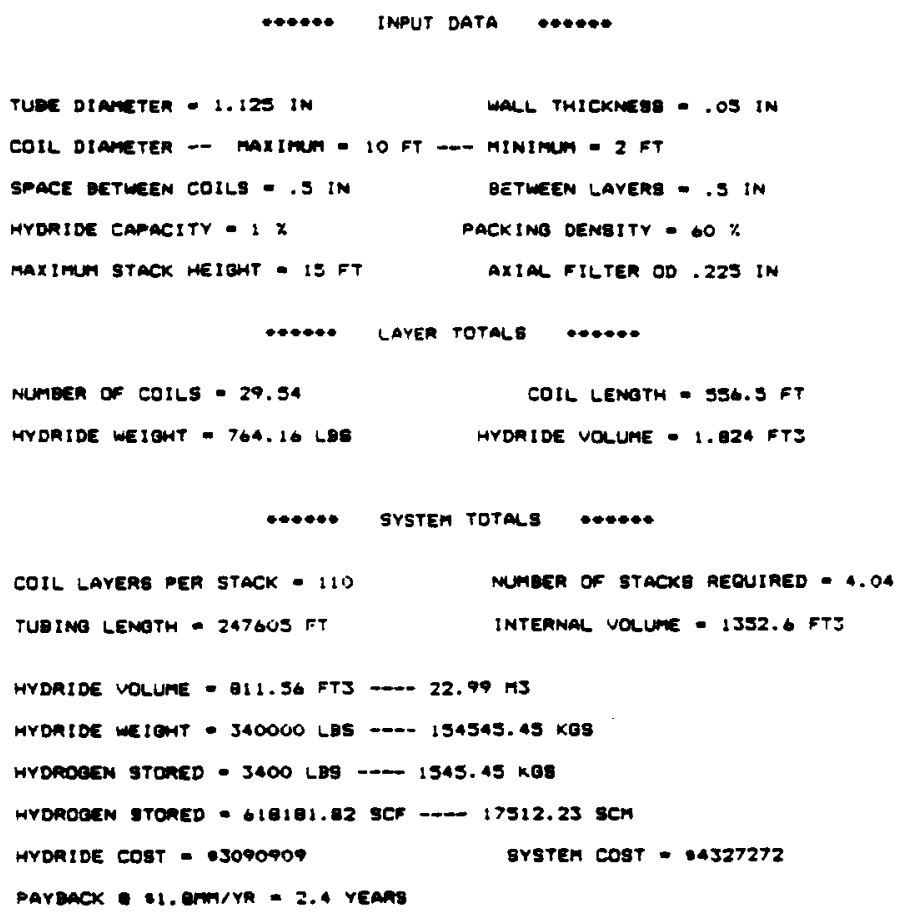

TABLE 1: Computer Run for $10 \mathrm{ft}$. diameter coil, $15 \mathrm{ft}$. stack height and $1 \%$ hydride storage capacity.

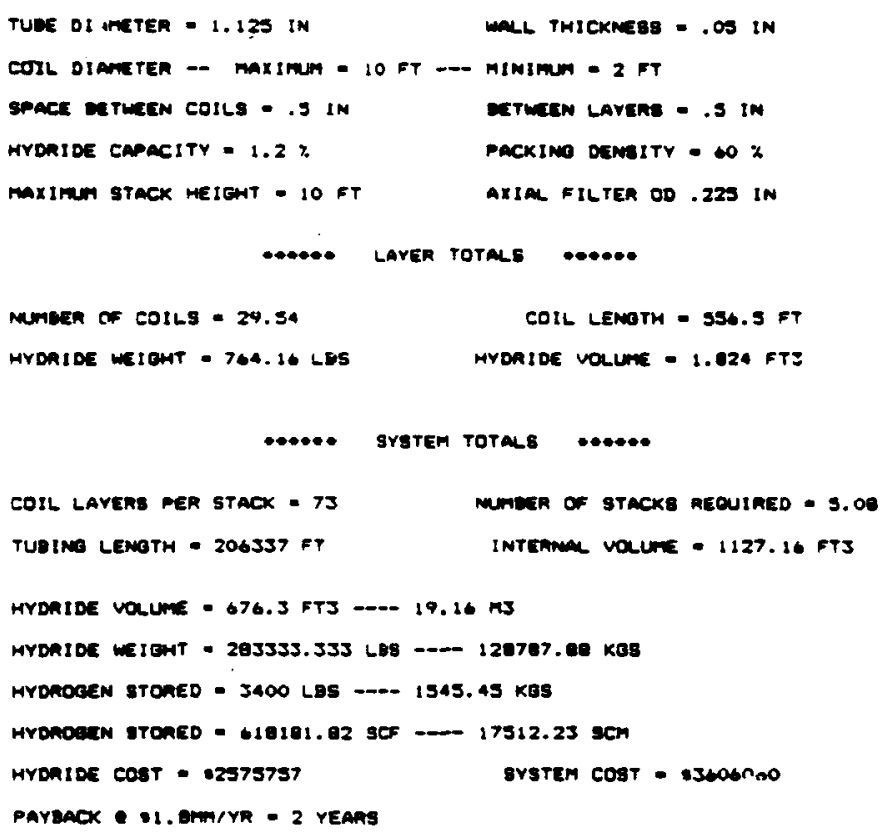

TABLE 2: Computer Run for $10 \mathrm{ft}$. diameter coil, $10 \mathrm{ft}$. stack height and $1.2 \%$ hydride storage capacity. 


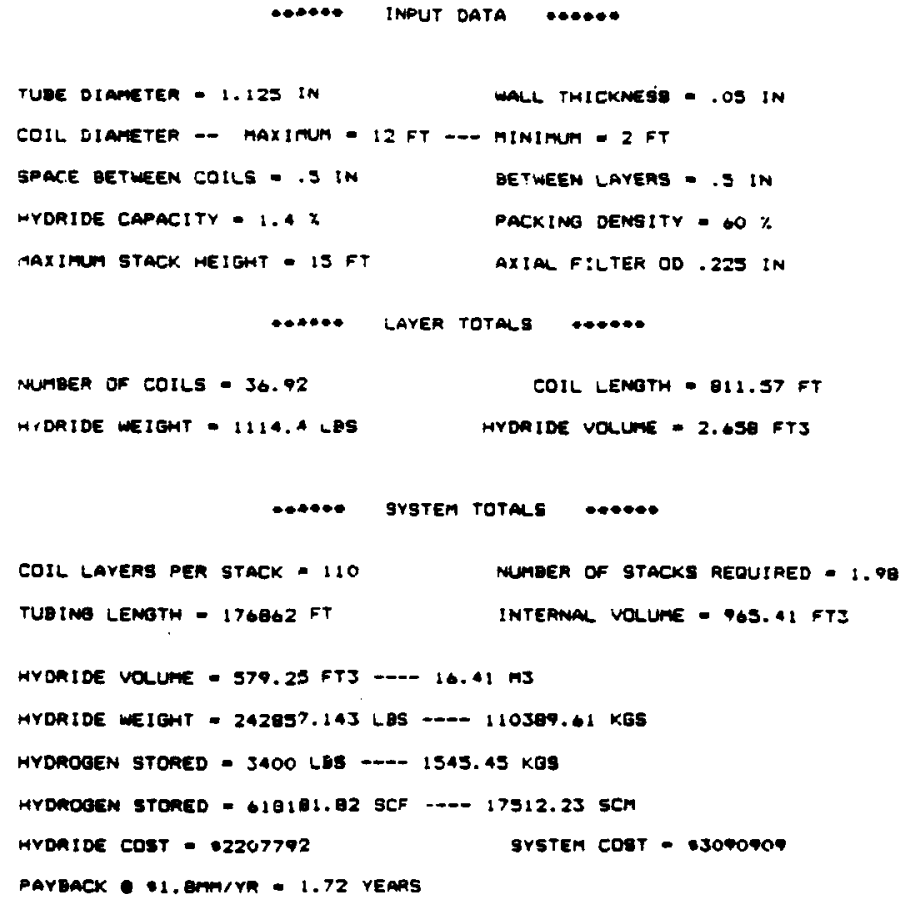

TABLE 3: Computer $R$ un for $12 \mathrm{ft}$. diameter coil, $15 \mathrm{ft}$. stack height and $1.4 \%$ hydride storage capacity.

\section{Recommendations}

The next phase should include the following tasks:

1) The device fabricated in the performance of this contract should be tested using hydrogen from $\mathrm{LH}_{2}$ boiloff.

2) An engineering analysis should be made of the various options available for hydrogen capture and storage for the purpose of identifying the most cost effective approach.

3) A single, full-scale component should be fabricated to operate in-situ at LC-39 to field test $\mathrm{LH}_{2}$ boiloff capture capability.

4) Based on the results of all previous work, a full-scale system should be designed.

5) An RFQ should be issued to solicit bids for construction of the full-scale capture system. 


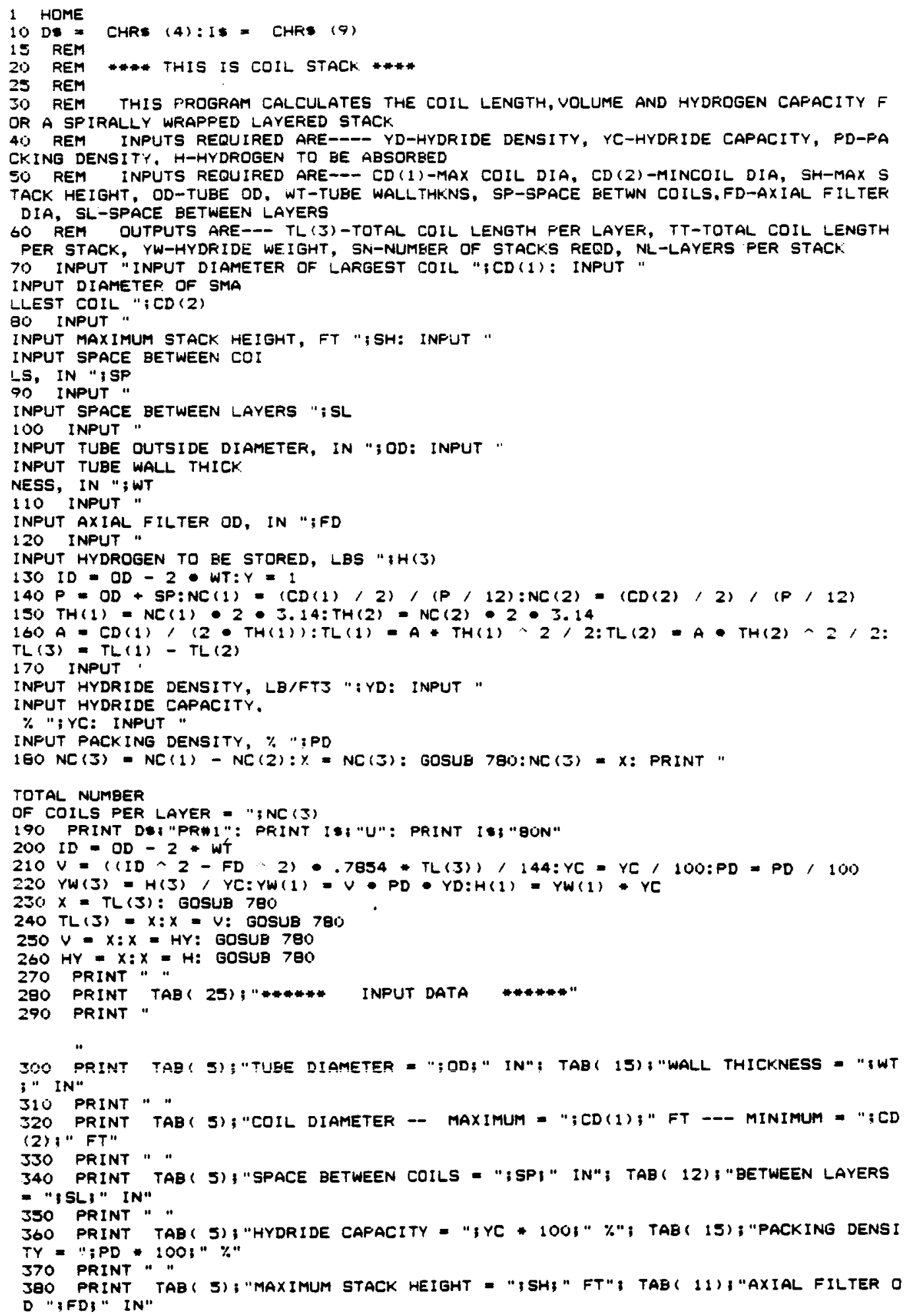

TABLE 4: Computer listing of program to calculate $\mathrm{H}_{2}$ parameters of a spirally wrapped layered stack. (Continued on page 6.) 


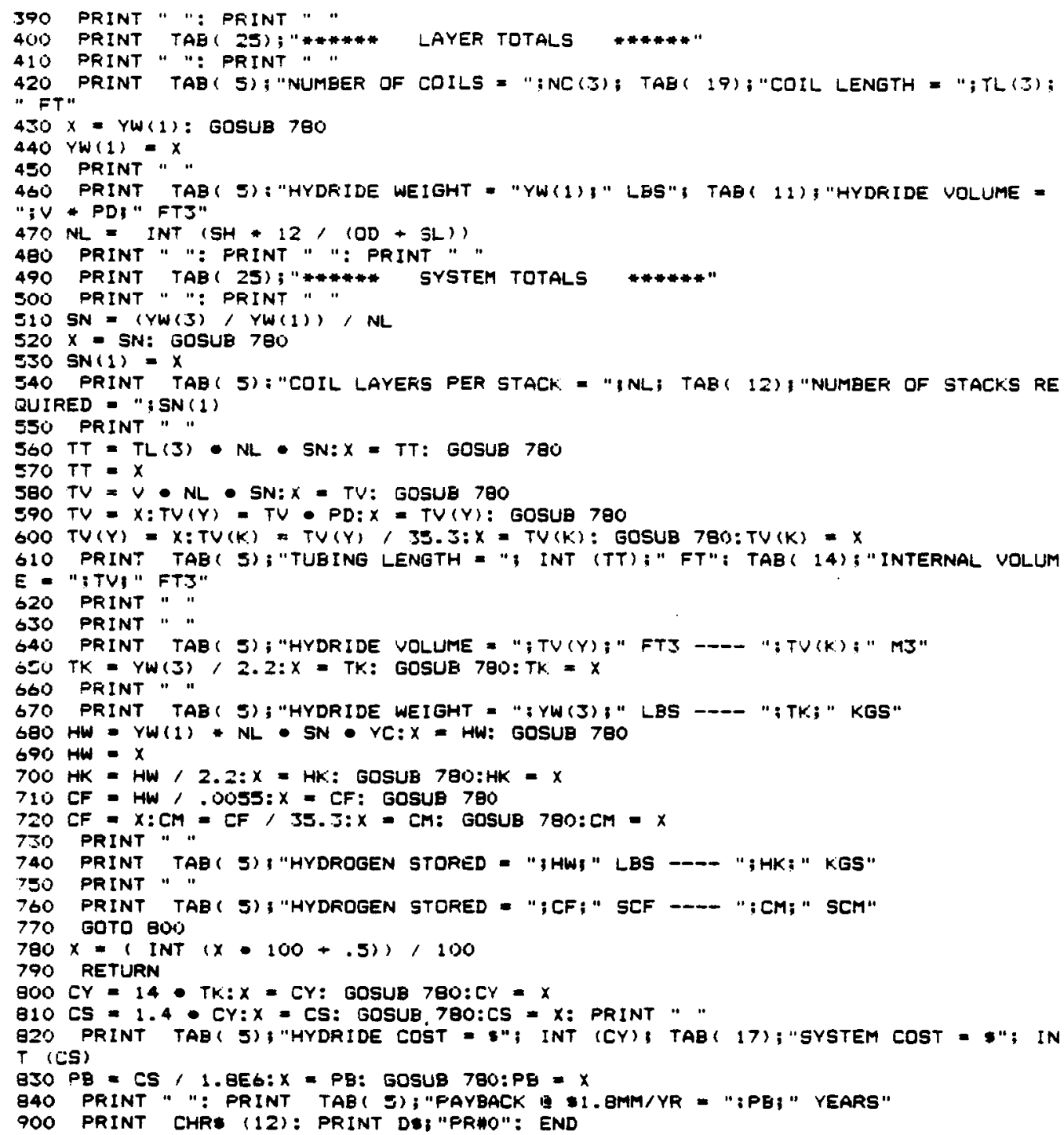

\section{TABLE 4: Continued}

\begin{tabular}{|c|c|c|c|c|c|c|c|c|c|}
\hline HYDAIDE CAPACITY, $\$$ & \multicolumn{3}{|c|}{1.0} & \multicolumn{3}{|c|}{1.2} & \multicolumn{3}{|c|}{1.4} \\
\hline TUBING REO'D, $10^{5}$ it & \multicolumn{3}{|c|}{3.40} & \multicolumn{3}{|c|}{2.83} & \multicolumn{3}{|c|}{2.43} \\
\hline HYORIOE REO'O, $10^{5}$ IOE & \multicolumn{3}{|c|}{2.48} & \multicolumn{3}{|c|}{2.08} & \multicolumn{3}{|c|}{1.77} \\
\hline SYSTEM COST: $10^{6} \mathrm{~S}$ & \multicolumn{3}{|c|}{4.33} & \multicolumn{3}{|c|}{3.61} & \multicolumn{3}{|c|}{3.09} \\
\hline STACK HEIGHT, It & 10 & 15 & 20 & 10 & 15 & 20 & 10 & 15 & 20 \\
\hline COIL DIAMETER, It & \begin{tabular}{|l|l|l|l|l|}
5 & 10 & 12 & 15 \\
\end{tabular} & $510 / 1215$ & \begin{tabular}{|l|l|l|l|l|l|l|}
5 & 10 & 12 & 15 \\
\end{tabular} & \begin{tabular}{|l|l|l|l|}
5 & 10 & 12 & 15 \\
\end{tabular} & 5110112115 & \begin{tabular}{|l|l|l|l|l|}
5 & 10 & 12 & 15 \\
\end{tabular} & $5: 101 / 2 / 15$ & $5|1012| 15$ & $5 / 1012115$ \\
\hline VESSELS REQUIRED & 289643 & $1 8 \longdiv { 3 } 2$ & $\left.14\right|_{1} / 23$ & $23: 5 / 4: 2$ & $|15| 3 \mid 2: 1.5$ & \begin{tabular}{|l|l|l|}
12 & 3 & 2 \\
\end{tabular} & $2014: 32$ & $13|3| 2 \mid 1.3$ & $10|2| 1.51$ \\
\hline PAYBACK TIME, Y๑A & & 2.40 & & & 2.00 & & & 1.72 & \\
\hline
\end{tabular}

TABLE 5: Computer projections for typical capture systems. 


\section{INTRODUCTION}

Several million gallons of liquid hydrogen boiloff losses are anticipated annually when the Space Shuttle program reaches full stride during the late 1980's unless means are found to prevent or reclaim this boiloff. The subject work tested the concept of using metal hydride hydrogen absorption systems to rapidly capture low pressure ( $<2$ psig) gaseous hydrogen for subsequent reliquefaction at a greatly reduced rate.

\section{A. Background}

In 1978, Mr. Ed Snape of Ergenies and Dr. Gerry Golub of PRC Systems Service began discussing the possibilities for using metal hydrides to reduce hydrogen loss at the Kennedy Space Center (KSC). After a period of inactivity, the discussion was resumed between Greg Egan of Ergenics and Dr. Golub in April 1981.

In October 1981, Frank Lynch of Hydrogen Consultants, Inc., a subsidiary of Ergenics and Greg Egan traveled to KSC to meet with Jim Spears of NASA and others to explain hydride technology and begin a detailed discussion of possibilities for using the hydrogen normally lost during KSC operations.

The first possibility, which was considered in earlier discussions between Snape and Golub, was to fuel the buses which carry visitors on tours of the KSC. This presented a number of operational problems since NASA has developed hydrogen handling procedures and regulations which would need many modifications to permit the use of hydrogen in buses. The bus conversion would also involve a contractor (TWA) who operates the bus fleet for NASA.

In January of 1982, Egan and Matt Rosso of Ergenics met with Spears and others at KSC to present other possibilities for $\mathrm{LH}_{2}$ boiloff utilization and reliquefaction. The possibilities considered were to:

1. Use steady-state boiloff to fuel a $50 \mathrm{~kW}$ Motor Generator $(M-G)$ set.

2. Alter $\mathrm{LH}_{2}$ delivery schedules so that transfer losses would be more uniform thus permitting the use of larger $V-G$ sets producing 200-400 KW of electrical power. 
3. Combine $M-G$ sets with hydride technology (storage and compression) to augment the performance of a reliquefaction device.

These suggestions were well-received by NASA personnel. After additional preparation, Egan, Mark Golben and Rosso of Ergenics with Lynch of $\mathrm{HCI}$ returned to present a more detailed discussion of these concepts in April 1982. During this meeting it became clear that one of the most attractive possibilities for hydride use at KSC was the capture of large boiloff losses during transfer operations since this would complement the reliquefaction processes currently under consideration by NASA.

As the team of hydride experts became more familiar with the KSC Standard Operating Procedure (SOP) it became increasingly apparent that viable technical projects would require a sizeable effort to become familiar with the details of the hydrogen systems and with the people, procedures and regulations which control their use.

An unsolicited proposal was submitted in June, 1982 seeking a contract to demonstrate the technical feasibility of the most critical part of the hydrogen boiloff capture/reliquefaction concept - - rapid capure of the low pressure hydrogen vapor. In April, 1983 the subject contract (NAS10-10625) was awarded to Ergenics to perform the ten month program.

\section{B. Hydride Applications at KSC}

Most of the hydrogen vented at LC-39 is released in rapid bursts of short duration while cooling transfer plumbing or relieving pressure. It is uneconomical to install liquefiers large enough, or to use conventional gas compression and storage devices, to counter these losses. Metal hydrides, however, are capable of rapidly absorbing hydrogen gas at low presssures and normal temperatures and storing the captured gas until an economically sized liquefier can return it to the storage tank as liquid.

Figure 1 shows the cumulative loss estimate during one year of operation. At the bottom of the graph the relatively small stable boiloff is shown. 
All of the reliquefaction schemes under consideration at NASA have the capability of capturing the stable boiloff so no hydrides are necessary for that purpose.

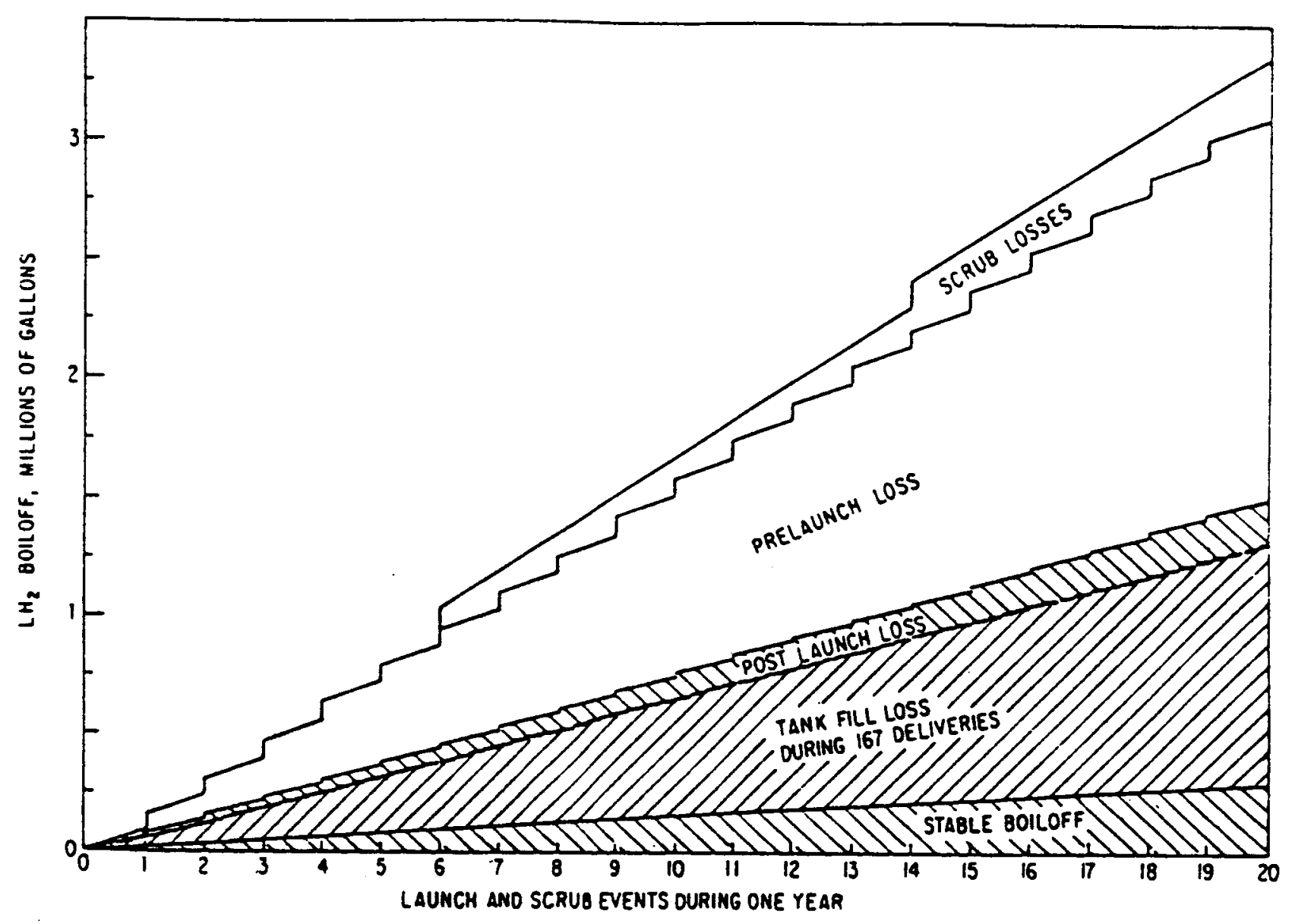

Figure 1: Cumulative boil off losses during one year. Capturable losses are shown as cross-hatched area.

The region just above the stady-state boiloff line in $F$ igure 1 represents the cumulative loss from truck and railcar deliveries of liquid hydrogen. Over one million gallons will be lost each year during these short (1.0 hour) $\mathrm{LH}_{2}$ delivery periods.

The contribution of the pre-launch, post-launch and scrub losses represents more than $50 \%$ of the total boiloff; but hydrogen from these sources is not readily recoverable since they are too intimately associated with shuttle launch operations. Hydrogen vapor generated during the "pre-launch" operation is the largest single source of vented vapor. This hydrogen is vented at the Space Shuttle during the cooldown and filling of its external tanks (ET's), where as much as 
250,000 gallons are lost during the refueling operation. The "post-launch" losses result from blow-down of the fill line which transports liquid hydrogen from the $\mathrm{LH}_{2}$ storage dewar to the launch pad. The pressurized contents of this line is typically drained back to the dewar until pressures are equalized. The residual, low-pressure, hydrogen is then sent to the burn pond where it is ignited. 8000 gallons are flared for each launch episode which may be recoverable in the future when confidence in the capture system has been established. Capture of losses resulting from scrubbed missions, although large (100,000 gallons), are not cost effective since they are infrequent, unpredictable and too intimately associated with shuttle launch operations.

The present feeling at the $\mathrm{KSC}$ is that it is preferable to vent the hydrogen from the above three sources rather than risk over-pressurizing the external liquid hydrogen tank by preventing the free flow of hydrogen boiloff. In this study, we, therefore, addressed only the capture of hydrogen from the two remaining sources; the daily, stable boiloff and the $\mathrm{LH}_{2}$ tanker off-loading losses.

During the transfer of hydrogen from the liquid hydrogen delivery trucks to the pad storage tank, approximately $10 \%$ of the fuel is lost. Five trucks arrive at the site, each with 13,000 gallons of $\mathrm{LH}_{2}$. The hydrogen boiloff available for capture was estimated by NASA personnel to be about 6,500 gallons. "First-hand" observation of the off-loading procedure by Ergenics personnel and a fundamental modeling analysis conducted during the course of this program indicate that only 6,000 gallons are lost during this operation.

It was assumed, as shown in Figure 2, that the largest fraction of this hydrogen was boiloff produced during cooling of the transfer piping. In reality, the results of the study portion of this program show that the greatest contribution to boiloff is made by flashing of the liquid as the pressure decreases from the tanker transfer pressure (20-25 psig) to the dewar storage pressure (2.5 psig). See Appendix $A(2)$. The time scale of Figure 2 is based on the NASA estimate of 1.5 hour total delivery period, with $1 / 2$ hour of actual $\mathrm{LH}_{2}$ transfer to the pad storage tank. Two "off-ioadings" witnessed by Ergenics personnel required only one hour with $\mathrm{LH}_{2}$ being transferred to the dewar for the entire period. The boiloff rate was more controlled than was originally anticipated with vapor being vented to the 
atmosphere at a fairly uniform rate. The expected initial rapid discharge of vapor, as the transfer line is cooled to $\mathrm{LH}_{2}$ temperatures, was not evident; and based upon the modeling study is not a significant contributor to the total boiloff. The dotted line on Figure 2 is more representative of the actual boiloff rate.

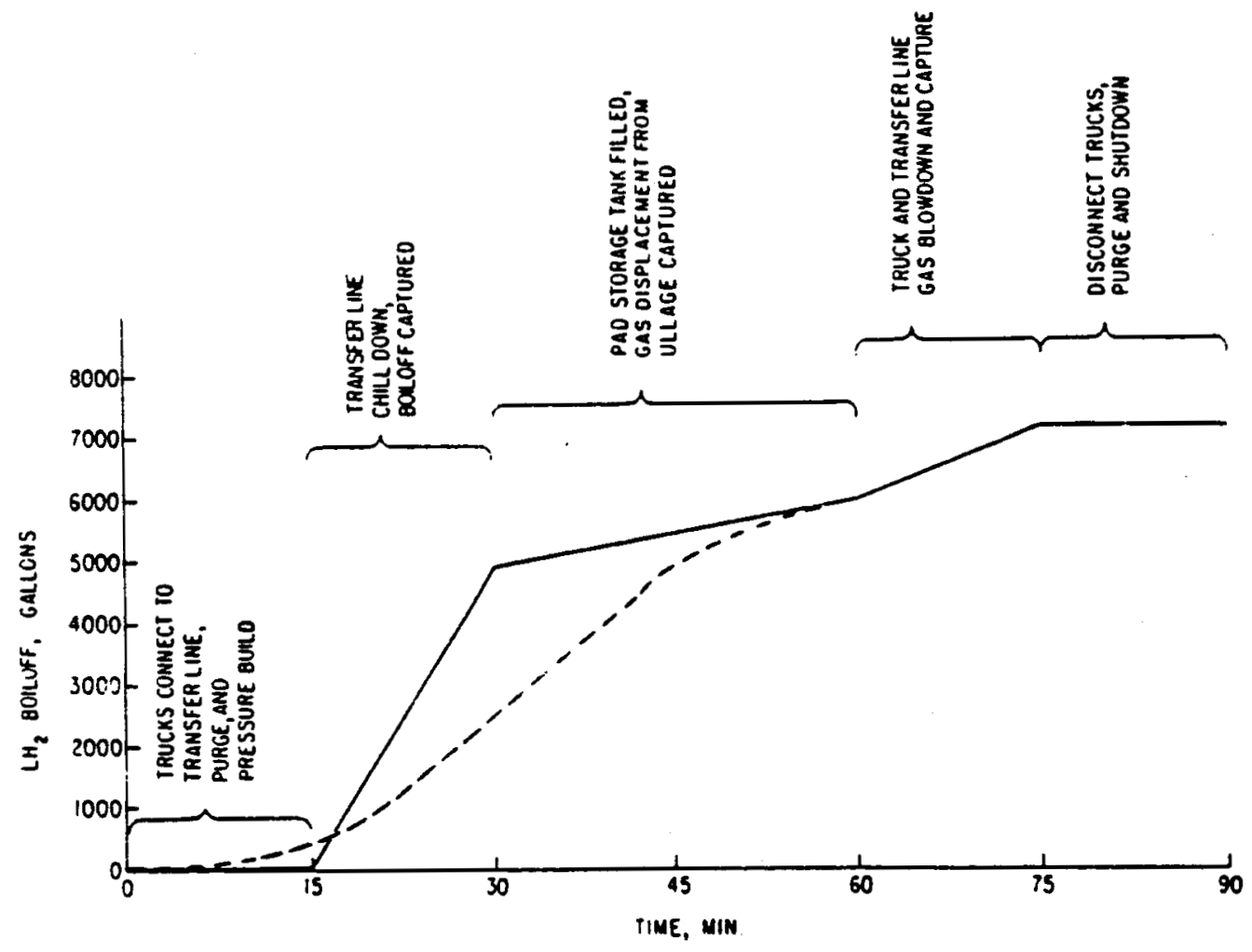

FIGURE 2: Estimated boiloff profile during a tank fill event.

\section{Capture Demonstration}

Capture of this vapor is not readily accomplished by normal means because of the extremely high mass flow-rate $(>10,000$ SCF M) and low presure $(<2.5$ psig). Certain low pressure metal hydrides operating near ambient temperatures can absorb hydrogen very rapidly and well below atmospheric pressure. In the course of this work a proof-of-concept and a field test device were fabricated to demonstrate the rapid absorption of low pressure hydrogen. The body of this report contains a description of the device, the test results and recommendations for additional work culminating in the implementation of a full-scale capture/reliquefaction system at the KSC. 


\section{APPROACH}

The approach is described in Section 4.0 TECHNICAL REQUIREMENTS section of the original Statement of Work, which follows:

\subsection{TECHNICAL REQUIREMENTS}

4.1 The effort will include the following tasks:

\subsubsection{Task 1 - System Performance Requirement}

The project team will meet with KSC personnel in order to study and specify the following boiloff capture design criteria:

4.1.1.1 Pad Storage Tank Fill Operation Boiloff:

Pressure

Temperature

Flow

Time Allotment

4.1.1.2 Hydride Capture Unit to Liquefier Transfer:

Pressure

Flow

Time Allotment 


\subsubsection{Task 2 - Hydride Alloy Selection}

Based on the results of Task 1 , one or more hydride alloys will be specified. Preliminary estimates of thermal ballast fraction, heat capacity, thermal conductivity, and heats of formation will be made.

\subsubsection{Task 3 - Hydride Container Design}

The hydride alloy selected in Task 2 and the performance requirements of Task 1 will be used as inputs to the design of a suitable container which must provide for ample gas flow means for heating and/or cooling and for control of powder expansion.

\subsubsection{Task 4-Alloy/Container Design Verification}

A small batch of one or more alloys selected in Task 2 will be formed and inserted in a small-scale container representative of the design created in Task 3 . The assembled unit will be tested on a Sieverts apparatus to verify performance.

\subsubsection{Task 5 - Hydride Alloy Manufacture}

The selected hydride alloy, verified in Task 4, will be formed in a quantity sufficient for the construction of a proof-of-concept boiloff capture unit.

\subsubsection{Task 6-Container Construction and System Assembly}

The basic container design verified in Task 4, will be followed in constructing the proof-of-concept boiloff capture unit. The hydride alloy will be inserted, and readied for performance testing. 


\subsubsection{Task 7 - System Test}

The completed boiloff capture unit will undergo a series of tests representative of the $\mathrm{KSC}$ pad storage tank transfer operations, specified in Task 1.

\subsubsection{Task 8 - Report Preparation}

A final project report will be prepared, detailing the design and performance of the boiloff capture unit. The report will also include the proposed future work statement and discussion of a full-scale system design for LC-39.

\subsubsection{Task 9 - Proof-of-Concept Demonstration and Project Review}

The complete boiloff capture unit will be shipped to $\mathrm{KSC}$ and demonstrated to key personnel. While the demonstration is being performed, it will be reviewed by the NASA project team who will notify interested parties at $\mathrm{KSC}$ who want to witness the demonstration.

The task sequence will be used as a format for the technical discussion.

\section{A. Task 1-System Performance Requirements}

It became apparent during discussions with NASA and EG\&G personnel that very little "hard" data existed concerning hydrogen vapor mass-flow-rates. It was also recognized that to attempt to make definitive measurements would be a major undertaking. We, therefore, agreed to base the engineering design of the test unit on whatever subjective information could be compiled as well as projections generated by computer modeling from first principles. Two liquid off-loadings were viewed by Ergenics personnel and some subjective measurements made. The estimated vapor flow-rates, based on these data, agreed very well with projections made by independent consultants working from engineering drawings of the LC39A $\mathrm{LH}_{2}$ Storage Area (See Appendix A). The drawings and whatever other data were available were supplied by the NASA Technical Representative. The peak and 
a verage hydrogen flow-rates were taken to be 10,650 and 10,300 SCF M (58.6 and $56.6 \mathrm{Lb} / \mathrm{Min}$ ) respectively. It was also determined by thermodynamic analysis that the temperature of the gas entering the recovery unit will be from 35 to $85^{\circ} \mathrm{K}$ for capture line lengths up to 500 feet long. The relatively small temperature increase is attributed to the high linear velocity of the gas and, consequently, short residence time. The sensible heat capacity of the cold vapor will assist in the removal of the exothermic heat of reaction which is generated as the hydrogen is absorbed by the hydride.

In practice, the delivery trucks undergo a pressure building step in order to force the liquid through the transfer plumbing. The pressure within the truck's dewar is increased to 20-25 psig by vaporizing some of the liquid in an external heat exchanger. The pressure is maintained on the liquid until the truck's tank has discharged all of its $\mathrm{LH}_{2}$. The first liquid to enter the transfer line plumbing boils a way until cryogenic temperatures are reached.

After the transfer line has been chilled to allow liquid flow, the second opportunity for hydrogen capture occurs. As the pad storage tank is filled, the cold, gaseous hydrogen in the tank's ullage is displaced and vented. This gas is available for capture during the entire 1 hour fill period. After transfer, the high pressure gaseous hydrogen which remains in the trailers is vented before the trucks depart and is, therefore, available for capture during the latter stage of the delivery cycle.

The shape of the $\mathrm{LH}_{2}$ boiloff profile, shown in Figure 2, is quite similar to the shape of a hydride charging profile, as shown in Figure 3. Both curves are shown together in order to illustrate their similar characteristics of initially high flowrates followed by a period of lower flowrates. The hydride charging profile is taken from laboratory data for a hydride with an absorption pressure of 0.5 atmospheres absolute at $25^{\circ} \mathrm{C}$ and an applied hydrogen pressure of 1 atmosphere absolute. The dotted line represents the more representative hydrogen boiloff rate as measured during this work. The actual capture mission is less demanding than originally anticipated, as the slope of the dotted curve indicates. 


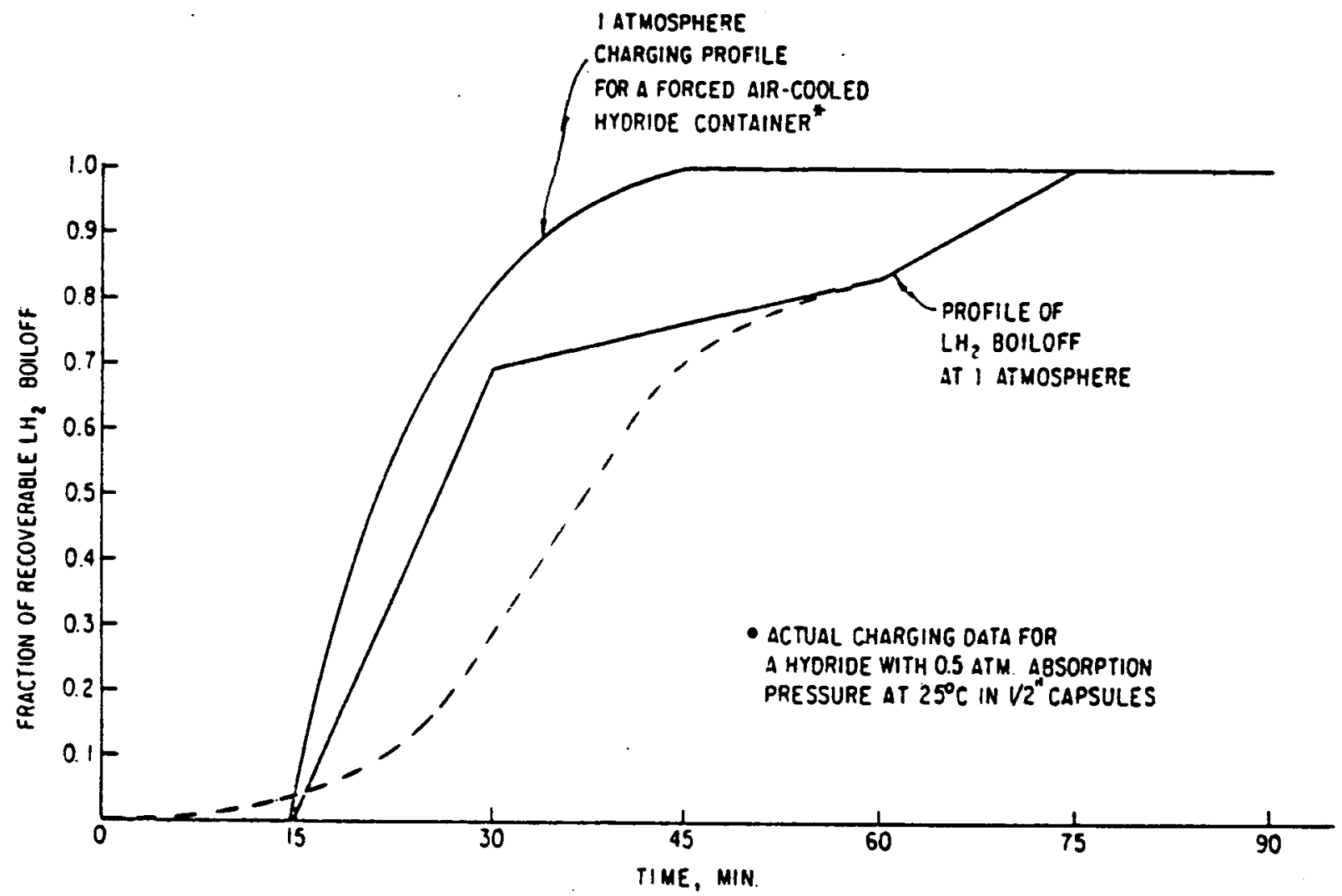

FIGURE 3: Comparison between the estimated boiloff loss profile and a hydride charging profile shows the feasibility of boiloff capture.

The parameters used for the design of the full-scale recovery system follow:

Hydrogen flow-rate (PEAK) $\quad 10,600$ SCF M

Hydrogen storage capacity $3400 \mathrm{lbs} .(620,000$ SCF $)$

Cold water temperature'

flow-rate

$20^{\circ} \mathrm{C}\left(68^{\circ} \mathrm{F}\right) / 400 \mathrm{GPM}$ for a $10^{\circ} \mathrm{C}\left(18^{\circ} \mathrm{F}\right)$ Rise

Hot water temperature/

flow-rate

$80^{\circ} \mathrm{C}\left(176^{\circ} \mathrm{F}\right) / 40 \mathrm{GMP}$ for a $10^{\circ} \mathrm{C}\left(18^{\circ} \mathrm{F}\right)$ Rise

Maximum vessel diameter/height $15 \mathrm{ft} / 20 \mathrm{ft}$

Tubing diameter/wall thickness $1.125 \mathrm{in} / 0.050 \mathrm{in}$

Axial filter $O D \quad 0.225$ in

hydride packing density $\quad 60 \%$ 


\section{B. Task 2-Hydride Alloy Selection}

The critical criteria that impact alloy selection will be discussed for each alloy considered. They include:

- Hydrogen absorption capacity

- Chemical kinetics

- Dynamic hysteresis

- Isotherm slope

- Dynamic absorption plateau pressure $<0.4$ atma at $25^{\circ} \mathrm{C}$

- Alloy components availability

- Dynamic desporption plateau pressure $>2$ atma at $75^{\circ} \mathrm{C}$

\section{DEFINITIONS}

- Hydrogen Absorption Capacity is the amount of hydrogen that can be reversibly stored in a metal hydride and is usually given as weight per cent of the metal, $\left(\mathrm{W}_{\mathrm{H}_{2}} / \mathrm{W}_{\mathrm{Hydride}}\right) \times 100$.

- Chemical Kinetics is a measure of the time required for a hydrogen molecule to attach to the metal surface, dissociate into two $\mathrm{H}+$ ions and be absorbed into the crystal lattice of the metal. Ideally the chemical kinetic rate is measured independently from heat transfer effects; but can have a measurable influence on the effective hydrogen absorption rate. Figure 4 depicts the absorption rate to $50 \%$ of full capacity for three different alloys. Differences greater than an order of magnitude are attributed to the inherent chemical kinetics for each alloy. These curves were generated at Ergenics under contract to Sandia National Laboratories in Albuquerque, New Mexico(3). Figures 5-9, also taken from the Sandia final report, present the measured wide range of absorption rates for some of the alloys considered. Figures 5 and 6 depict the typical variation in kinetic rates as a function of temperature. Even smail additions of aiuminum seem to slow the chemical kinetic rate and increase its sensitivity to temperature change. This result makes it imperative that we know the temperature of the hydrogen vapor entering 
the boiloff capture vessel. The effect of alloying elements, other than aluminum, is evident when Figures 7-9 are compared. Data are not available for LaNi $i_{.6} \mathrm{Al}_{0.4}$; but reliable extrapolations can be made from the information presented here.

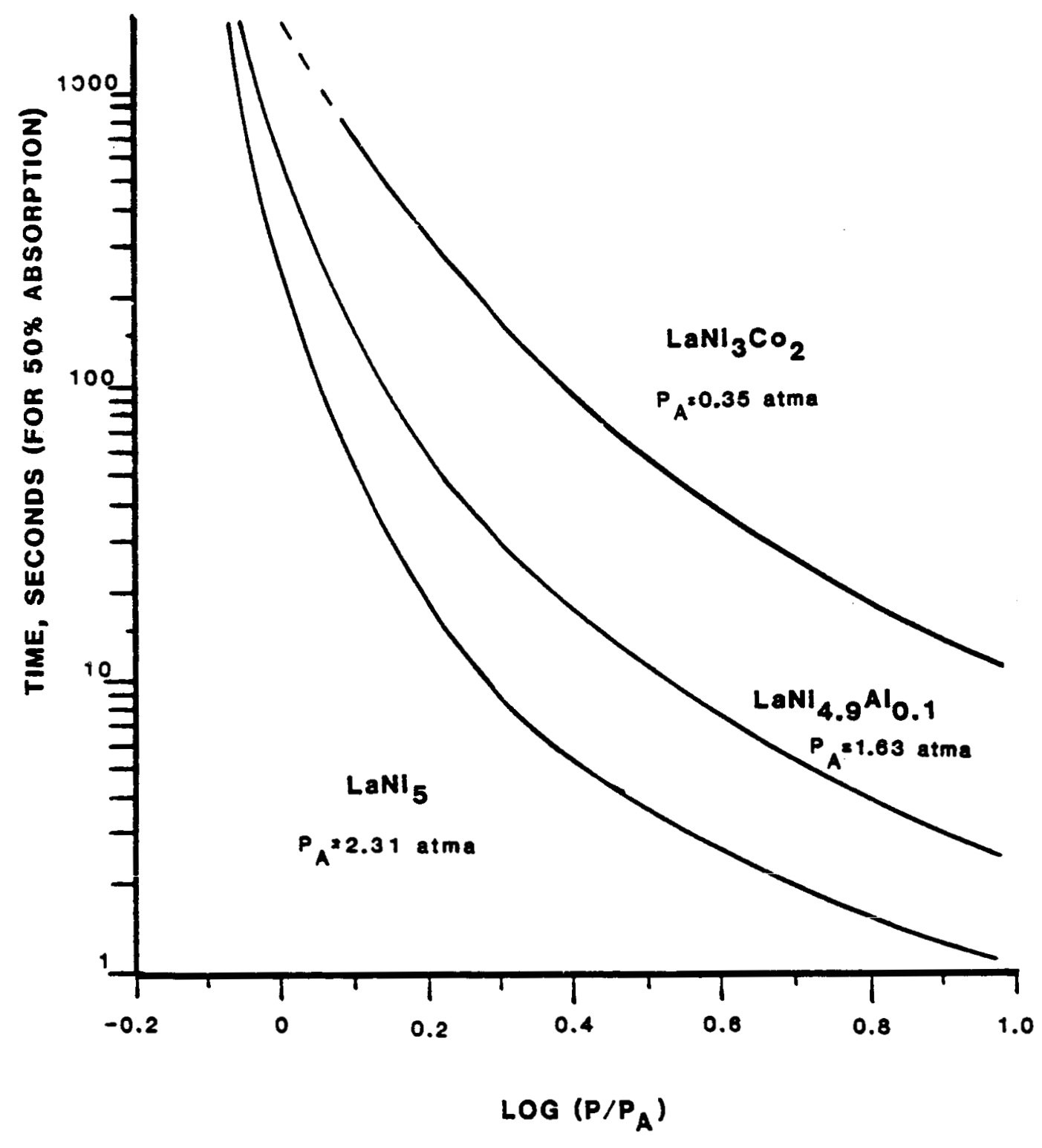

FIGURE 4: Absorption rate to $50 \%$ of full hydrogen capacity for three $A_{5}$ alloys. Ref. 3 


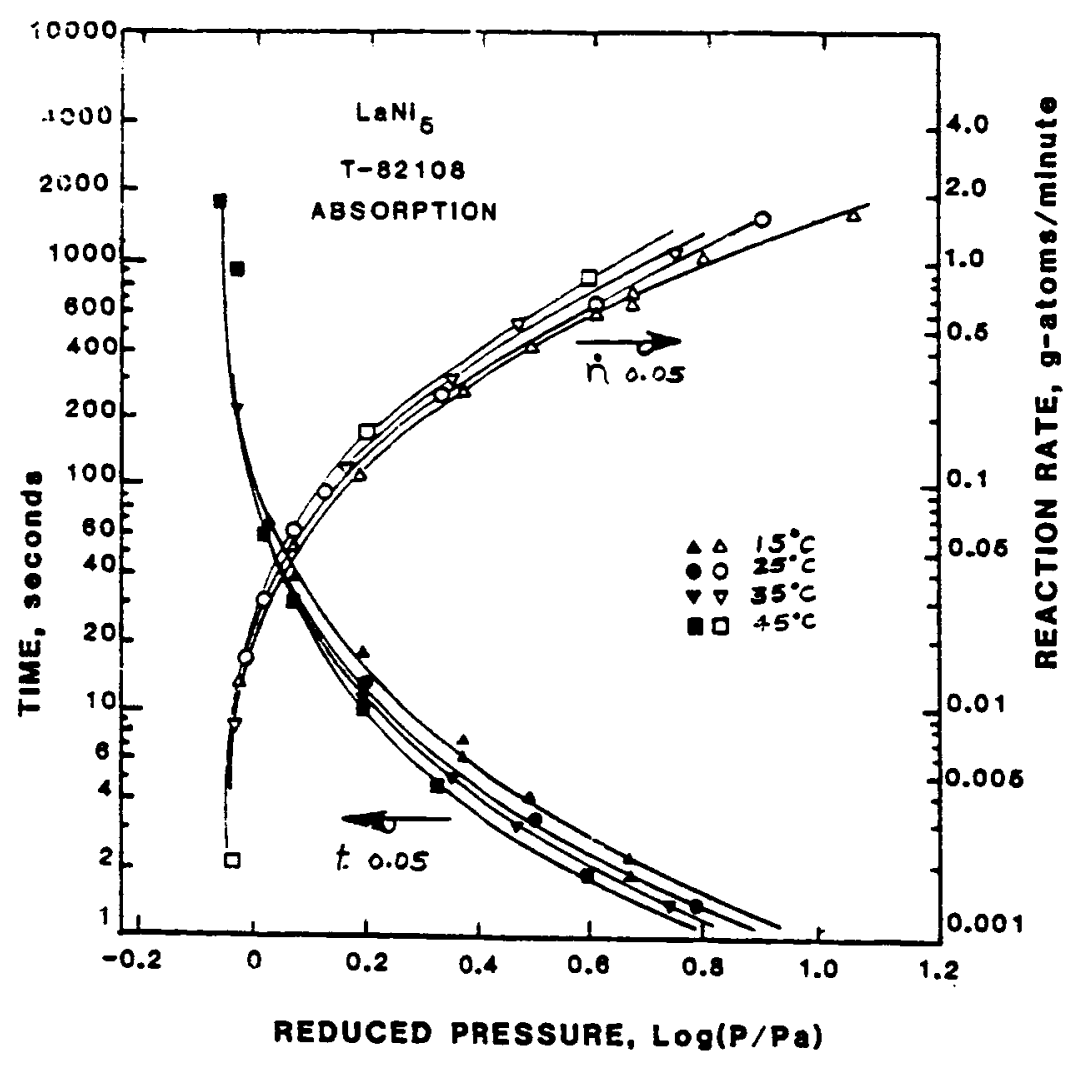

FIGURE 5: Comparison based on reduced pressure of LaNi5 absorption kinetic data showing the rate and time to $0.05 \mathrm{~g}$-atom $\mathrm{H}$ reacted at all pressures and temperatures tested $(s 0.5 \mathrm{H} / \mathrm{M})$. Ref. 3.

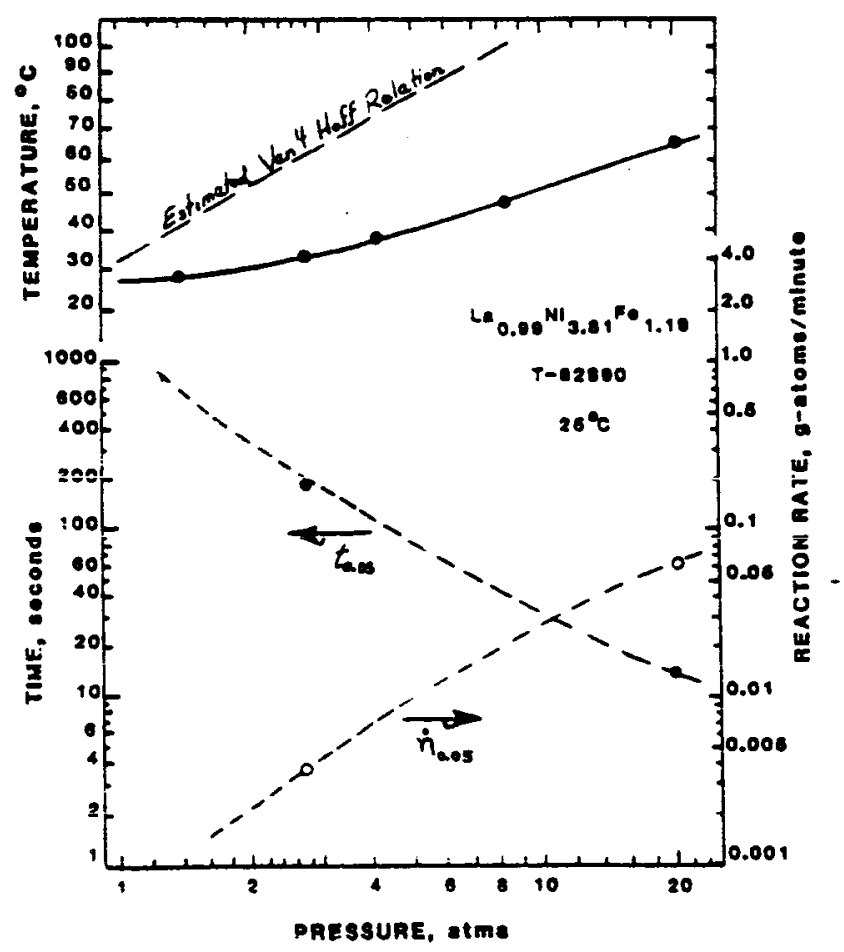

FIGURE 6: Summary of absorption kinetic data at $25^{\circ} \mathrm{C}$ showing the maximum temperature excursion as well as the reaction rate and time at $0.05 \mathrm{~g}-$ atoms hydrogen reacted $(\sim 0.5 \mathrm{H} / \mathrm{M})$. Ref. 3 . 


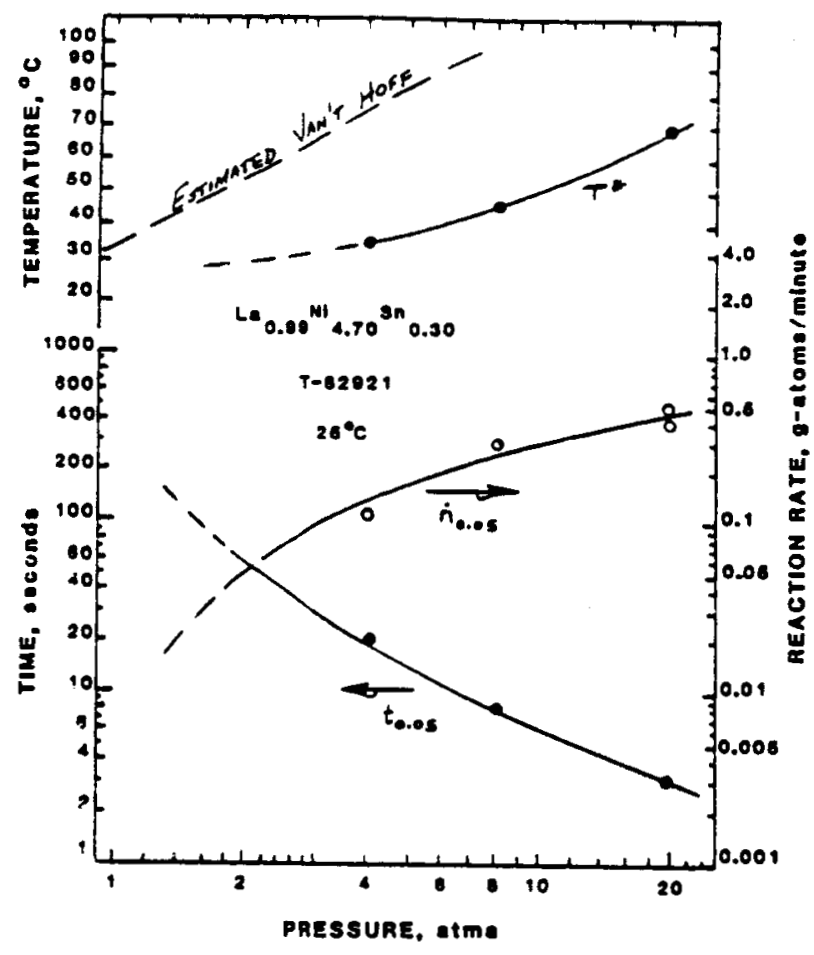

FIGURB 7: Summary of absorption kinetic data at $25^{\circ} \mathrm{C}$ showing the maximum temperature excursion as well as the reaction rate and time at $0.05 \mathrm{~g}$ atoms hydrogen reacted $(\sim 0.5 \mathrm{H} / \mathrm{M})$. Ref. 3 .

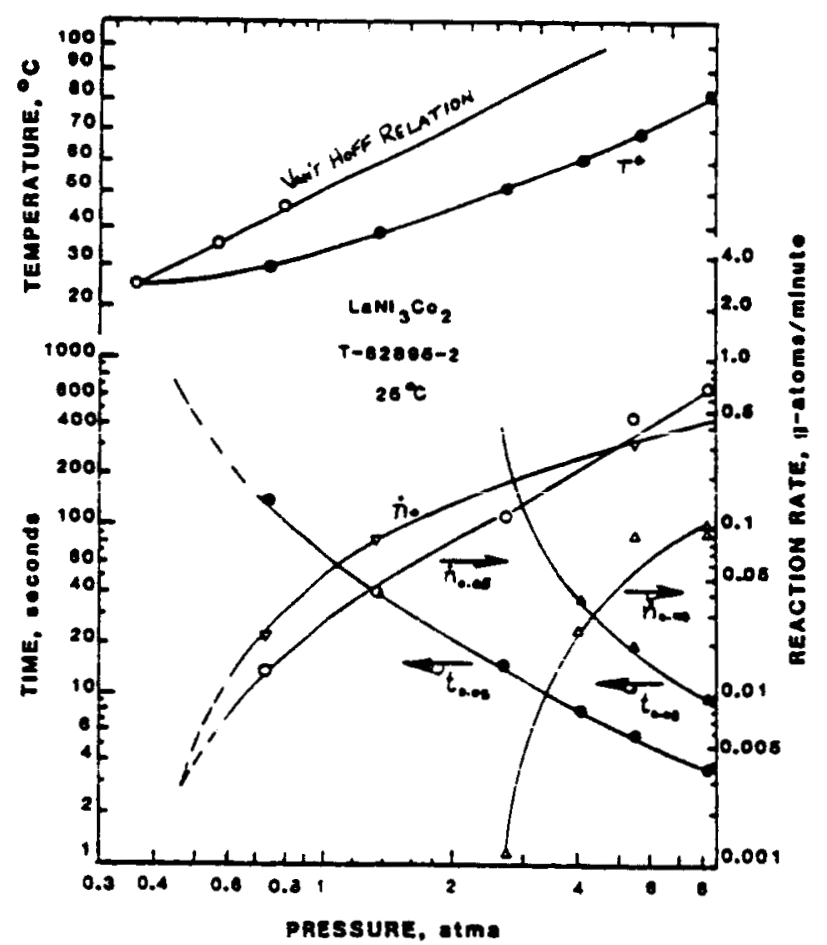

FIGURE 8: Summary of $\mathrm{LaNi}_{3} \mathrm{CO}_{2}$ absorption kinetic data at $25^{\circ} \mathrm{C}$ showing the maximum temperature excursion as well as the reaction rate and time parameters. Ref. 3. 


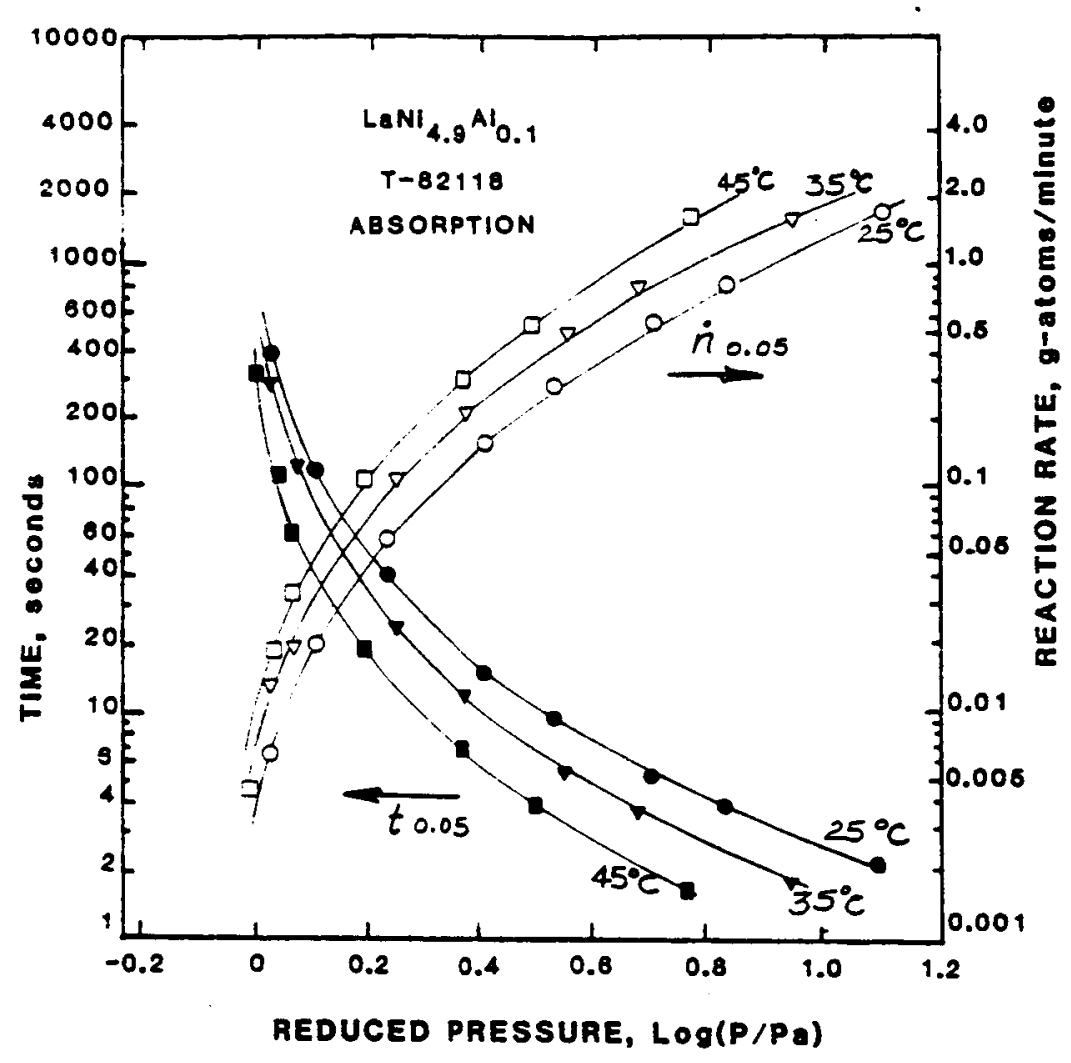

FIGURE 9: Comparison based on reduced pressure of LaNi4.9Al 0.1 absorption kinetic data showing the rate and time to react $0.05 \mathrm{~g}$-atom $\mathrm{H}$ at all pressures and temperatures tested ( $(0.5 \mathrm{H} / \mathrm{M})$ Ref. 3.

- Dynamic Hysteresis - is the difference between the absorption and the desorption plateau pressure for a particular alloy while in the transient mode. The plateau pressures are significantly different for different hydrogen mass flow-rates. The desorption and absorption plateaus are depressed and raised respectively when compared with its equilibrium isotherm, as can be seen in Figure 10. For applications, such as the one being considered here, where hydrogen flow-rates are extremely rapid, the system design must be based upon dynamic values. Because the magnitude of this loss is an inherent characteristic of each hydride formulation, it is important to consider it when evaluating alloys for any application.

- Isotherm Slope - some hydrides, such as $\mathrm{LaNi}_{3.8} \mathrm{Fe}$ (.2 (Figure 11) and LaNi $4.7 \mathrm{Sn}_{0.3}$ (Figure 12), exhibit a sloping plateau which has a profound effect on a hydride's applicability. For example, the tin substituted hydride (Figure 12) has a plateau that slopes from 0.15 to 1.5 atma at 
$25^{\circ} \mathrm{C}$ which makes it totally unsuitable even though its other characteristics (capacity and hysteresis) are acceptable.

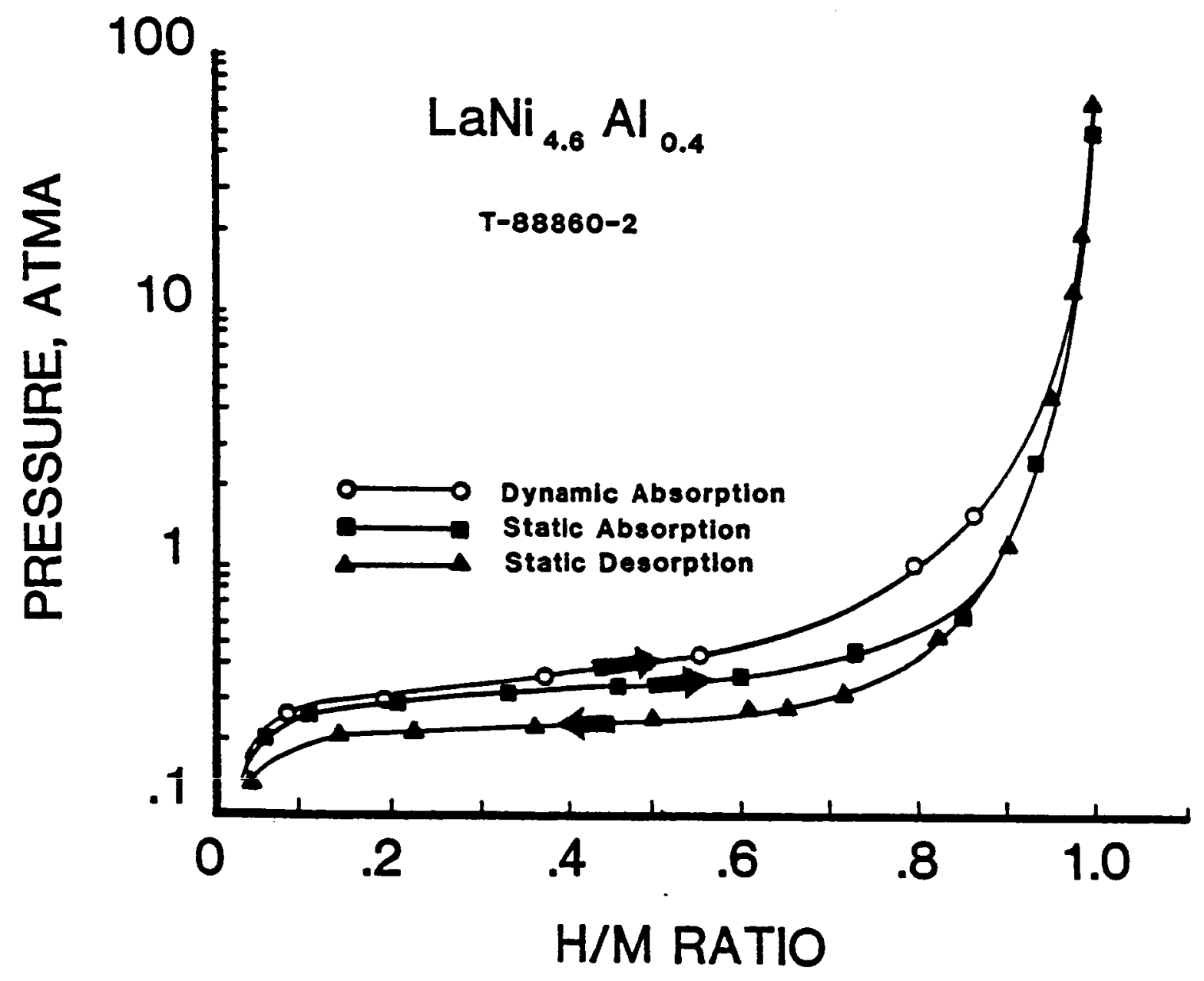

FIGURE 10: Static and dynamic $25^{\circ} \mathrm{C}$ isotherms for LaNi $\mathrm{L}_{4.6} \mathrm{Al} 0.4$. Heat \#T-88860-2. 

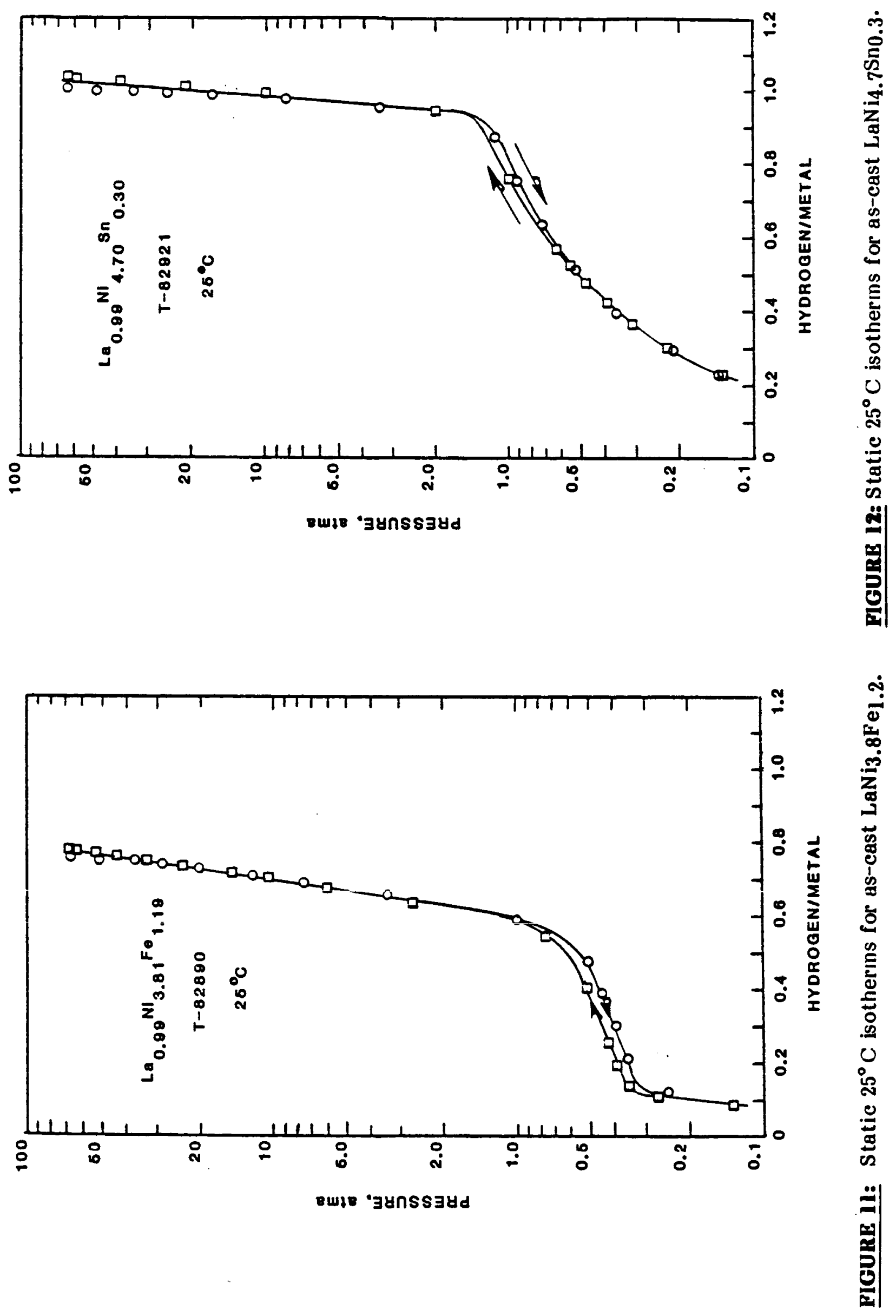
- Dynamic Absorption Plateau Pressure - is a primary aspect to be considered since the greater the pressure difference between the charging hydrogen stream and the hydride's absorption plateau, the greater will be the absorption rate. We, therefore, want this value to be as low as possible at normal temperatures $\left(<0.4\right.$ atma at $25^{\circ} \mathrm{C}$ ).

A vailability of Alloy Components - while not a major concern, should be addressed when making a hydride selection. The use of rare, expensive or sensitive materials must be avoided particularly where large quantities of hydride are to be used. Of the five candidates considered only the cobalt containing alloy might fit in this category.

Dynamic Desporption Plateau Pressure - must be high enough to generate pressures above atmospheric pressure at moderate temperatures. Liberating the captured hydrogen with the use of lowgrade waste heat from some other process is extremely attractive from the economic point-of-view. Hydrogen release can be considered an extreme bottoming cycle for any co or poly generation system (target Pd $>2$ atma at $80^{\circ} \mathrm{C}$.

Initially five alloy compositions were considered for this application. Four of the candidate alloys were lanthanum-nickel with small addition of various other metals ( $\mathrm{Al}, \mathrm{Co}, \mathrm{Fe}, \mathrm{Sn}$ ). The fifth alloy considered contained $\mathrm{Ca}, \mathrm{Ni}$ and $\mathrm{Al}$. See Figures 11-15.

Alloys I and II, the iron and tin substitutions, $\operatorname{LaNi}_{3.8} \mathrm{Fe}_{1.2}$ and LaNi4.7 $\mathrm{Sn}_{0.3}$ respectively, were eliminated because of their sloping plateau and greatly reduced capacity, See Figures 11 and 12 . Even though the plateaus were approximately at the correct presssure, demonstrated poor kinetics was also a contributing factor in this decision.

Alloy III ( $\left.\mathrm{CaNi}_{4.9 \mathrm{Al}} \mathrm{A}_{0.1}\right)$, although it had a flat plateau at the right pressure, its excessive hysteresis and low capacity caused it to be rejected., The undesirable hysteresis characteristic would require water temperature to be greater 
than $80^{\circ} \mathrm{C}$ to raise the desorption plateau above the desired discharge pressure of 2 atmospheres absolute, see Figure 13.

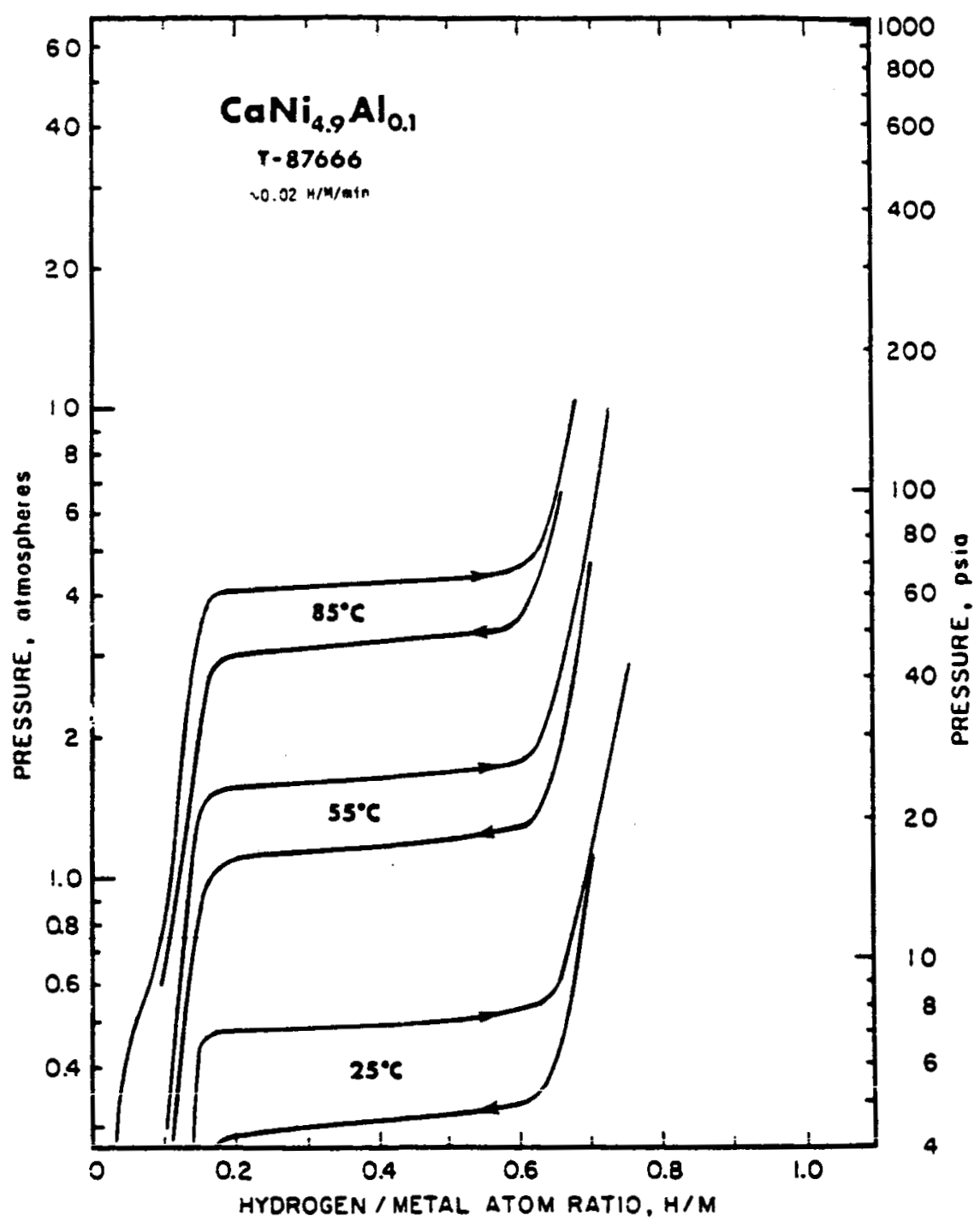

FIGURE 13: Dynamic pressure-composition isotherms for $\mathrm{CaNi}_{4.9} \mathrm{Al}_{0.1}$. Ref. 4 .

Candidate alloy IV, ( $\mathrm{LaNi}_{3} \mathrm{Co}_{2}$ ), or a slightly modified version of it, will probably work very well; but because it contained cobalt which might be a problem to obtain in large quantities, it too was eliminated. Figure 14 depicts its acceptable properties and Figures 4 and 8 show its moderately poor kinetics. 


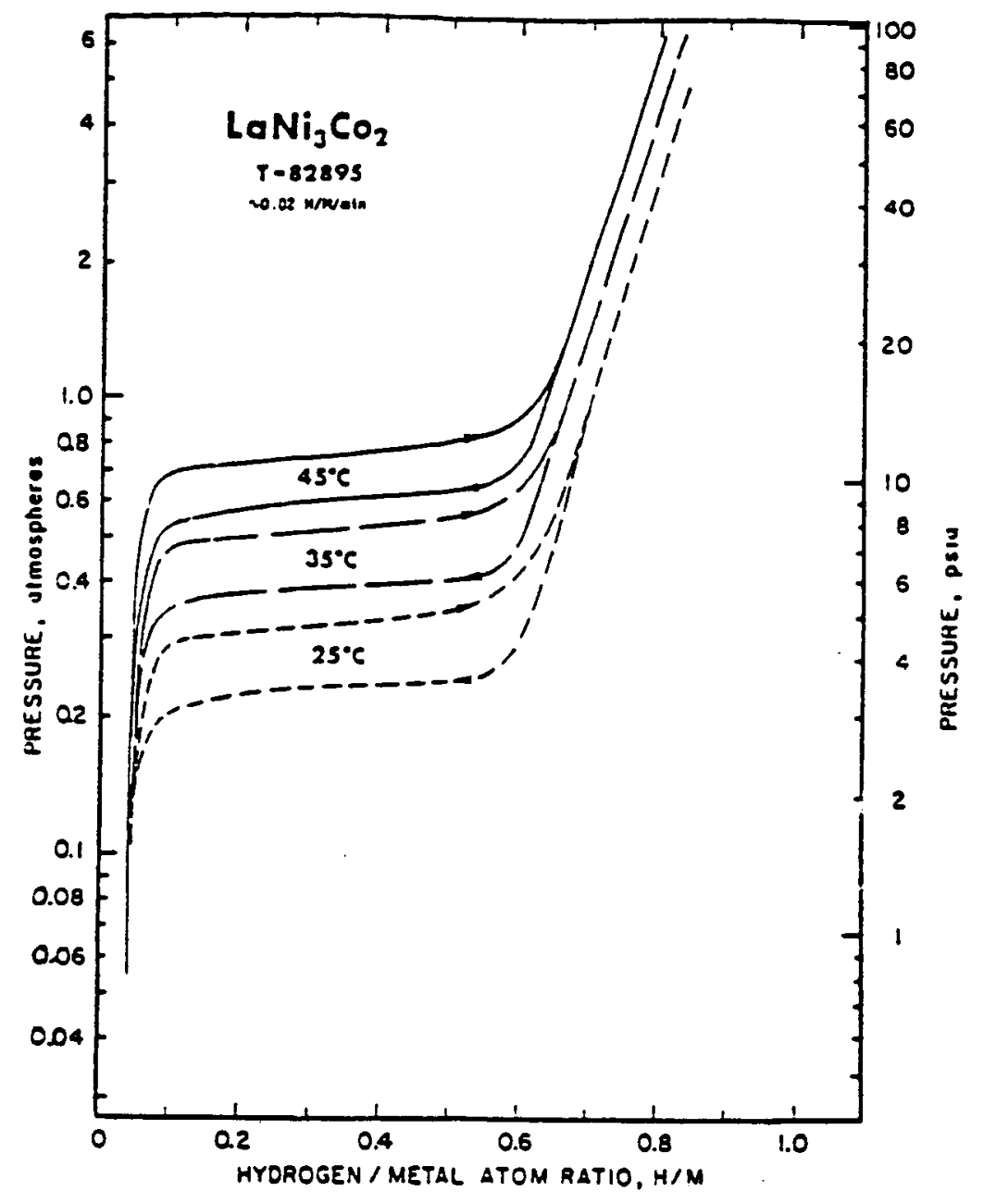

FIGURE 11: Dynamic pressure-composition isotherms for $\mathrm{LaNi}_{3} \mathrm{CO}_{2}$. Ref. 4 .

Alloy $\mathrm{V}$ ( $\operatorname{LaNi}_{4.7} \mathrm{Al}_{0.3}-\mathrm{H}$ YSTOR 207 ) closely approximated all the desired qualities except that the absorption plateau pressure was too high. By comparing Figures 15, 16, 17 the negative eff ect on the hydrogen storage capacity of aluminum substitutions for nickel is apparent. Greater additions of aluminum would have two major effects on the alloy developed; one desirable and one undesirable. The absorption plateau would be further depressed to the desired pressure but further reduction in hydrogen capacity would undoubtedly result. Because past work in this area had shown that the capacity loss would be small; and because the kinetics of this family of alloys is known to be extremely fast, we chose to melt a sixth alloy with an even higher aluminum content.

Alloy VI ( $\mathrm{LaNi}_{4.6} \mathrm{Al}_{0.4}$ Heat $\left.\mathrm{T}-8885 \mathrm{j}-2\right)$ was melted and annealed $\left(1125^{\circ} \mathrm{C}\right.$ for 17 hours) and although the exact composition was not attained, the plateau depression can be seen by comparing Figures 15 and 18 . 

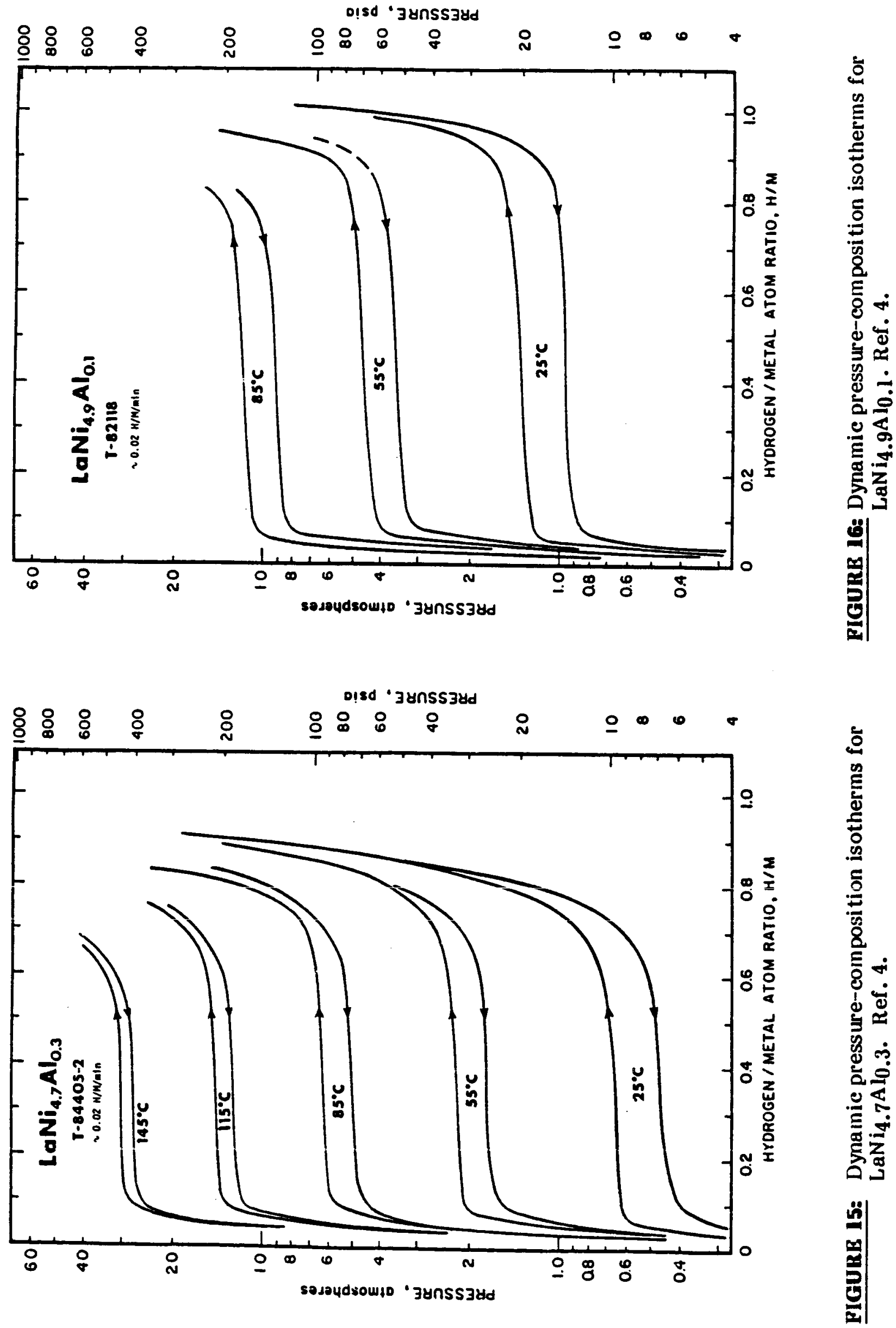

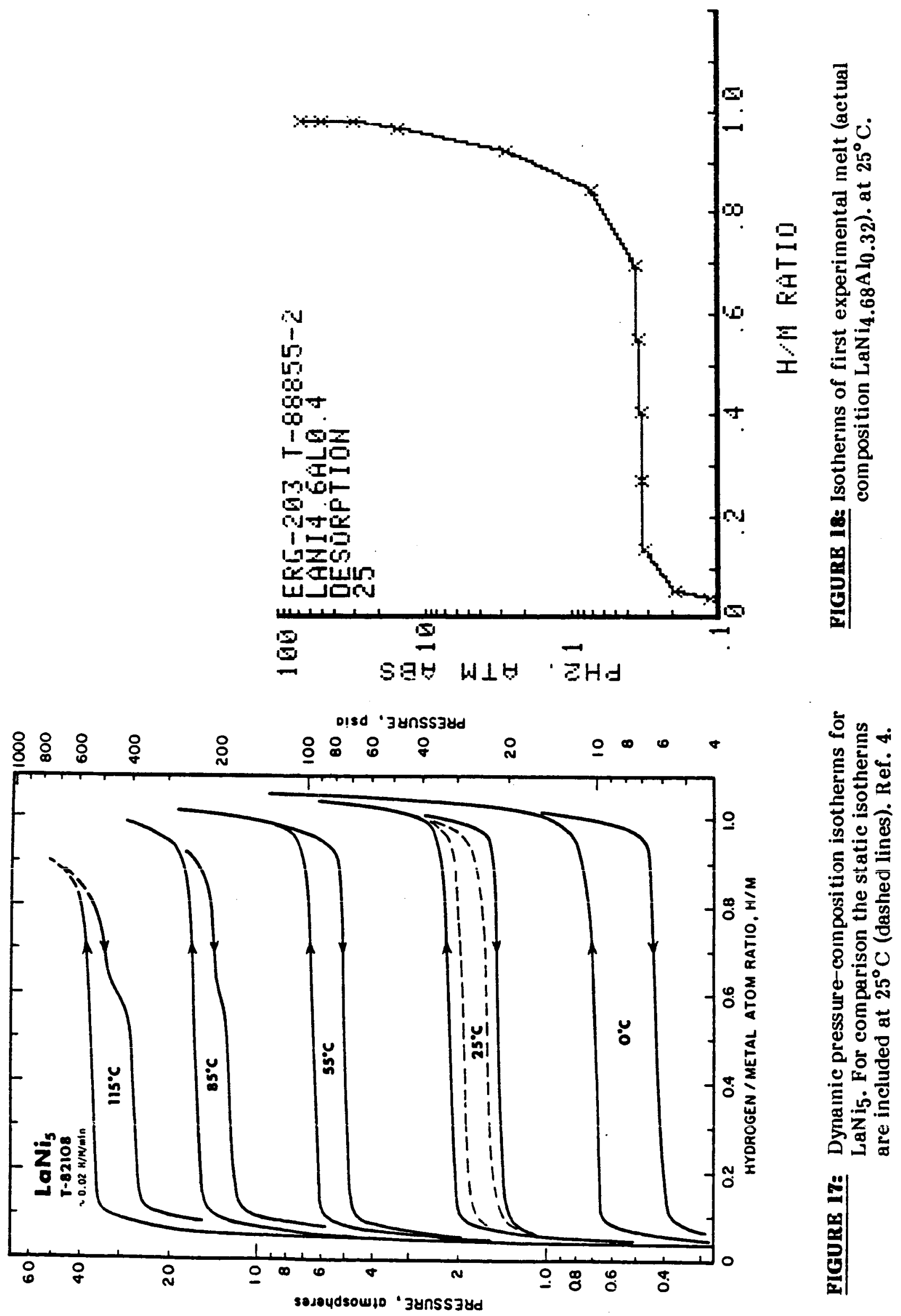
When the natural log of pressure is plotted vs. reciprocal absolute temperature, for a fixed hydrogen concentration (usually mid-plateau), the result is linear and is referred to as a Van't Hoff plot. Figure 19 is a composite plot of a few of the alloys considered. LaNi5 is also presented for reference purposes. It can be seen that Alloy VI can absorb $\mathrm{H}_{2}$ at sub-atmospheric pressures at $25^{\circ} \mathrm{C}$ and can liberate the gas at pressures $>1$ atmosphere at $80^{\circ} \mathrm{C}$. See Table 6 for the properties of the candidate alloys.

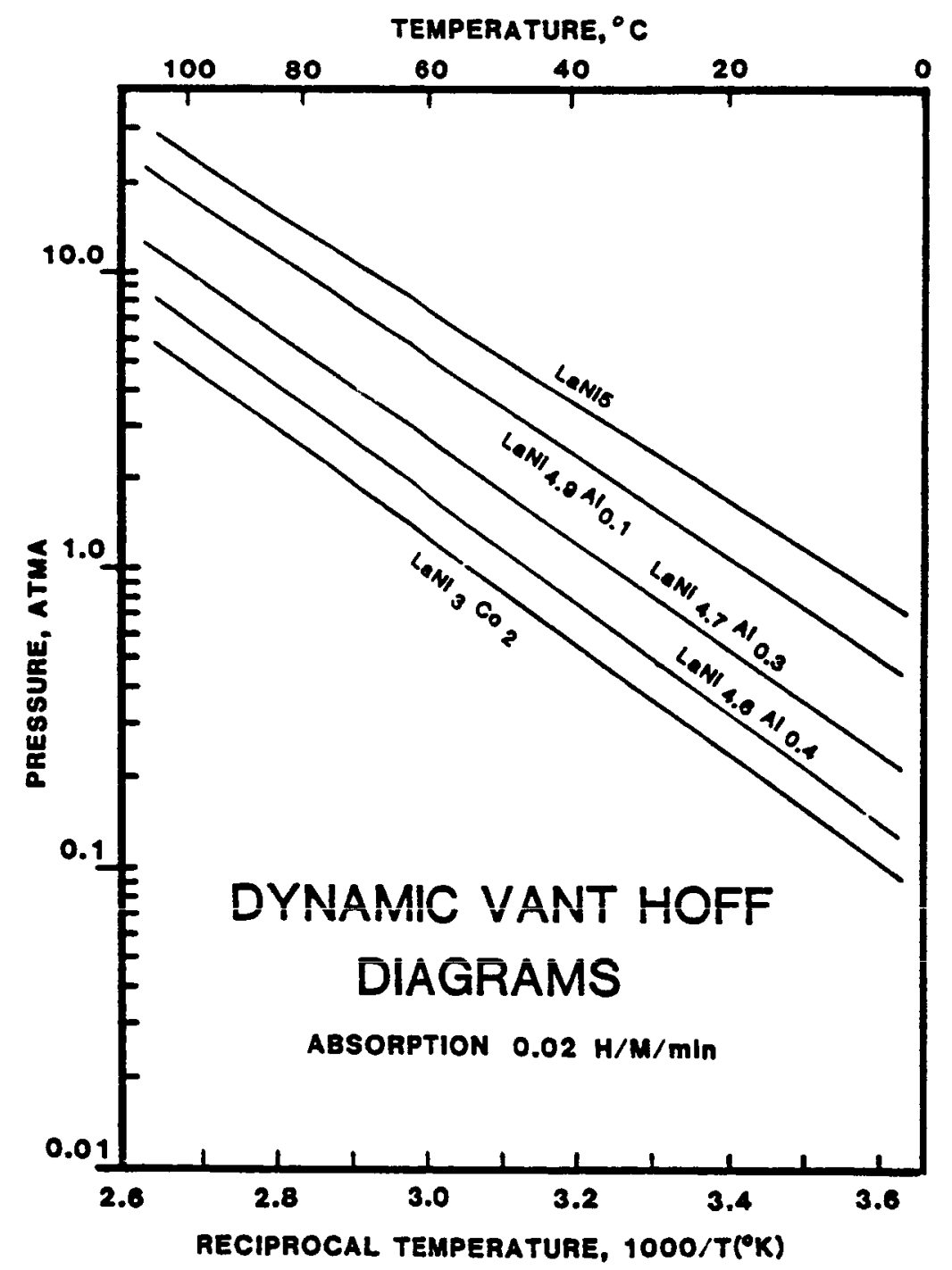

FIGURE 19: Van't Hoff diagrams for candidate alloys with LaNi5, for reference. 


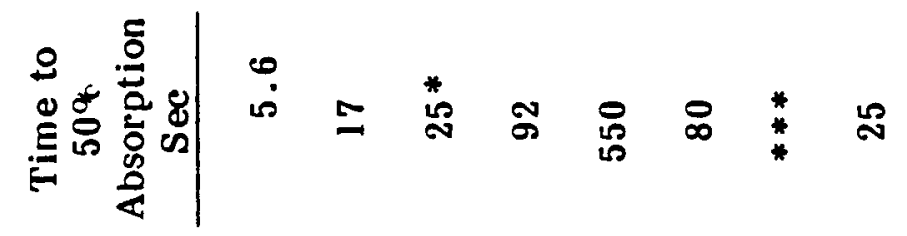

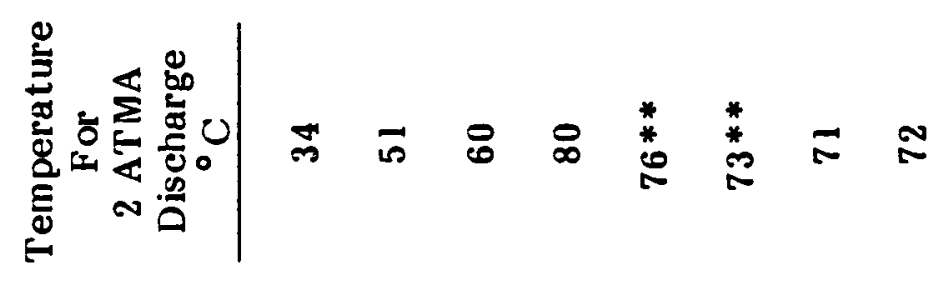

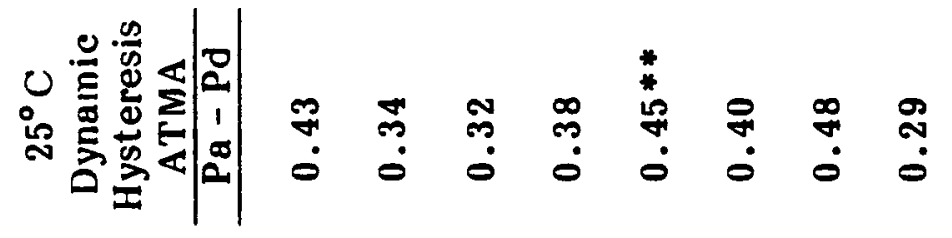

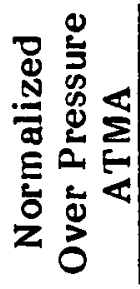

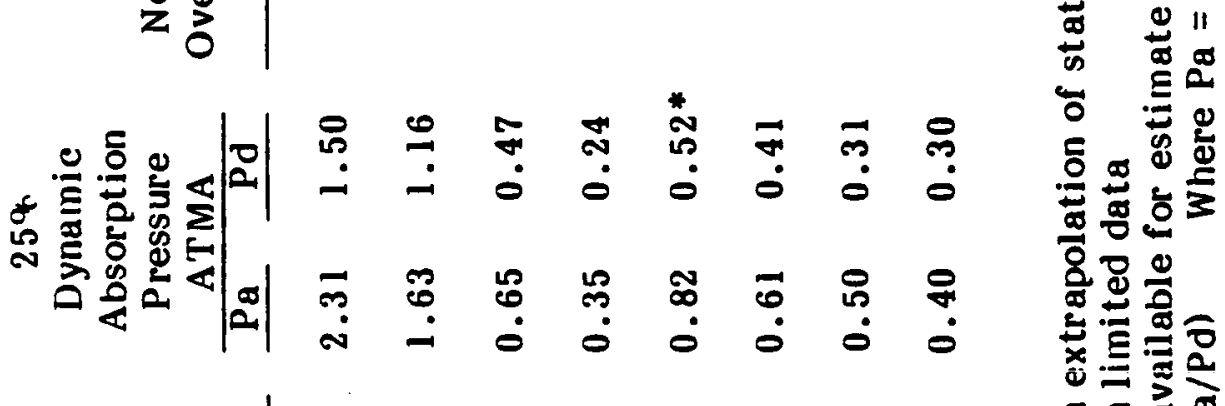

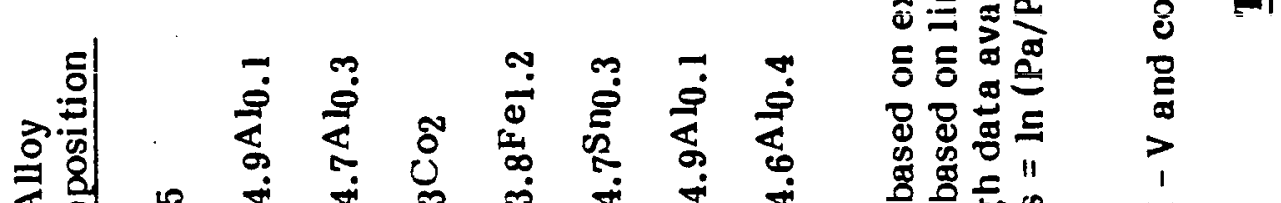

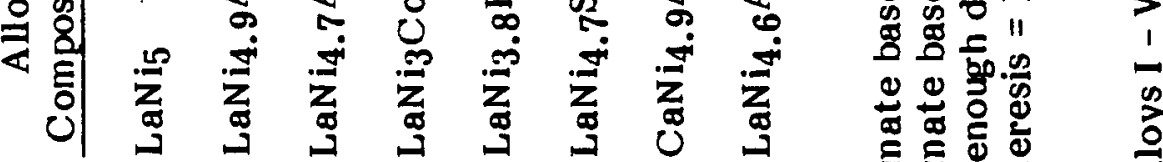

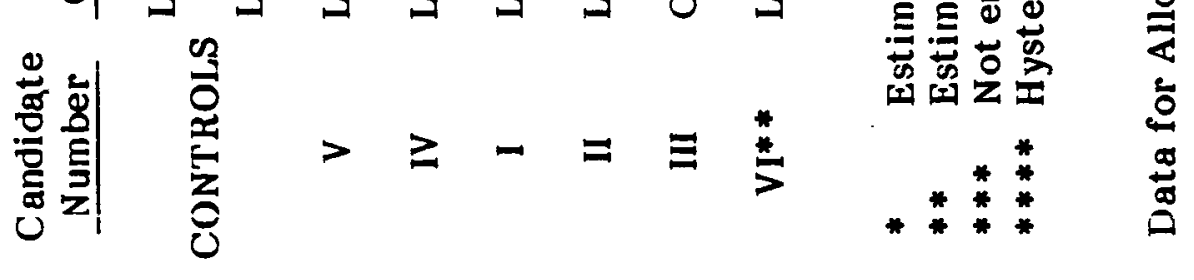




\section{Task 3-Hydride Container Design}

The absorption of hydrogen by metal hydride is a highly exothermic reaction and conversely is endothermic upon desorption. The rate at which the hydrogen must be absorbed or desorbed determines the method of heat management used. Two approaches generally used in the design of hydride vessels is an isothermal design, where the heat of reaction is ei ther removed or added by means of a heat exchanger with a thermal transport fluid and an adiabatic design where the heats of reaction are stored within the bed by the incorporation of large quantities of high heat capacity-inert materials. Since the heat transport paths are shorter in the adiabatic system, that approach is used for the higher hydrogen absorption/desorption rates. Where hydrogen flow-rates are low enough the isothermal process is used since smaller and fewer vessels are required with a greatly reduced hydride inventory leading to a desirable effect on the economics of the syst em.

Because of the encouraging results obtained during the performance of Task 1, a decision was made to use an isothermal design for the management of the generated heat. The rapid hydrogen flow-rate made it mandatory to keep the hydride "bed" thin thus reducing the length of the heat transfer path. During absorption, cooling water is made to flow around small diameter (.375 in. OD) tubes in which the hydride is contained. A flexible filter, of cylindrical cross section, is placed in the tube with the hydride occupying the annular space between the filter and the cylinder wall. Since the filter runs the full longitudinal length of the tube it provides a low pressure-drop path for the low pressure hydrogen vapor to enter the system.

The gas is very rapidly absorbed by the metal to which it is exposed and the heat of reaction dissipates through the outer wall in to the cooling water. For details of construction see Figure 20. As shown on the same figure, four of the 25 ft. long 0.375 in. OD tubes are placed into a 1.125 in. OD water jacket, and spirally wound to a 27 in. diameter flat coil. Three coil assemblies were fashioned in this way, placed inside an enclosure and the water jackets connected in series. The hydrogen lines, each equipped with a filter, pressure relief valve and a manual shutoff valve were connected in parallel to a central manifold through which the 
hydrogen enters and exits the system. The enclosure also housed two electrically operated solenoid valves to control the hot (for desorption) and cold (for absorption) water flow through the jacket. Two motor-operated rotary-valves provide a lowpressure path for the hydrogen to flow from the source to the "bed". A differential pressure transducer, located between the two rotary valves, enabled monitoring of the pressure in the coil, at the source or both. The transducer range, -10 psi to +10 psi, accurately transmitted the low pressures and small changes witnessed during the operation of the device. A thermocouple in the hydride, another in the water jacket and a third in the air enabled recording of hydride, water and ambient temperatures during a test run. A pressure transducer $(0-600$ psig) was installed on the highpressure side of a regulator to track pressure changes in the hydrogen cylinder source as the hydrogen was absorbed by the hydride. 
All temperatures and pressures as well as all electrical valve switches were monitored and operated remotely, from 50 feet away, for safety considerations.

\section{Task 4 - Alloy/Container Design Verification Test}

The design described in section $C$, i.e. 0.375 in. diameter copper tube with axial flexible filter and hydride filling the annular space between the two, had to be verified by flow tests. A single coil $10 \mathrm{ft}$. long was fabricated using 380 grams $(38 \mathrm{~g} / \mathrm{ft})$ of the specially melted alloy ( $\mathrm{LaNi}_{4.6} \mathrm{Al}_{0.4}$ heat $\left.\mathrm{T}-88860-2\right)$ after grinding to $\mathbf{- 3 5}$ mesh. The hydride was vibrated into the tube/filter assembly's hydride space where the resulting void fraction is typically $40 \%$. The tube was equipped with a pressure relief valve and a manual shut-off valve. The coil was not fitted with a water jacket; but was immersed in an agitated temperature-controlled bath instead. This provided better temperature control and nearly isothermal test conditions.

The verification test program emphasized the absorption half of the cycle since the rapid absorption of the low pressure hydrogen vapor was recognized as the constraining factor in this application. Hydrogen gas at various pressures slightly above and below atmospheric pressure was used to charge this coil while it was held at $25^{\circ} \mathrm{C}$ by the water bath. The time to reach $90 \%$ of full charge was recorded and the results are presented in Figure 21 and Table 7 . At the system design pressure point ( 2 psig) the coil exhibited the capability to absorb 44 liters of hydrogen, $90 \%$ of the hydride's full capacity (1.16 wt\%) within 2 minutes. This rate is 30 times faster than required for the subject application. The results of the tests verified the present heat exchanger design and suggested newer and less expensive approaches to hydride encapsulation. 


\begin{tabular}{|c|c|c|c|}
\hline $\begin{array}{c}\text { Hydrogen } \\
\text { Pressure } \\
\text { psia } \\
\end{array}$ & $\begin{array}{c}\text { Time } \\
\text { To } \\
90 \%, \text { Min }\end{array}$ & $\begin{array}{l}\text { Abs. Rate } \\
\text { Max, SLP M }\end{array}$ & $\begin{array}{l}\text { Abs. Rate } \\
\text { Avr, SLP M } \\
\end{array}$ \\
\hline $\begin{array}{c}7 \\
20 \\
15 \\
20 \\
25 \\
* 17\end{array}$ & $\begin{array}{r}>7.35 \\
4.35 \\
2.58 \\
1.25 \\
1.15 \\
2.0\end{array}$ & $\begin{array}{l}15.0 \\
18.4 \\
32.2 \\
56.0 \\
80.0 \\
40.0\end{array}$ & $\begin{array}{r}6.0 \\
10.1 \\
17.1 \\
35.2 \\
38.3 \\
22.0\end{array}$ \\
\hline
\end{tabular}

* Interpolated values for dewar design pressure.

TABLE 7. Hydride Test Coil absorption rates at various charging pressures

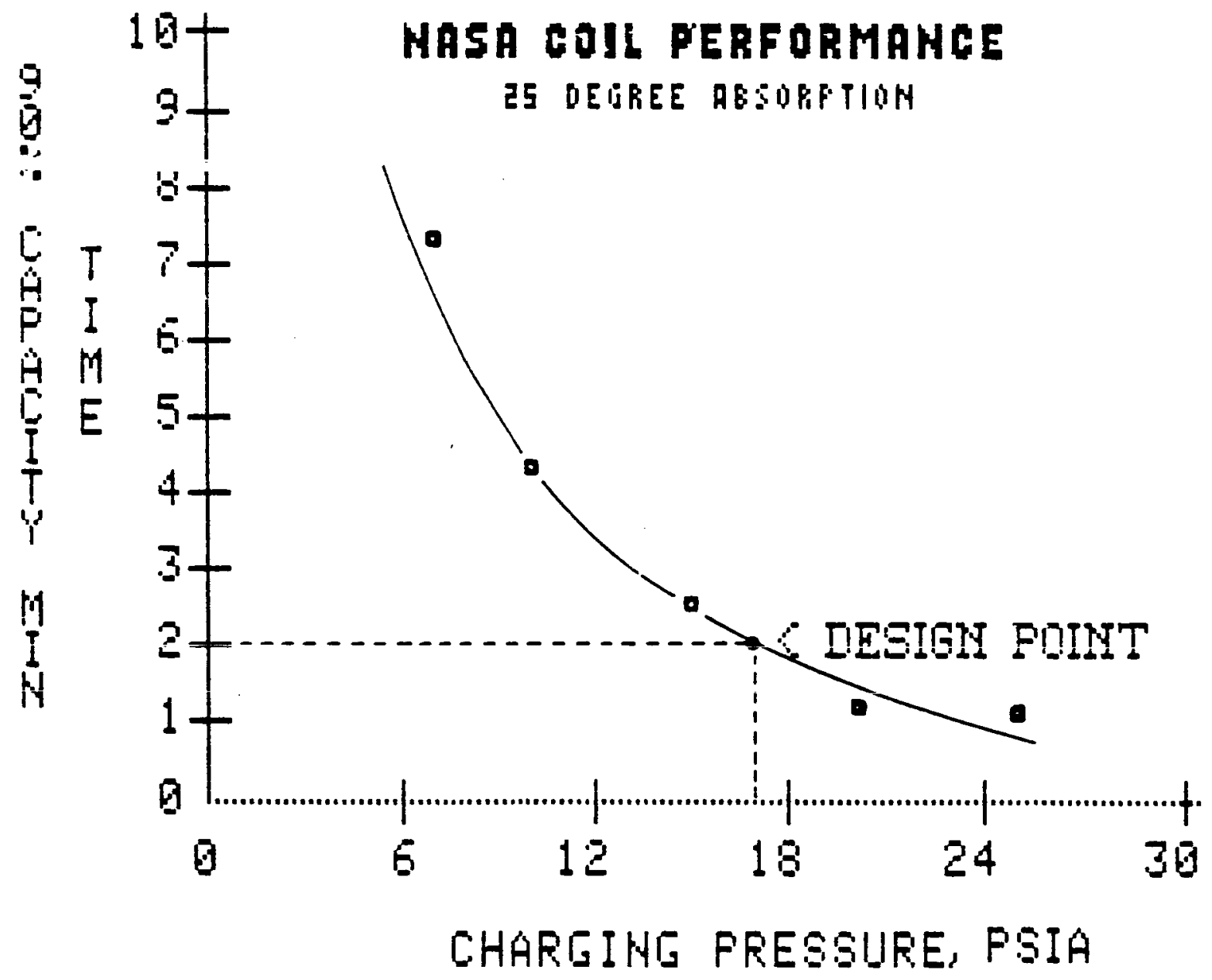

FIGURE 21: $25^{\circ} \mathrm{C}$ absorption rate performance of NASA test coil as a function of charging pressure. 


\section{E. Task 5 - Hydride Alloy Manufacture}

Based upon the system design constraints and known hydride characteristics, a custom alloy of Lanthanum Nickel Aluminum was identified as the "hydride-of-choice". As described in Section B, Task 2, the hydride contained a higher aluminum content than Ergenies standard HYSTOR-207 (LaNi4.7 Al0.3) alloy. A 30 lb melt was made in a vacuum induction furnace at the International Nickel Research and Development Center (IRDC) in Sterling Forest, NY. The melt was supervised by Dr. G. D. Sandrock of the Ergenics staff and the Chemical Analysis is presented in Table 8. The billet was normalized by heat treating at $1125^{\circ} \mathrm{C}$ for 17 hours and crushed in a Gyro Mill grinder to -35 mesh. A small representative sample (8.0 grams) was enclosed in a hydriding reactor and both absorption and desorption equilibrium isotherms were generated at three different temperatures. Figures 2223 depict the measured Pressure-Composition-Temperature (PCT) characteristics of heat $\mathrm{T}-88860-2$ melted for the application.

\begin{tabular}{|c|c|c|c|c|c|c|c|c|}
\hline \multirow{2}{*}{$\begin{array}{l}\text { Analysis } \\
\text { Number }\end{array}$} & \multirow[b]{2}{*}{ Date } & \multirow{2}{*}{$\begin{array}{c}\text { Heat } \\
\text { Number }\end{array}$} & \multicolumn{6}{|c|}{ Constituents, Weight Percent } \\
\hline & & & $\underline{\mathrm{LA}}$ & $\mathrm{Ni}$ & $\mathrm{Al}$ & $\mathrm{O}_{2}$ & $\mathrm{~N}_{2}$ & C \\
\hline 35631 & $8 / 12$ & $\begin{array}{c}\text { T-88855 } \\
\text { Target } \\
\text { Actual }\end{array}$ & $\begin{array}{l}33 \\
33.2\end{array}$ & $\begin{array}{l}65 \\
65.1\end{array}$ & $\begin{array}{l}2 \\
1.7\end{array}$ & $\begin{array}{l}.05 \\
.02\end{array}$ & $\begin{array}{l}.01 \\
.01\end{array}$ & .02 \\
\hline & & nic Form & $\mathrm{la}-\mathrm{La}$ & $.02 \mathrm{Ni}$ & $.73 \mathrm{~A}$ & .2 & & \\
\hline 35713 & $8 / 16$ & $\begin{array}{l}\text { T-88860 } \\
\text { Target } \\
\text { A ctual }\end{array}$ & $\begin{array}{l}33.1 \\
32.9\end{array}$ & $\begin{array}{l}64.3 \\
65.0\end{array}$ & $\begin{array}{l}2.6 \\
2.1\end{array}$ & $\begin{array}{l}.02 \\
.01\end{array}$ & $\begin{array}{r}.01 \\
.002\end{array}$ & .02 \\
\hline
\end{tabular}

Table 8: Chemical Analysis Report 


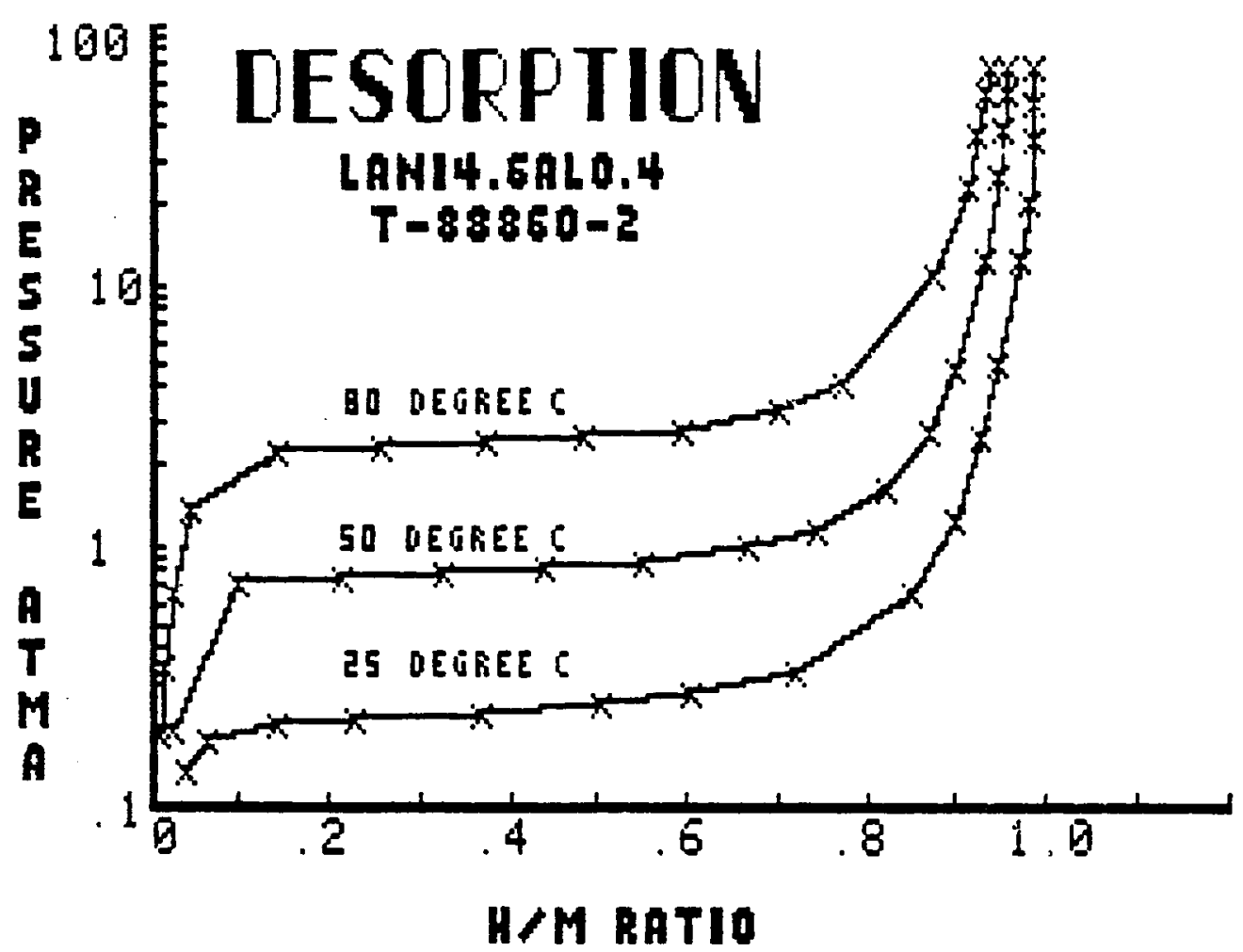

FIGURE 22: 25,50 and $80^{\circ} \mathrm{C}$ desorption isotherms for LaNi ${ }_{4.6} \mathrm{Al}_{0.4}$, heat \#T-88860-2

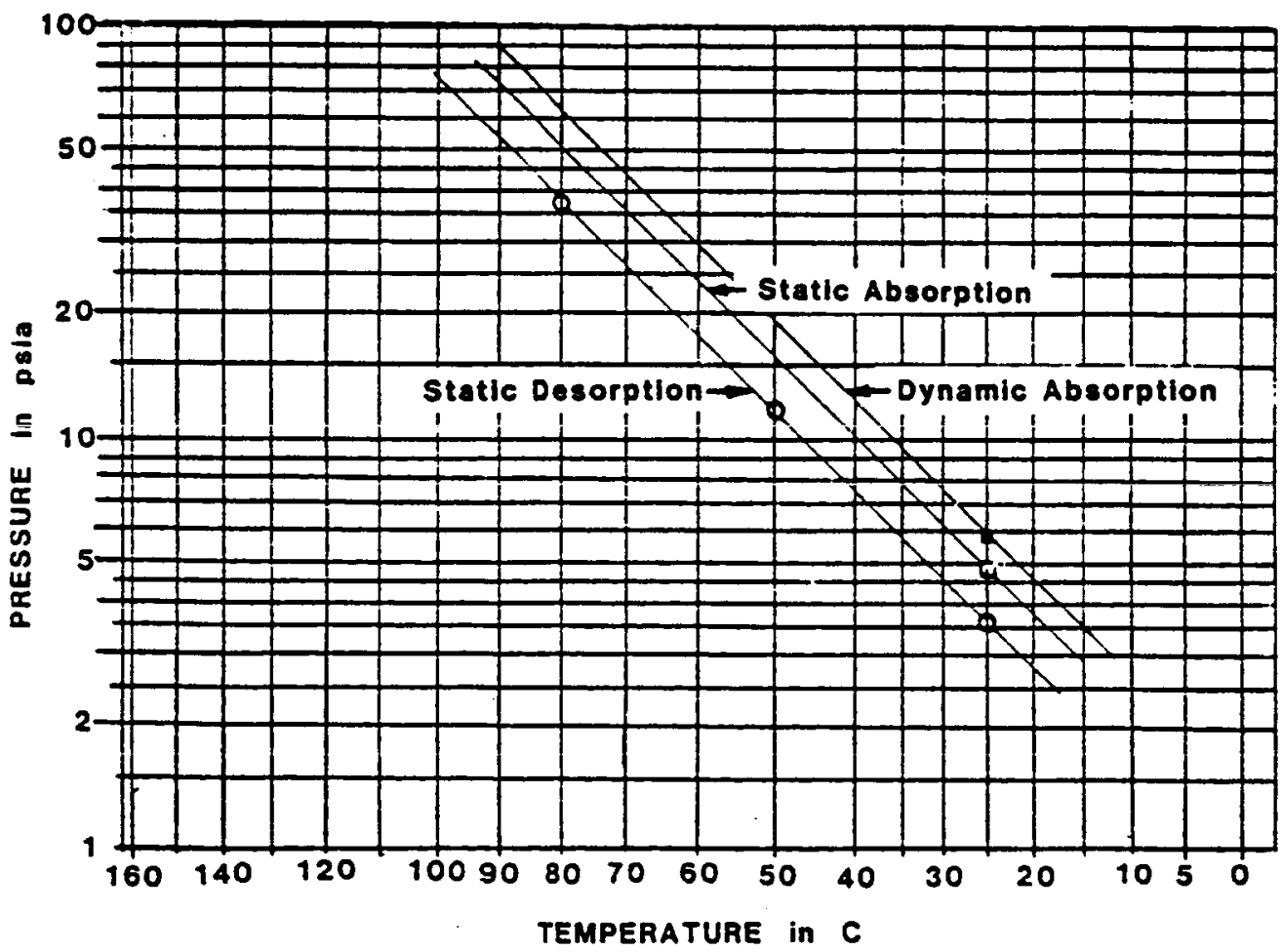

FIGURE 23: Equilibrium (Static) and Transient (Dynamic) $25^{\circ} \mathrm{C}$ Absorption and Desorption Van't Hoff curves for LaNi $4.6 \mathrm{Al}_{0.4} \mathrm{~T}-88860-2$ 
An earlier melt, heat $\mathrm{T}-88855-2$, did not meet composition or performance specifications. See Table 8 and Figure 18. Figure 22 shows the Pressure-Temperature relationship with the hydrogen concentration held constant at the isotherm plateau mid-point $(H / M=0.5)$. The dynamic absorption and desorption lines indicate that $25^{\circ} \mathrm{C}, 1.0$ atma absorption and $75^{\circ} \mathrm{C}, 3.0$ atma desorption is possible with this hydride.

\section{F. Task 6 -Container Construction and System Assembly}

The system design, as described in section $C$, is based on coiled hydride tubes in a water jacket, See Figure 20. Twelve $25 \mathrm{ft}$. long, $3 / 8$ inch diameter copper tubes were each fitted with a 0.225 inch diameter hollow flexible filter. The tubes with full length filters, were attached to a vibrator and positioned to stand on end. The annular space between the filter and the inner tube wall was filled with -35 mesh hydride powder to a packing density of $60 \%$. Four tubes were inserted into each of three 1-1/8 inch diameter copper water jackets and soldered in place. The water jackets, with internal hydride tubes, were coiled into a flat spiral layer of approximately three wraps.

The hydride tube ends were fitted with individual $2 \mu \mathrm{m}$ filters and connected in parallel to a central manifold through which the hydrogen both enters and exits the hydride beds. Each coil layer was equipped with a 150 psi pressure reỉef vaive anỏ a manuai snut-ô̂î vaive. The ṫhree iayereo coîs were stacked ano bound together with their hydrogen manifolds connected in parallel, thus insuring free access by the entering gas to all the hydride beds simultaneously. This configuration provides the lowest possible pressure drop loss. The coil stack was placed in to a steel-box-housing $\left(30^{\prime \prime} \times 36^{\prime \prime} \times 16^{\prime \prime}\right)$ and the water jackets connected in series. Series connection of the water lines results in greater sensible heat recovery and higher efficiencies. This method of cooling and heating was chosen even though more rapid absorption can be obtained by connecting the water jackets in parallel. Two thermocouples were placed in the coils; one in the hydride bed and one in the water jacket. The thermocouples would be used during the test program to monitor temperature transients as hydrogen is admitted or discharged from the coil and as water temperatures are changed. A third thermocouple was placed in the housing to monitor ambient temperature. Two motorized rotary valves were used to direct the 
hydrogen flow from the low pressure source to the coil during absorption and from the coil to the low pressure gas accumulator during the discharge phase of the test $(\mathrm{V}-1$ and $\mathrm{V}-2$ in Figure 24). The hydrogen line was also fitted with an oxygen purifier and a molecular sieve dryer to protect the hydride surface from poisoning by the inadvertant admission of air during the performance of the test.

A low pressure differential pressure transducer $(-10$ psi to +10 psi) is located at a "tee" junction between $\mathrm{V}-1$ and $\mathrm{V}-2$, thus enabling very accurate pressure measurements of the hydride coil, the hydrogen source and during absorption, both. A pressure transducer was also installed on the high pressure side of the regulated hydrogen supply to monitor changes in the cylinder pressure as the hydrogen is absorbed by the hydride. From these measurements of gas volume absorbed as a function of time, absorption rates can be calculated. Two solenoid valves (SV-1 and SV-2 in Figure 24) control the hot and cold water to the coil water jackets. External to the housing, manual shut-off valves are provided for evacuating and purging the system during set-u as well as for choosing the preferred hydrogen supply for each test. The motorized and solenoid valves are operated remotely (50 feet) by toggle switches mounted on the face of the control panel. Temperatures and pressures are monitored from digital readout instruments which are also mounted on the panel face. See Figures 25 and 26 for photographs of capture device and remote control panel. 


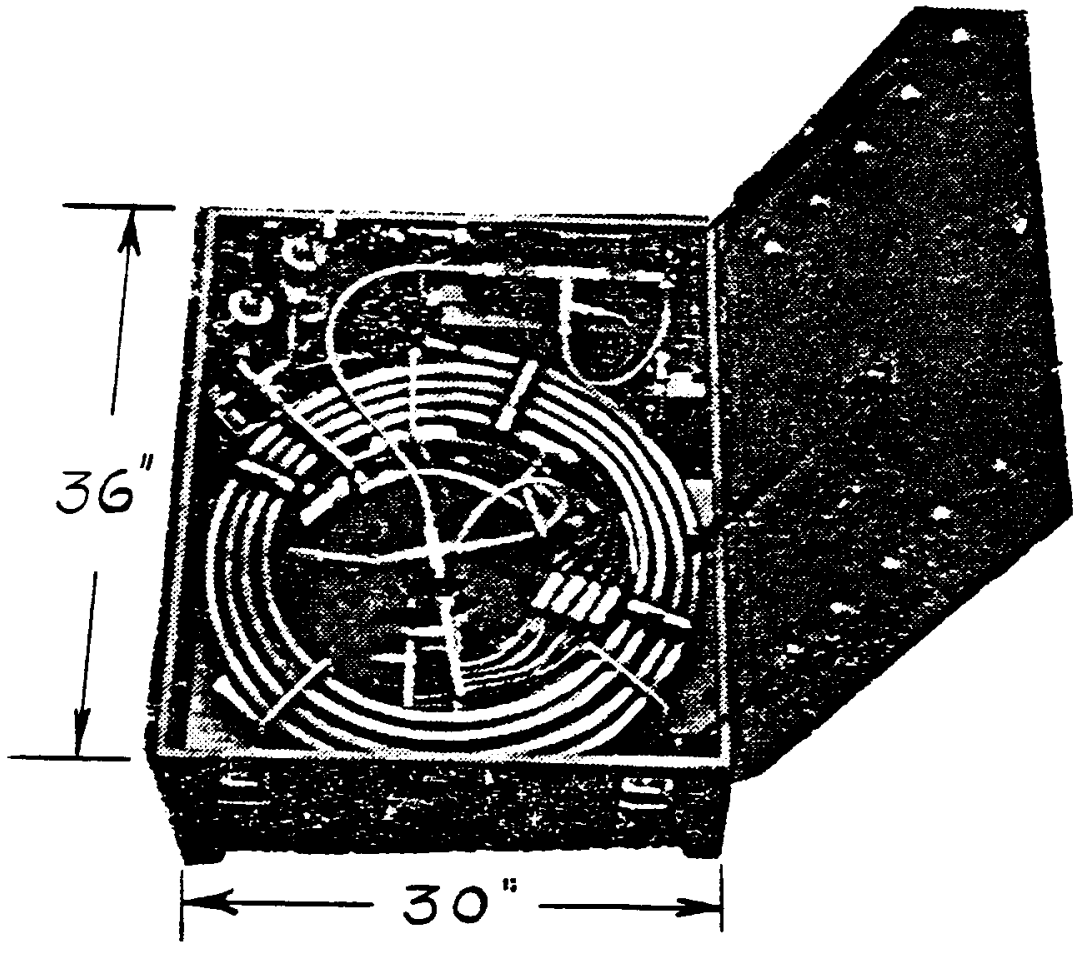

FIGORE 25: Hydrogen boiloff capture system.

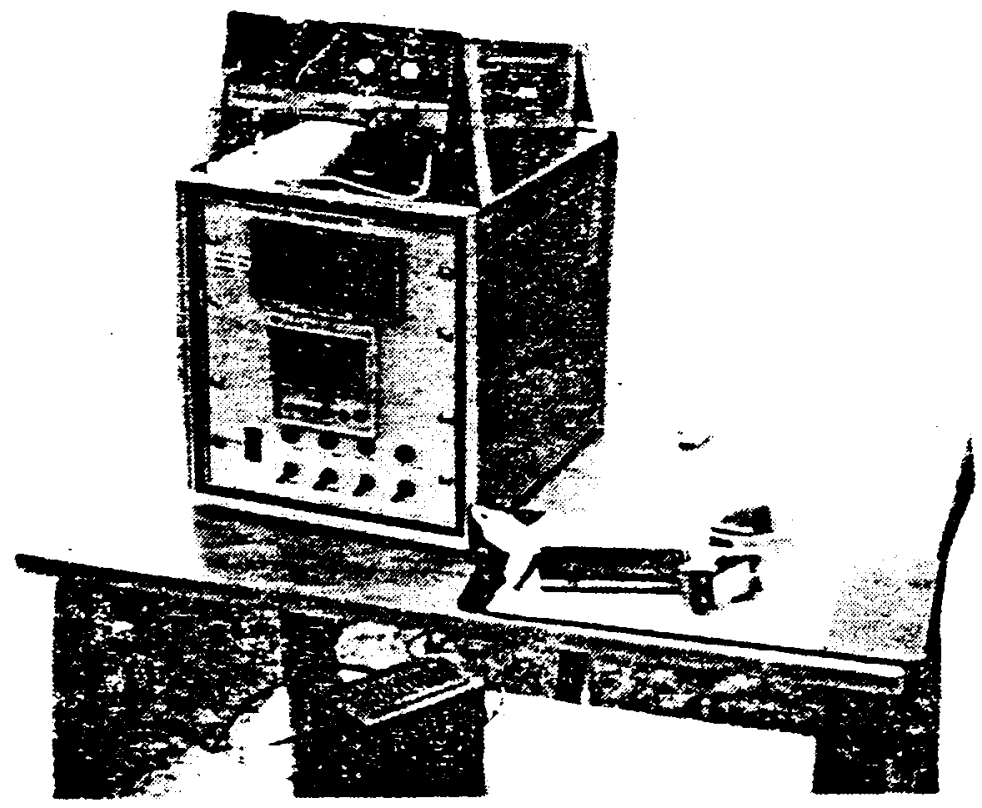

FIGURE 26: Remote control panel for KSC demonstration. 


\section{G. Task 7 - System Test}

The test of the demonstration device was conducted in two parts. The first, Task 7, involved testing under controlled conditions at the Ergenics, Inc. laboratory in Wyckoff, NJ and the second, Task 9, was conducted "in-the-field", under less controlled conditions, at the Kennedy Space Center.

To simulate the low-pressure high-flow-rate hydrogen boiloff stream it was decided to use large balloons as the hydrogen source. This seemed, at first, to be a very simple and more-than-adequate solution since a balloon's internal pressure is extremely low (measured to be 0.01 to $0.05 \mathrm{psig}$ ) and essentially constant for the entire deflation period. Hydrogen absorption rate by the hydride is graphic and can be recorded as the balloon's diameter, hence its volume, is measured periodically during the run. A problem arose as this scheme was attempted with the small test coil as a result of a) residual air in the baloon due to insuf ficient purging, b) oxygen and/or water vapor permeation through the skin of the balloon or c) leached from the balloon material by the hydrogen. Whatever the reason, the effect was to poison the hydride's surface and reduce its storage capacity and chemical kinetics. The hydride was readily restored to its full capacity by evacuation to $1 \mathrm{~mm} \mathrm{Hg}$ at $80^{\circ} \mathrm{C}$ and exposure to UHP hydrogen. Three different balloon materials were tried with various levels of success. See Figure 27. In the as-received" condition none of the materials were acceptable. Washing with freon and acetone seemed to improve their performance; but the best results were obtained by coating the inside of natural-rubber advertising balloons with silicone vacuum grease. Using this procedure an eight foot diameter natural-rubber balloon was prepared for the demonstration at the kSC with the large coil system. 


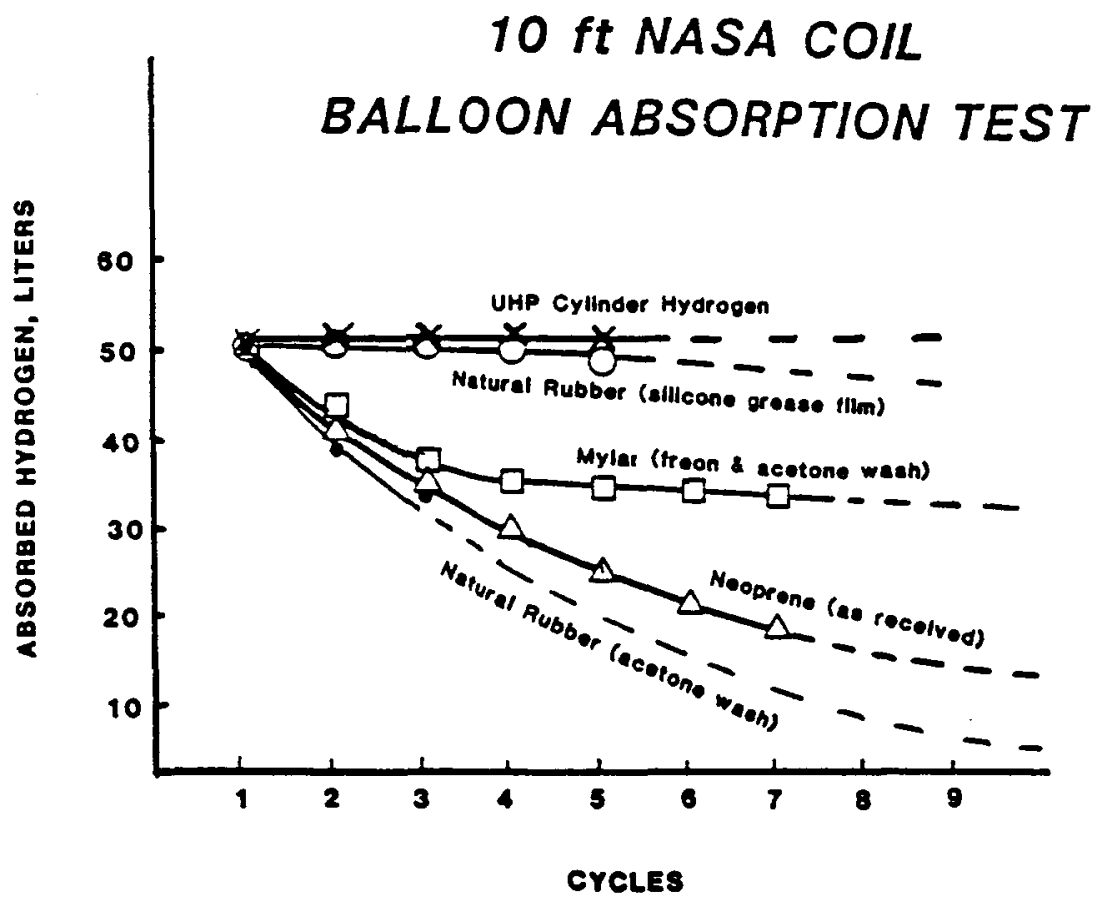

FIGURE 27 Effect of hydrogen stored in various elastomers on cyclic absorption capacity of hydride.

The laboratory absorption tests were conducted using a compressed gas cylinder as the hydrogen source and low-pressure regulation to reduce the pressure to atmospheric. The cooling water temperature was unregulated at an average temperature of $12^{\circ} \mathrm{C}$ and was circulated through the water jacket at a flow-rate of 6 GPM. With valve $\mathrm{V}-1$ closed and $\mathrm{V}-2$ open, the coil (hydride plateau) was measured at the pressure transducer as 3 psia ( 0.2 atma). The hydrogen absorption rate was measured by recording the cylinder pressure as a function of time. Ideally, as shortiy as possible after opening V-1 the system pressure should have risen to near atmospheric pressure, which would most closely simulate the anticipated conditions during boiloff recovery at the KSC. This did not happen since the hydride's ability to absorb hydrogen, even at the sub-atmospheric charging pressures ( 10 psia, 0.7 atma) was much greater than the regulator's ability to dispense hydrogen. The result of this test is depicted as the solid dots ( $\mathrm{Small} \mathrm{C}_{\mathrm{v}}$ Regulator on Figure 28. A second run with the same test conditions, but using a regulator with a larger $C_{v}$, resulted in the curve described by the open dots (Large $C_{v}$ Regulator) also in Figure 28. Even in this run, although much improvement is evident, the coil was still "starved" by the regulator's inability to output hydrogen at a rate rapid enough to 
satisfy the coil. Desorption of the coil af ter each run under controlled conditions confirmed that the maximum storage capacity, $68 \mathrm{SCF}$, of hydrogen had been absorbed in less than 10 minutes and that $90 \%, 60 \mathrm{SCF}$, had been absorbed in less than 3 minutes. A third test was run after returning from the KSC demonstration to confirm that the storage capacity and kinetics are unaffected after poisoning and subsequent reclamation. Using a bank of gas cylinders as a low-pressure (14.7 psia, 1 atma) surge and "feeding" the surge through a very large $C_{v}$ regulator it was possible to run the test under conditions that more closely simulated the boiloff capture conditions during off-loading. The results are presented in Figure 28 as the open square points. The rapid initial rise, $50 \%$ absorbed in less than 1.5 minutes, is somewhat balanced by a slowing down above $80 \%$. We attribute this to heat transfer limitations; but it should be recognized that the hydride need only reach $90 \%$ in less than 60 minutes to capture the off-loading boiloff.

\section{NASA LARGE COIL} ABSORPTION

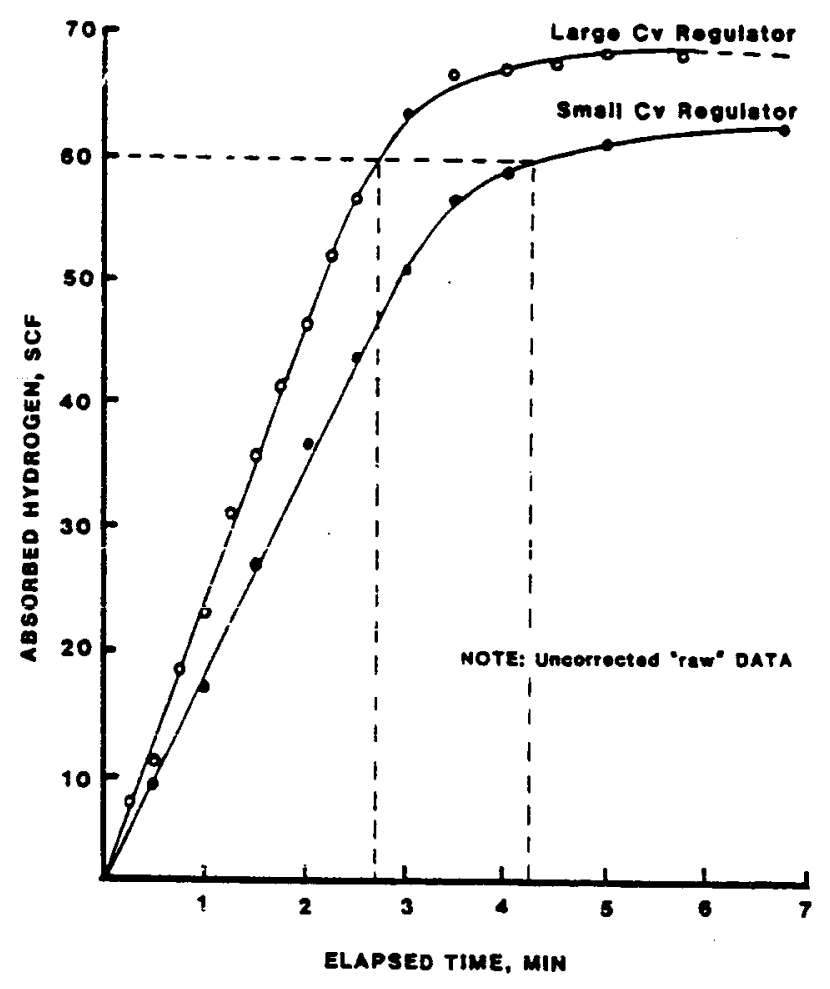

FIGURE 28: NASA hydrogen capture demonstration system performance. 
H. Task 8 - Report Preparation

The preparation of the final report was an on-going effort with sections, figures and tables being prepared as required for monthly Progress Letter reporting. At the conclusion of the test program approximately $15 \%$ of the final report had been completed.

\section{Task 9-Proof of Concept Demonstration and Project Review}

The device was operated at the KSC for evaluation by the Project Manager and other interested NASA and EG\&G personnel.

Because of the uncertainties that still existed concerning the balloon poisoning effect, the field test procedure was planned to first demonstrate the absorption of pure hydrogen from a compressed gas cylinder, the second was to inflate the balloon with the hydrogen liberated by the hydride as hot water was circulated through the water jacket, and finally an attempt would be made to reabsorb the hydrogen from the balloon into the hydride.

The two regulators used at Ergenics for the first two absorption tests were piped in parallel so that the contribution of each might be enough to adequately "feed" the coil. Because of a water main break, cooling water had to be pumped from a water tanker. The cooling water was warmer $\left(19-20^{\circ} \mathrm{C}\right)$ than optimum and once again the hydrogen flow-rate through the regulators was insufficient to supply the hydrogen at the hydride's absorption rate. The system pressure stayed below 0.5 atma for 2.5 minutes and rose to 0.8 atma when the regulator setting was increased to $>40$ psig. The total time to $90 \%$ capacity when the system pressure finally reached 1.0 atma was 8.0 minutes; much longer than the laboratory results but still very acceptable.

The liberation of the hydrogen from the hydride bed into the balloon was attempted. With $\mathrm{V}-1$ closed and $\mathrm{V}-2$ opened $\mathrm{SV}-2$ was closed and $\mathrm{SV}-1$ opened. This permitted hot water $\left(73^{\circ} \mathrm{C}\right)$ to flow through the water jackets, raising the hydride temperature and thus increasing the system pressure. In about 1.0 minute, when the system pressure was above 2.0 atma, $\mathrm{V}-2$ was opened to permit the hydrogen to 
inflate the balloon. The balloon inflated rapidly, accepting approximately $70 \%$ of the hydrogen stored in the hydride within 5 minutes. Due to windy conditions, it was decided to abort and begin the third test quickly. The positions of SV-1 and SV -2 were reversed causing cold water to flow through the water jackets. With both $V-1$ and V-2 open, the balloon's diameter began to decrease as the hydrogen was reabsorbed into the bed. Due to a number of problems only half the balloon's volume was absorbed into the bed. The hydride had been damaged as a result of poisoning by oxygen, water vapor or some other substance emitted by the balloon's material. The apparatus was returned to the Ergenics Laboratory where the hydride was regenerated and additional tests run. The tests confirmed that hydrides can absorb low-pressure hydrogen at a rate that is adequate to capture $\mathrm{LH}_{2}$ boiloff during the off-loading operation and liberate the hydrogen at pressures greater than atmospheric using hot water at reasonable temperatures.

A presentation, including slides of the figures and tables in this report, was made describing the fabrication and test program. Copies of all presentation materials and computer programs used during the performance of this program will be delivered to NASA/KSC wi th this report.

\section{FULL SCALE SYSTEX}

During the off-loading operation, hydrogen vapor is liberated at an average rate of 10,300 SCFM. A liquefier capable of producing 40 tons/day of liquid would be required to handle this off-gas in "real-time". Obviously, this is not a costeffective approach. Even though a full-scale metal hydride boiloff capture system will require miles of tubing and many pounds of hydride, this work indicates that it is a feasibie and economically justifiable approach to reducing launch costs at the KSC. See Tables 1-3, 5 .

The system must be capable of capturing and storage, albeit short-term, 3,400 lbs. (620,000 SCF) of hydrogen for subsequent liberation to a small, approximately 2 tons/day, liquefier. Some combination of a smaller hydride capture system operating in parallel with the 12 ton/day liquefier presently being considered by NASA might be an even more cost-effective approach. 
Generally, the system outline in Table 2 is representative of what a reasonable system would look like. For all computer runs we assumed 1-1/8 inch OD copper tubing with 0.05 inch wall. The space between each spirally wrapped coil was held at 0.5 inches as was the vertical space between the stacked coil layers. The axial filter was held to be 0.225 inches with a hydride packing density of $60 \%$ in the annular space between the filter and the copper tube wall. The hydride's bulk density was assumed to be $420 \mathrm{lb} / \mathrm{ft}^{3}$ which is a good approximation for the alloy to be used. The minimum diameter for the smallest coil wrap was held constant at 2 feet. Only the coil layer's large diameter, the allowable stack height and the hydride's storage capacity were allowed to vary. The computer program allows changing any of the physical dimensions or constraints, and a program dise is included with this report which allows NASA personnel to investigate the system's sensitivity to parameter changes.

A typical system of this design would require 290,000 lbs. of hydride housed in 200,000 feet of tubing. With coil diameters and stack heights limited to 10 feet, we need 5 stacks of coils, each in its own cooling water vessel. The rough approximation of the hydride and the system cost was based solely upon the assumed storage capacity (e.g. $1 \%, 1.2 \%$ or $1.4 \%$ ) and the total hydrogen stored, 3,400 lbs. The system cost was assumed to be 1.4 times the hydride cost $(\$ 20 / \mathrm{kg}, \$ 9 / \mathrm{b})$. For the computer run presented in Table 2, the hydride's storage capacity was assumed to be $1.2 \%$; and the resulting costs of $\$ 2.6 \mathrm{M}$ for hydride, $\$ 3.6 \mathrm{M}$ for the total system and a payback time of 2 years are projected. The payback time is based on 20 launches/year and is computed as follows. It does not include the liquefier initial cost, operating costs or interest on capital outlay.

20 launches $\times 9$ off-loadings/launch $\times 6000 \mathrm{gal} /$ of $\mathrm{f}$ - loading $=1.08 \times 10^{6} \mathrm{gal} /$ year $400 \mathrm{gal} /$ day normal boil of $\mathrm{f} \times 360$ days $=144,000 \mathrm{gal} /$ year

Total boiloff reclaimed $1.22 \times 10^{6} \mathrm{gal} /$ year or $\$ 1.84 \mathrm{M} /$ year at $\$ 1.50 / \mathrm{gal}$

The capture system can be integrated into the existing facility at LC-39 as pictured in Figure 29. The reliquefier, being small, can be located at the storage dewar ton where its discharge can be added directly to the existing liquid. Multiple 
capture vessel modules with appropriate valving will permit discharging of some while others may still be absorbing boiloff. Additional modules may be added as needed.

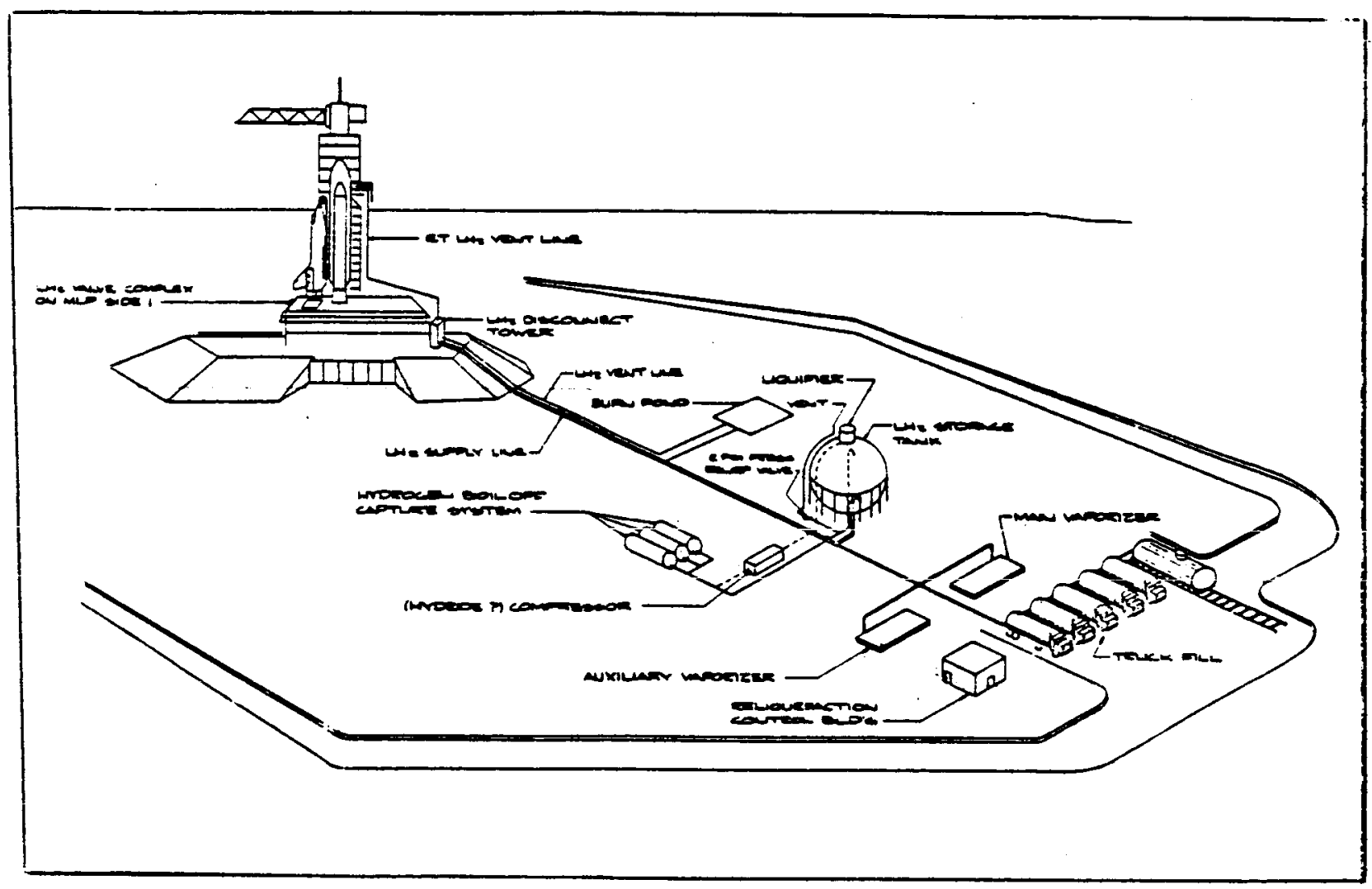

FIGURE 29: Artists concept of hydrogen boiloff recovery system at LC-39. Ref. 5 . 
Figure 30 shows schematically how the capture vessel, pictured in the upper right-hand corner, can be incorporated into the present system with a minimum of interruption and no change in present operating procedure. During installation the existing 10 inch $-150 \mathrm{lb}$. manual valve in the vent line would be temporarily closed, and the flanges broken, see Figures 31 and 32 . The spool piece between the manual valve and the 10 inch - $150 \mathrm{lb} .2 .5$ psi check valve will be replaced by a flanged tee with the branch leading to another 10 inch - $150 \mathrm{lb}$. manual valve. At this point the existing manual valve can be reopened since all additional construction can take place downstream of the new 10 inch manual valve. The location of the check valve insures that the dewar cannot be subjected to excessive back pressure. Should the capture vessels not be able to absorb the boiloff vapor for some reason, the back pressure will unseat the check valve, venting the vapor as is presently done.

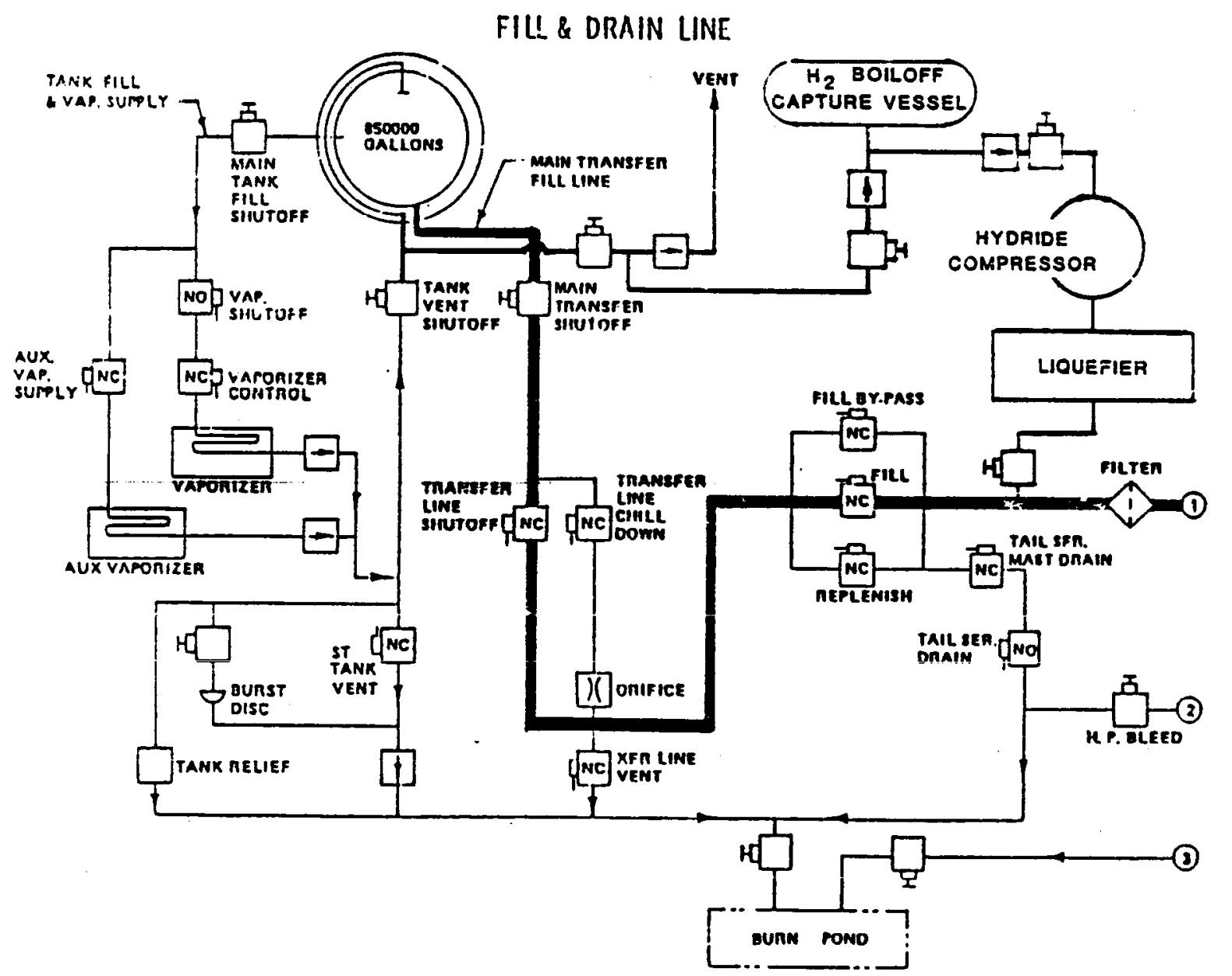

FIGURE 30: Schematic of hydrogen vapor recovery system addition to existing $\mathrm{LH}_{2}$ fill and drain lines. Ref. 1. 


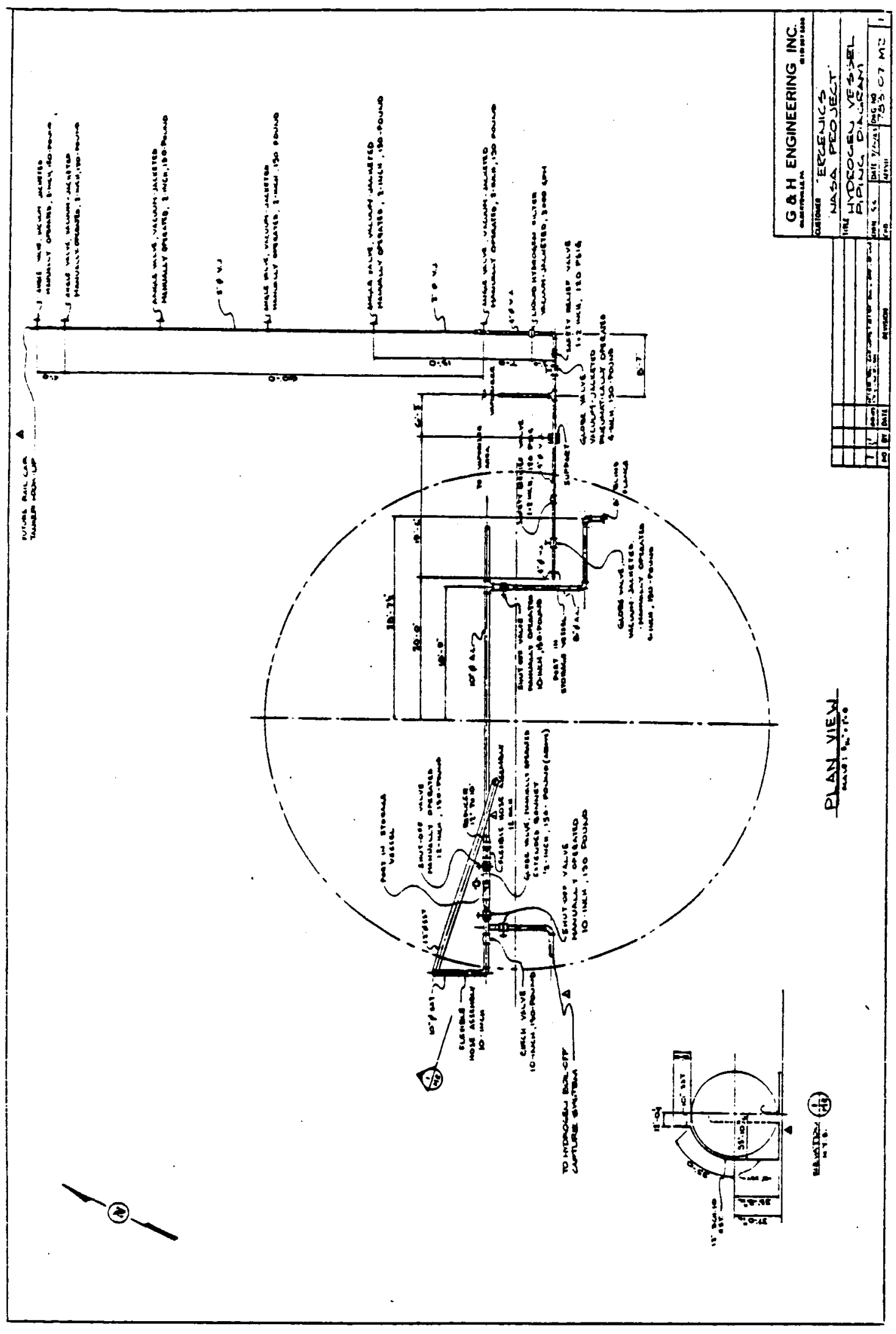

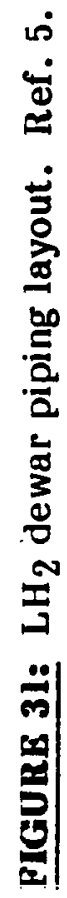




\section{FINAL COMMENTS AND RECOMMENDATIONS}

The program accomplished its stated mission; to demonstrate the technical feasibility of capturing low pressure hydrogen vapor as a reversible metal hydride at very rapid rates for subsequent reliquefaction. Based upon the results presented in this report, Ergenics believes the hydrogen capture system can be scaled directly for full scale operation. The extremely rapid absorption capability of metal hydrides suggests the alternative possibility of using a much smaller system operating on a short ( 3 to 5 minute) absorption/desorption cycle and acting as a staged compressor; the boiloff being stored as a compressed gas. Potential savings may be realized since at pressures as low as 1000 psi only fifteen tube trailers would be required to store all the gas for the slower reliquefaction process. Future work by Ergenics teamed with a suitable engineering construction firm should include:

1. An engineering analysis and cost study be done for each of the capture/reliquefaction scenarios identified.

2. Fabrication of a single full-scale component be completed for testing at the $\mathrm{KSC}$ on an actual $\mathrm{LH}_{2}$ boiloff stream.

3. Based upon the single component test results, design improvements should be added and a complete system fabricated at one launch complex.

4. Similar systems to be constructed at other launch sites. 


\section{ACKNOWLEDGEMENTS}

The authors; M. J. Rosso, Project Supervisor and P. M. Golben, Design Engineer, express their gratitude to Mr. J. Spears and Mr. F. Howard of NASA/KSC for their assistance in initiating this program and in gathering technical information. Our appreciation to Dr. E. L. Huston and Dr. G. D. Sandrock for their expertise and many helpful discussions regarding hydride alloy technical information. We also acknowledge the contributions of Mr. D. J. Hanley in the fabrication and testing of the demonstration device. Many thanks to Ms. Rosemarie Maslak and Ms. Barbara Tuthill for editing and typing the final report. 


\section{REFERENCES}

1. Information supplied by Mr. Frank Howard, NASA Technical Representative.

2. Mr. Robert Gibbs and Dr. Richard Thomas of Cryogenic Consultants, Inc. with Mr. Lynn Terry, private consultant.

3. Goodell, P. D., Sandrock, G. D. and Huston, E. L., International Nickel Company, Inc. "Microstructure and Hydriding Studies of $\mathrm{AB}_{5}$ Hydrogen Storage Compounds." January 1980 Final Report prepared for Sandia National Laboratories, SAND79-7095.

4. Goodell, P. D., Inco Alloy Products Company Research Center Project Report 3101.3, "Dynamic Hydriding Alloy Data", February 23, 1983.

5. G \& H Engineering, Inc., Gilbertsville, PA. 
APPENDIX A

CR YOGENIC CONSULTANTS REPORT

by

L. E. TERRY

RICHARD THOMAS

AND

ROBERT GIBBS

EDTTED BY M. J. ROSSO 
The boiloff or vaporization of $\mathrm{LH}_{2}$ as it is "of $\mathrm{f}$-loaded" from the tankers to the main storage Dewar at $\mathrm{KSC}$ is a product of the following four contributions.

1. Cooldown of the vacuum jacketed lines.

2. Boiloff from flashing of a high pressure liquid into a low presssure volume.

3. Boiloff from cooling down of dewar as liquid fills the dewar.

4. Ullage displacement.

Several steps are necessary in order to find the boiloff from each of the above contributions.

1. Find the equivalent length of piping of the fill lines to the dewar.

2. Determine the $\mathrm{LH}_{2}$ flow rate from the known transfer line pressure.

3. Calculate the heat capacity, cool down time and boiloff based on the fill-line length determined in Step 1.

4. Determine the gas displaced from the dewar's ullage space as the liquid level rises in the dewar.

5. Estimate the liquid evaporated during the cool-down of the dewar walls. The temperature differential between the top and bottom of the dewar was assumed to be $5^{\circ} \mathrm{K}$.

6. Calculate flashing into the dewar using the First Law of Thermodynamies and known states to determine the final quality of the liquid in the dewar. 
The contributions are added and the total flow-rate as a function of liquid initially in the dewar may be determined.

The actual length of the vacuum fill line is approximately 178 feet. Also in the line are 1 flexible hose, 1 elbow, 2 relief valves, and 3 globe valves. These fittings are equal to about 66 equivalent elbows. The equivalent length of piping is,

therefore, approximately 700 feet. (1). Using the equivalent length of piping and a known pressure drop between the line pressure and the dewar, the approximate mass flow rate of liquid can be determined.

The pressure drop ( $\left.1 \mathrm{~b} / \mathrm{ft}^{2}\right)$ in terms of viscosity, Reynold's number and mean fluid density is:

$$
\mathrm{P}=\mathrm{fL} \mu^{2} \mathrm{~N}_{\operatorname{Re}} \mathrm{e}^{2 / \log _{\mathrm{c}} D^{3}}
$$

Eq 1

where:

$f$ is the coefficient of friction, dimensionless

$\mathrm{L}$ is the equivalent length, $\mathrm{ft}$.

$D$ is the inside diameter, 4 inch sed $5, \mathrm{ft}$.

$\mu$ is the viscosity, $1 \mathrm{bm} / \mathrm{ft}$-sec.

$\mathrm{N}_{\mathrm{Re}}$ is the Reynold's number, dimensionless

$\rho$ is the mean density of the liquid, $\mathrm{lbm} / \mathrm{ft} .^{3}$

$g_{c}$ is the gravity conversion constant, $\mathrm{ft} / \mathrm{sec}^{2}$

The same equation can be reduced to the following when known terms are substituted:

$$
\mathrm{P}=2.2 \times 10^{-8} \quad \mathrm{~N}_{\mathrm{Re}^{2}} / \mathrm{p}
$$

here the viscosity is $9.54 \times 10^{-6} \mathrm{lbm} / \mathrm{ft}-\mathrm{sec}$. at $20^{\circ} \mathrm{K}$.

Table I is a compilation of the results of the pressure drop calculations. The results were obtained by assuming a pressure drop, then guessing at a Reynold's number and getting the corresponding coefficient of friction. Using these numbers 
in the pressure drop equation, the calculated results were checked to see if both sides of the equation were equal. If not, then a new Reynold's number was guessed at and the results checked. The iteration was continued until the correct Reynolds number was obtained for the pressure drop assumed. The mass flow rate of liquid hydrogen could then be determined from the following equation:

$$
\dot{\mathrm{m}}=\mathrm{N}_{\mathrm{Re}} \mu \mathrm{A} / \mathrm{D}
$$

Eq 3

where:

$\dot{\mathrm{m}}$ is the mass flow rate, $1 \mathrm{bm} / \mathrm{sec}$.

$\mathrm{N}_{\mathrm{Re}}$ is the Reynold's number, dimensionless

$\mu$ is the viscosity, $1 \mathrm{bm} / \mathrm{ft}$-sec.

$A$ is the internal cross-sectional area of the pipe, ft.2

$\mathrm{D}$ is the internal diameter, $\mathrm{ft}$.

Which is actually a rearrangement of the equation for computing the Reynold's number

$$
\begin{gathered}
\mathrm{N}_{\mathrm{Re}}=\dot{\mathrm{mD}} / \mu \mathrm{A} \text { and as } \mathrm{A}=\pi \mathrm{D}^{2 / 4} \\
\mathrm{~N}_{\mathrm{Re}}=4 \dot{\mathrm{m}} / \pi \mu \mathrm{D}
\end{gathered}
$$

The results of the pressure drop and mass flow rate calculation are given in Table I. The equivalent volume flow rate of the liquid if all liquid were converted to gas at standard conditions is given in column 4. Columns 5,6 and 7 present the

\begin{tabular}{|c|c|c|c|c|c|c|}
\hline $\mathrm{P}$ & & $\dot{\mathrm{m}}$ & $Q$ & $m$ & V & \\
\hline PSIG & $\mathrm{N}_{\mathrm{Re}}$ & $\mathrm{lbm} / \mathrm{sec}$ & SCF M & lbm/cu.ft. & $\mathrm{ft} / \mathrm{sec}$ & $\mathrm{M}$ \\
\hline $\begin{array}{l}30 \\
25 \\
20 \\
15 \\
10\end{array}$ & $\begin{array}{l}6.8 \mathrm{E} 6 \\
6.2 \mathrm{E} 6 \\
5.5 \mathrm{E} 6 \\
4.7 \mathrm{E} 6 \\
3.8 \mathrm{E} 6\end{array}$ & $\begin{array}{l}18.36 \\
16.74 \\
14.85 \\
12.69 \\
10.26\end{array}$ & $\begin{array}{l}2.11 \mathrm{E} 5 \\
1.93 \mathrm{E} 5 \\
1.71 \mathrm{E} 5 \\
1.46 \mathrm{E} 5 \\
1.18 \mathrm{E} 5\end{array}$ & $\begin{array}{l}4.17 \\
4.21 \\
4.23 \\
4.25 \\
4.27\end{array}$ & $\begin{array}{l}86.6 \\
78.2 \\
69.0 \\
58.7 \\
47.3\end{array}$ & $\begin{array}{l}.077 \\
.070 \\
.062 \\
.052 \\
.042\end{array}$ \\
\hline $\begin{array}{l}7 \\
5\end{array}$ & $\begin{array}{l}3.2 \mathrm{E} 6 \\
2.6 \mathrm{E} 6\end{array}$ & $\begin{array}{l}8.64 \\
7.02\end{array}$ & $\begin{array}{l}9.95 \mathrm{E} 4 \\
8.09 \mathrm{E} 4\end{array}$ & $\begin{array}{l}4.27 \\
4.29\end{array}$ & $\begin{array}{l}39.8 \\
32.2\end{array}$ & $\begin{array}{l}.035 \\
.028\end{array}$ \\
\hline
\end{tabular}
mean density of the liquid, the velocity of the liquid in the pipe and corresponding Mach number, respectively.

TABLE I: Mass flow rate of liquid in the fill line as a function of differential pressure between the fill line and dewar. 
The next thing to calculate is the cooldown of the vacuum jacketed piping. There are two contributions to the liquid boiloff as it first flows down the piping. One term is the steady state heat transfer through the insulation. Since the temperature varies from approximately ambient down to the liquid temperature, one-half of the steady state heat gain is used. The allowable heat gain by NASA specifications is $1000 \mathrm{BTU} / \mathrm{hr}$ for the dewar and $1800 \mathrm{BTU} / \mathrm{hr}$ for fill lines. (2) The external heat transfer gain is then about $1400 \mathrm{BTU} / \mathrm{hr}$. Assuming that the cooldown time is about $\mathbf{5}$ minutes, the amount of heat transferred in that time is $1.2 \times 10^{5}$ Joules. This term will be shown to be negligible as compared to the sensible heat of the lines, which is the other contributing term to liquid boiloff during the cooldown of the transfer lines. The vacuum jacketed inner line is constructed of Schedule 5,4 inch Invar pipe. The heat capacity for nickel as a function of temperature was obtained from the Handbook of Chemistry and Physics, 41 st Ed. page 2273 (5). The heat capacity for iron is roughly the same as that for nickel. The data were fitted to a curve and over the range of $20-300 \mathrm{~K}$, the equation is:

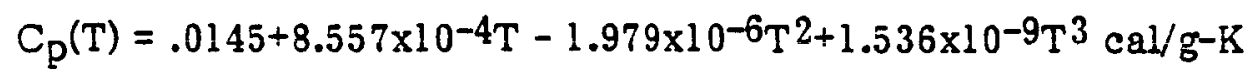

The average sensible heat capacity over the temperature range of $20-300 \mathrm{~K}$ is $0.070 \mathrm{cal} / \mathrm{g}-\mathrm{K}$.

The length of tubing is about 178 feet and the mass of metal per foot is $3.915 \mathrm{lbm} / \mathrm{ft}$ for Schedule 5, 4 inch pipe. Allowing $25 \%$ extra for supports, valve bodies and getter material, the mass used to determine the heat capacity was 870 $1 \mathrm{bm}$. The amount of energy needed to cool down this mass is $3.27 \times 10^{7}$ Joules. This amount is more than a factor of one hundred greater than the heat leak from ambient. Using the calculated heat capacity and the external heat gain, it would take about 2.8 days for the transfer lines to warm up to ambient temperature.

A calculation must be done to find the mass of liquid required to cool down the fill line and also find the time required to cool the line down. To find the 
time to cool down the line, it is assumed that the boiloff is so fast that choked flow is reached in the line, which is normally the case. The calculation is based on a 4 inch line with a discharge coefficient of 0.60 and a cross-sectional area of 0.020 sq. $\mathrm{ft}$. at the exit of the fill line. The equation for the velocity of the choked flow is:

$$
V=C_{d} \quad\left(\gamma g_{c} R T g\right)^{1 / 2}
$$

where:

$\mathrm{V}$ is the velocity, $\mathrm{m} / \mathrm{sec}$.

$\mathrm{C}_{\mathrm{d}}$ is the discharge coefficient, dimensionless

$Y$ is the ratio of $C_{p} / C_{v}$, dimensionless

$g_{c}$ is the gravity conversion coefficient, $\mathrm{m} / \mathrm{sec}^{2}$

$\mathrm{R}$ is the Gas Constant for hydrogen, $\mathrm{m}-\mathrm{Kg} / \mathrm{Kg}-^{\circ} \mathrm{K}$

$\mathrm{T}_{\mathrm{g}}$ is the average gas temperature, ${ }^{\circ} \mathrm{K}$

At 1.17 atmospheres pressure and $160 \mathrm{~K}$ the density of hydrogen is $16.77 \times 10^{-5} \mathrm{~g} / \mathrm{cc}$. The mass flow rate of hydrogen gas is therefore $.197 \mathrm{lbm} / \mathrm{sec}$ or $5.83 \times 103 \mathrm{gm} / \mathrm{min}$ at choked flow conditions. This is equivalent to $2.27 \times 10^{3} \mathrm{SCFM}$. The time that this flow is taking place is only for the amount of time that it takes to cool down the fill lines. Time to cool down the line is given by the following equation:

$$
t_{s s}=\left(\Sigma \dot{m}\left(T_{j}-T_{s s}\right) C_{p}-V\left(\rho_{s s}\left(\mu_{s s}-H_{f}\right)=\rho_{i}\left(\mu_{i}-H_{f}\right) /\left(m_{g}\left(H_{g}-H_{f}\right)-0.5 Q_{s s}\right)\right.\right.
$$

where:

$t_{S S}$ is the time to reach steady state, sec. 
$\sum \dot{m}\left(T_{i}-T_{s S}\right) C_{p}$ is the energy to cool down the fill line due to heat capacity, Joules

$V$ is the volume of the line, ce

$\rho_{S S}$ and $\rho_{i}$ are the steady state and initial densities in the line, $\mathrm{g} / \mathrm{cc}$

$u_{S S}$ and $u_{i}$ are the steady state and initial internal energies of the hydrogen, $\mathrm{J} / \mathrm{g}$

$\mathrm{H}_{\mathrm{f}}$ is the enthalpy of the hydrogen liquid at steady state, $\mathrm{J} / \mathrm{g}$

$\mathrm{m}_{\mathrm{g}}$ is the mass flow rate of hydrogen gas calculated at choked flow, $\mathrm{g} / \mathrm{sec}$

$\mathrm{H}_{\mathrm{g}}$ is the enthalpy calculated for the hydrogen gas at the average temperature in the line, $J / g$

Qss is the steady state heat gain, cal/sec.

It was assumed that the quality did not change very much for the liquid and was considered to be zero. Doing this, the states necessary to complete the above equation are:

$\rho_{\text {SS }}=.0663 \mathrm{~g} / \mathrm{cc}$ at 2.5 atm. sat. liquid

$\mathrm{H}_{\hat{f}}==219.6 \mathrm{~J} / \mathrm{g}$ at $2.5 \mathrm{~atm}$. sat. liquid

$u_{S S}=-223.4 \mathrm{~J} / \mathrm{g}$ at 2.5 atm. sat. liquid

$\rho_{\mathrm{i}} \quad=8.18 \times 10^{-5} \mathrm{~g} / \mathrm{cc}$ at $\mathrm{l}$ atm. and $300 \mathrm{~K}$

$u_{i} \quad=2.989 \times 10^{3} \mathrm{~J} / \mathrm{g}$ at 2.5 atm. and $160 \mathrm{~K}$

$\mathrm{Hg}_{\mathrm{g}}=2.012 \times 10^{3} \mathrm{~J} / \mathrm{g}$ at 2.5 atm. and $160 \mathrm{~K}$

Substituting these into the equation for time to reach steady state, the result is 1.47 minutes. 
One more equation is needed and that is the mass of liquid hydrogen needed to cool down the fill piping. It is as follows:

$$
M_{f} / M_{W}=C_{W}\left(T_{i}-T_{s s}\right) /\left(H_{g}-H_{f}\right)+V\left(\rho_{s s}-\rho_{i}\right) / M_{W}+Q_{s s} t_{s s} /\left(2 M_{W}\left(H_{g}-H_{f}\right)\right.
$$

where:

$M_{f} / M_{W}$ is the lbm of liquid hydrogen needed per lbm of metal

The rest of the terms are as above. Substituting the necessary values the mass of hydrogen needed per $\mathrm{lbm}$ of metal is $.209 \mathrm{lbm} \mathrm{H} / \mathrm{lbm}$ metal.

The pressurization of the dewar can be calculated from the saturation rule given on page $\mathbf{4 7 5}$ of Barron. Thus rule, especially for hydrogen is in error on the liberal side, but for lack of information, this rule will serve well enough since the time to pressurize is on the order of only a few minutes. The saturation rule is the difference in the volume times density at the initial and final states.

$$
\mathrm{V}_{\mathrm{g}}=\mathrm{V}_{\mathrm{g} 2} \rho_{\mathrm{g} 2}-\mathrm{V}_{\mathrm{gl}} \rho_{\mathrm{gl}}
$$

where $\mathrm{m}_{\mathrm{g}}$ is the change in mass of the gas from state 1 to 2

$V_{g 2}$ and $V_{g 1}$ are the volumes the gas occupies at states 1 and 2 respectively

$\rho_{\mathrm{g} 2}$ and $\rho_{\mathrm{g} l}$ are the densities of the gas at states 1 and 2 respectively

In terms of the number of gallons of the system, the volumes can be written as follows:

$$
\begin{aligned}
& V_{g 2}=1.13 \times 10^{5}-0.134 \mathrm{~V} \\
& V_{g 1}=1.13 \times 10^{5}-(V+55,000) 0.134
\end{aligned}
$$

where $\mathrm{V}$ is the initial volume of liquid in the dewar

The saturation rule can then be written as

$$
m_{g}=\left(1.13 \times 10^{5}-0.134 V\right) \rho_{g} 2-\left(1.13 \times 10^{5}-0.134(V+55,000)\right) \rho_{g} 1
$$


The time to pressurize can be determined by the maximum flow rate of liquid into the dewar as a function of the pressure drop. This is where much of the error comes in. The liquid must be able to flash entirely into vapor or be boiled off by heat transfer. The time to pressurize is given by

$$
\mathrm{t}=191.8 \mathrm{~m} \mathrm{~g} / \dot{Q}_{t}
$$

where:

$\dot{Q}_{t}$ is the volume flow rate based on the pressure drop, SCF M

Table II gives the results of the saturation rule for a pressure drop of 20 psig and pressurizing from 1 atm to 1.17 atm.

$\begin{array}{llcl}\text { Volume } & \text { Mass, Mg } & Q & \text { Tima } \\ \text { Gallon } & \text { ibm } & \text { SCF } & \text { Min } \\ 100,000 & 664 & 1.27 E 5 & 0.745 \\ 200,000 & 615 & 1.18 E 5 & 0.690 \\ 300,000 & 567 & 1.09 E 5 & 0.636 \\ 400,000 & 519 & 9.95 E 4 & 0.582 \\ 500,000 & 471 & 9.03 E 4 & 0.528 \\ 600,000 & 422 & 8.10 E 4 & 0.473 \\ 700,000 & 374 & 7.18 E 4 & 0.419 \\ 750,000 & 350 & 6.71 E 4 & 0.392\end{array}$

TABLE II Pressurization of the dewar from 1 atm at a pressure flow rate of 20 psig. 
Another contribution to the boiloff is the heat capacity of the dewar walls. On page 450 of Barron, an equation is given to determine the minimum thickness necessary for the walls of an elliptical shape. For a shpere, the minor diameter is the same as the major diameter. The equation for the thickness is:

$$
t_{h}=P D K /\left(2 S_{Q} E_{W}-0.2 P\right)
$$

where:

$P$ is the maximum operating pressure

$\mathrm{D}$ is the diameter, $\mathrm{ft}$.

$\mathrm{K}=0.167\left(2+(\mathrm{D} / \mathrm{Dl})^{1 / 2}\right)$ and $\mathrm{D} / \mathrm{Dl}$ is 1 for a sphere

$\mathrm{S}_{\mathrm{Q}}$ is the allowable stress, psi

$E_{W}$ is the weld efficiency, per cent

$P$ is assumed to be 75 psia, $D$ is $60.5 \mathrm{ft} . . S_{Q}$ is 18,750 , and $E_{W}$ is 100 . Substituting these values into the equation, one obtains for the minimum thickness of 0.71 in. Using the density of steel of $7.84 \mathrm{~g} / \mathrm{cc}$ and finding the net volume of the dewar wall, the mass of the inner wall is $9.3 \times 10^{8} \mathrm{gm}$.

An equation for the internal volume of a sphere as a function of the height from the bottom of the sphere and the radius of a sphere is:

$$
V=0.33 \pi^{2}(3 R-h)
$$

This equation can be written as a cubic equation in $\mathrm{h}$ with the radius as $30.25 \mathrm{ft}$. and $V$ in gallons, the equation is

$$
h^{3}-90.75 h^{2}+0.12766 V=0
$$

The surface area of the sphere at this height can also be written as a function of the radius and the height. It is 


$$
S=2 \pi R h
$$

Table III shows the amount of hydrogen boiled off as a function of the volume of liquid initially in the sphere. The calculations iterate to find the height necessary to solve the cubic equation and then the surface area is calculated. The net difference in going from one liquid level to another in increments of 50,000 gallons is given and the net surface area covered by liquid as it is filled to the next higher level is determined. The mass of steel knowing the wall thickness can then be calculated and the energy to cool it down $5 \mathrm{~K}$ is then arrived at. The mass of hydrogen boiled off can then be determined and the rate in SCF.M is taken over 60 minutes.

\begin{tabular}{|c|c|c|c|c|c|c|c|}
\hline$V, \quad 53$ & he $f l$. & $A_{1} P L_{2}$ & A, $P: 2$ & in steel, ge & Q, Joules & $\Rightarrow \quad H 2$ & SCFH \\
\hline 50,000 & 8.82 & 1676 & 1676 & 2.32E. & 2.957 & $3.25 E 4$ & 228 \\
\hline 100,000 & 12.80 & 2433 & 757 & $1.05 E 7$ & $1.31 E 7$ & $1.47 E 4$ & 103 \\
\hline 150,000 & 16.21 & 3043 & 610 & $8.46 E 6$ & $1.0 S E 7$ & $\therefore .13 E 4$ & 83 \\
\hline 200,800 & 18.84 & 3531 & 538 & $7.46 E 6$ & $9.33 E 3$ & $3.04 E 4$ & 73 \\
\hline 250,000 & 21.46 & 6079 & 498 & $6.91 E 6$ & $8.04 E 6$ & $9.67 E 3$ & 69 \\
\hline 300,000 & 23.94 & 4550 & 471 & $6.53 E 6$ & 8.1656 & $9.14 E 3$ & 64 \\
\hline 350,000 & 26.34 & 5006 & 456 & $6.33 E 6$ & $7.91 E 6$ & $8.36 E 3$ & 62 \\
\hline 400,000 & 28.68 & 5453 & 447 & $6.21 \mathrm{~Eb}$ & 7.7656 & $8.60 E 3$ & 61 \\
\hline 425,000 & 39.85 & 5673 & 220 & $3.05 E 6$ & $3.81 E 6$ & $4.27 E 3$ & 30 \\
\hline 450,000 & 31.02 & 5893 & 220 & $3.05 E 6$ & $3.81 E 6$ & $4.27 E 3$ & 30 \\
\hline 500,000 & 33.36 & 6340 & 447 & $0.21 E 6$ & 7.7 SES & 8.6053 & 61 \\
\hline 550,000 & 35.76 & 6796 & 456 & $6.33 E 6$ & $7.91 E 6$ & $8.85=3$ & 02 \\
\hline 500,000 & 38.24 & TZóó & $47:$ & ó.JjEó & Qิ. JóEO & $9.14 E J$ & of \\
\hline 650.000 & 40.86 & 7765 & 498 & $0.91 E 6$ & $8.64 E 6$ & $9: 67 E 3$ & 68 \\
\hline 700.000 & 43.69 & 8303 & 538 & $7.46 E 6$ & 9.3356 & $1.04 E 4$ & 73 \\
\hline 750,000 & 46.90 & 8913 & 610 & $8.46 E S$ & 1. OSE 7 & 1.1854 & 83 \\
\hline 800,000 & 50.88 & 9670 & 757 & $1.05 E 7$ & $1.31 E 7$ & $1.47 E 4$ & 103 \\
\hline 850,000 & 60.25 & 11340 & $157 t$ & $2.32 E 7$ & $2.90 \mathrm{E} ?$ & 3.2554 & 228 \\
\hline
\end{tabular}

TABLE III. Boiloff from cooling down the heat capacity of the dewar. 
The largest contribution to boiloff is from flashing of the higher pressure liquid to partial vapor in to the low pressure dewar. An example of how to determine this is given in Van Wylen and Sonntag on page 122. (6) The First Law of Thermodynamics is used to find the state of the hydrogen in the dewar. The calculations were done twice; once using MKS units and once using English units. The results would be identical except that for the English calculation, I used the viscosity value of $9.54 \times 10^{-6} \mathrm{lbm} / \mathrm{ft}-\mathrm{sec}$ obtained from Scott. (4) In the MKS calculation, I used a value of $1.07 \times 10^{-5} \mathrm{~Pa}$-sec taken from a graph reprinted from Chapter II of Technology and Uses of Liquid Hydrogen. (7) The value $1.07 \times 10^{-5} \mathrm{~Pa}-$ sec equals only $7.19 \times 10^{-6} \mathrm{lbm} / \mathrm{ft}-\mathrm{sec}$, and, therefore, the results do not agree exactly with each other. They are, however, in exact agreement when the friction factor is limited to a minimum value at high Reynold's numbers

The mass flow is given by: (8)

$$
m^{\bullet}=\left(\pi^{2} \rho \Delta P D^{5} / 8 f L\right)^{l / 2}
$$

Friction factors were needed in order to calculate the flow. Barron gives friction factor equations on page 135 for smooth pipes, but the equations he gives are only for Reynold's numbers less than $3 \times 10^{6}$. (4) The reason for limiting the range for the validity of the equations can be seen from an examination of charts of friction factor versus Reynold's number as in "Flow of Fluids through Valves, Fittings, and Pipe, Technical Paper No. 410," (Crane Company), pp. A-24 and A-25. (9)

For all pipes, the friction factor levels off to a constant value at high Reynold's numbers. This constant minumum value depends on the relative roughness of the pipe. For very smooth pipes such as drawn tubing, the minimum will be 0.0085 to 0.0095 for 4 inch tubing at Reynold's numbers of $3 \times 10^{8}$ and greater. But for commercial steel pipe, the minimum will be about 0.016 for Reynold's number greater than $2 \times 10^{6}$. If the pipe in question has the roughness of commercial steel rather than drawn tubing, the Reynold's numbers of the mass flow are in this "minimum value" range and Barron's friction factor equations are not valid.

The mass flows were calculated using several assumptions: 
1) The friction factor equations are valid for all Reynold's numbers,

2) the friction factor reaches a minimum value of 0.0098 at Reynold's numbers $>3$ $\mathrm{x} 10^{6}$,

3) The limiting minimum value is 0.016 instead of 0.0098 .

The analysis assumes that the hydrogen state point moves along the saturated-liquid curve as it is transferred, that is, the hydrogen is at the boiling point appropriate for the pressure at that location. We will assume that the tanker pressure is 22.5 psig and that the hydrogen enters the transfer line as a liquid (the quality or ratio of mass of vapor to the total mass flow is zero at the tanker end of the pipe). As the liquid flows along, the pressure falls, finally reaching 2.5 psig at the storage tank. Since the pressure falls, the boiling point decreases so some of the fluid becomes liquid at this new lower boiling point and lower enthalpy while part of it is vaporized to a gas, also at this new lower temperature but with an enthalpy greater by the heat of vaporization. There would be no net enthalpy change if there were not heat leak in the transfer line, no change in the potential energy of the gas, and no change in the velocity of fluid along its path.

If there are elevations, some of the pressure drop goes in to raising the potential energy of the fluid. We will show later that the heat leak of about $300 \mathrm{~W}$ causes little additional vaporization of the hydrogen as compared to the pressure drop itself. Finally, since part of the fluid does change to vapor in the pipe, the mean density of the exiting hydrogen is less than that of the entering hydrogen. Thus, to conserve mass flow, the hydrogen must exit at a higher velocity then it enters. The increase in kinetic energy required "uses up" some of the pressure drop and leads to less liquid going to vapor.

From Barron,

$$
x_{2}=\frac{\int_{1}^{2}\left(\frac{d h}{d P}\right) \text { sat } d P-\frac{v_{2}^{2}-v_{l}^{2}}{2}-g\left(Z_{2}-Z_{l}\right)+\frac{Q}{m}}{h_{f_{g} 2}}
$$


NOTE: I decided to use "V" for velocity and " $v$ " for specific volume

where:

$\mathrm{X}_{2}=$ quality of hydrogen at exit,

$\frac{d h}{d p}$ sat $=\quad$ change in enthalpy of the liquid for a change in pressure along the saturated-liquid curve,

$\mathrm{V}_{2} \quad=$ velocity of exiting vapor and liquid, $\mathrm{ft} / \mathrm{sec}$.

$v_{1} \quad=$ velocity of entering liquid, $\mathrm{ft} / \mathrm{sec}$

$\left(\mathrm{Z}_{2}-\mathrm{Z}_{1}\right)=$ net change in elevation, $\mathrm{ft}$.

$\dot{Q} \quad=$ heat leak into transfer line, BTU/hr.

$\dot{\mathrm{m}} \quad=$ mass flow rate, $\mathrm{lb} / \mathrm{hr}$.

$\mathrm{h}_{\mathrm{fg} 2}=$ latent heat of vaporization for conditions at exit, BTU/lb

In Figure 1, I have plotted (dh/dp) versus $\mathrm{P}$ for liquid hydrogen over the range of interest. The data are from NBS Monograph 94.(9). For this example, the transfer conditions $w$ ill be assumed to be $\mathrm{P}_{1}=22.5 \mathrm{psig}=2.53 \mathrm{~atm}, \mathrm{P}_{2}=2.5 \mathrm{psig}=1.17 \mathrm{~atm}$. There fore $\triangle P=20 \mathrm{psi}=1.361 \mathrm{~atm}$. The first term in the numerator is just the area under the $d h / d p$ curve over the region $1.17<\mathrm{P}<2.53$. This area was approximated by taking $\Delta P$ times the value of $\mathrm{dh} / \mathrm{dp}$ at the midpoint, $s 25.5 \mathrm{~J} / \mathrm{g}$ atm, giving $34.7 \mathrm{~J} / \mathrm{g}$.

We will assume net elevation changes to be zero. The velocity change can not yet be calcuated - we must iterate to get a final answer. $\dot{Q}=1000 \mathrm{BTU} / \mathrm{hr}=$ 293 Watts, so the last term in the numerator is $293 \mathrm{~W} / \mathrm{m}$. If $\dot{\mathrm{m}} \sim 8 \mathrm{~kg} / \mathrm{s}$, then $\dot{Q}=$ $0.04 \mathrm{~J} / \mathrm{s}$ and is completely negligible for this high mass flow rate.

Then, as a first approximation, 


$$
\mathrm{X}_{2}=\frac{34.7 \mathrm{~J} / \mathrm{g}}{443 \mathrm{~J} / \mathrm{g}}=0.0783
$$

If, however, $7.83 \%$ of the transferred mass flashes to vapor, the mean density of the exiting liquid and vapor will be much less than the density of the liquid entering the transfer line. In order to conserve mass flow, the velocity of the exiting fluid must be greater than that of the entering liquid.

$$
\rho_{2}=\stackrel{1}{v_{m} 2}=\frac{1}{\left(1-x_{2}\right)} \quad \frac{1}{v_{f} 2}-x_{2} v_{g} 2
$$

where:

$\mathrm{v}_{\mathrm{m} 2}=$ the mean specific volume at exit,

$v_{f 2} \quad=$ liquid specific volume at $P=2.5$ psig, $T=T_{\text {sat }}, 1 / \mathrm{kg}$

$v_{g 2}=$ vapor specific volume at exit conditions, $1 / \mathrm{kg}$

Thus

$$
\begin{aligned}
& \rho_{2}=\frac{1}{(0.9217)(14.254)+(0.0783)(652.9)}=\frac{1}{64.26} \mathrm{~g} / \mathrm{cm}^{3} \\
& \rho_{2}=0.01556 \mathrm{~g} / \mathrm{cm}^{3}=15.56 \mathrm{~g} / 1=15.56 \mathrm{~kg} / \mathrm{m}^{3}
\end{aligned}
$$

Since the initial density was $66.21 \mathrm{~kg} / \mathrm{m}^{3}$, the velocity change is larger.

As $v=\dot{m} /\left(\rho_{1} A\right), v_{1}=12.69 \mathrm{~m} / \mathrm{s}$ for a mass flow rate of $8 \mathrm{~kg} / \mathrm{s}$.

Thus $\quad v_{2}=\rho_{\rho_{2}}^{\rho_{1}} v_{1}=4.255 \mathrm{~V}_{1}=54 \mathrm{~m} / \mathrm{s}$

$$
\mathrm{v}_{2}^{2}-\mathrm{v}_{1}^{2}=1377 \mathrm{~J} / \mathrm{kg}=1.377 \mathrm{~J} / \mathrm{g} .
$$

The energy of $1.4 \mathrm{~J} / \mathrm{g}$ is required to increase the momentum of the fluid and is supplied by part of the pressure drop. There is then less energy available to 
provide the heat of vaporization of the liquid hydrogen.

Our second approximation is kthen,

$$
\mathrm{X}_{2}=\frac{34.7 \mathrm{~J} / \mathrm{g}-1.4 \mathrm{~J} / \mathrm{g}}{443 \mathrm{~J} / \mathrm{g}}=0.0752
$$

We proceed in this manner and obtain the results shown in Table IV. We see the result converges to 0.0754 in three iterations.

\begin{tabular}{|c|c|c|c|}
\hline Iteration & $\begin{array}{c}\text { Kinetic Energy Change } \\
(\mathrm{J} / \mathrm{g})\end{array}$ & $\left(\mathrm{kg}^{2} / \mathrm{m}^{3}\right)$ & $x_{2}$ \\
\hline $\begin{array}{l}0 \\
1 \\
2 \\
3\end{array}$ & $\begin{array}{l}0.00 \\
1.38 \\
1.29 \\
1.29\end{array}$ & $\begin{array}{l}66.21 \\
15.56 \\
16.06 \\
16.02\end{array}$ & $\begin{array}{l}0.0783 \\
0.0752 \\
0.0754 \\
0.0754\end{array}$ \\
\hline
\end{tabular}

TABLE IV: Results of iterative calculation for quality of hydrogen at exit.

\section{Discussion of flashing results}

The resuits show that the density of the exiting hydrogen is only $24 \%$ of the density of the entering fluid. The kinetic energy change required uses 4.85 psi of the 20 psi pressure drop. This implies that the mass flow calculations done in the first part of ther report could be greatly in error since, for a pressure drop of 20 psi, only $r 15$ psi are available to overcome the friction losses. But more importantly, the assumption that the flow could be calculated using only the properties of the fluid (density and viscosity) is invalid. In fact, whereas every gram of entering hydrogen consisted of $15.1 \mathrm{ce}$ of liquid, every gram of exiting hydrogen consists of only $13.2 \mathrm{cc}$ of liquid plus $49.2 \mathrm{cc}$ of vapor. Moreover, the flashing results depend on 
the validity of the homogeneous model which requires bubble flow. In the example in Barron the vapor was only about $20 \%$ of the exiting volume. In our case, it is nearly $80 \%$ of the exiting volume. The problem is really one of two-phase flow because of the large amount of flashing produced by the 20 psi pressure drop.

Since the mass flow and flashing results are mutually interdependent, the results obtained above are not completely valid. The effect of flashing is to reduce the mass flow rate. The effect of the mass flow rate on the amount of flashing is to increase the amount due to the heat leak in to the transfer line. Also, the kinetic energy term will be smaller, but as seen in Table IV, this is a small effect. Since the amount of flashing depends mostly on the total pressure drop (frictional pressure drop plus momentum pressure drop), this value will probably not change much as long as the 20 psi drop is maintained during the transfer and as long as the flow remains mixed, i.e., the liquid and vapor don't stratify.

If we use the average density, $41.12 \mathrm{~kg} / \mathrm{m}^{3}$, and assume the flow is stiu fully turbulent so that the friction factor has bottomed out at a value of 0.015 , then after a few iterations we find

$$
\begin{aligned}
& \rho_{2}=15.75 \mathrm{~kg} / \mathrm{m}^{3}, \rho_{\mathrm{Qvg}}=40.98 \mathrm{~kg} / \mathrm{m}^{3} \\
& \Delta \mathrm{P}(\text { frictional })=17.7 \mathrm{psi}, \Delta \mathrm{P} \text { (momentum) }=2.3 \mathrm{psi} \\
& \dot{\mathrm{m}}=5.40 \mathrm{~kg} / \mathrm{s}, \text { and } \mathrm{X}_{2}=0.0771
\end{aligned}
$$

Therefore $416 \mathrm{~g} / \mathrm{s}$ would be produced by flashing, corresponding to

$$
\frac{(416 \mathrm{~g} / \mathrm{s})(60 \mathrm{~s} / \mathrm{m})}{2.362 \mathrm{~g} / \mathrm{ft}^{3}}=10,570 \mathrm{SCFM}
$$

where a standard cubic foot is taken to be at 1 atm and $70^{\circ} \mathrm{F}$

If the flow stratifies, the vapor and liquid may exit at different velocities. To handle that situation one might attempt to write down a set of 
equations describing the flow at different segments along the length of the pipe and match the end points of each segment. In any case, the flowing hydrogen is going to undergo a pressure drop, so, for a 20 psig trop, $\varsigma 7 \%-8 \%$ of the mass of hydrogen leaving the tankers will arrive at the storage vessel as vapor. Knowing this, it is probably easier just to empirically determine the mass flow rate by measuring the time it takes to fill up the storage vessel. Then the rate at which gas will be vented during the transfer (as a result of flashing) can be calculated.

Note that these results are a worst case since the tankers arrive with a pressure of only 5-10 psig and are then pressurized into 22.5 psig. The hydrogen is, therefore, not on the saturation curve when the transfer begins but is instead at some temperature below the boiling point at $P=22.5$ psig. To compute the flashing losses one needs to plot $\mathrm{dh} / \mathrm{dP}$ versus $\mathrm{P}$ for the liquid in going from its bulk temperature in the tanker to its boiling point at 2.5 psig in the vessel.

As the transfer proceeds, the liquid hydrogen in the tanker will warm through heat inleak, and the flashing losses will increase. If the heat transfer through the tanker insulation is known, the time required for the hydrogen to reach the boiling point can be calculated. (The heat capacity of the liquid hydrogen is about $11 \mathrm{~J} /(\mathrm{g}-\mathrm{k})$ for the conditions in the tanker.)

The amount of liquid needed to cool down the transfer line depends upon what happens to the "hot" gas that exits the transfer line during this process. Perhaps there are valves which allow the gas to be vented directly until the transfer line is cold, and then the valves are reconfigured to allow the fluid to enter the storage vessel.

If this is not the case, then one must compute how much liquid hydrogen will be boiled off when the storage vessel is not empty. If it is empty, then the amount of hydrogen required to cool the storage vessel down must be computed. In the former case, the amount of hydrogen that will be evaporated by the hot gas arriving at the beginning of the transfer will depend on the details of the construction. If there is a phase separator or vapor diffuser, the warm gas will be directed away from the surface of the cold liquid so that it vents before transferring much of its heat to the liquid hydrogen already in the vessel. 
One of the last things needed to know in designing a hydride storage vessel is the temperature of the hydrogen entering the storage vessel. If the hydrogen is cold, this will provide some cooling to the storage beds. To find the temperature, the external heat gain from the ambient air must be calculated and equated to the heating of an equivalent mass of hydrogen.

Three resistances are needed to find the external heat transfer rate. They are the external heat transfer coefficient, the internal heat transfer coefficient, and the resistance due to the conductivity of the pipe. The external heat transfer coefficient is assumed to be $20 \mathrm{BTU} / \mathrm{hr}-\mathrm{sq}$.ft-F for lack of better information. This is about midrange for a natural convection coefficient. The internal coefficient is more difficult to estimate. Since it depends on the temperature at which the properties of the hydrogen gas exist. If the bulk temperature of the hydrogen gas is used, then curves, iterations, or tables of values must be made to find where the external heat transfer from ambient temperature equals the sensible heating of the hydrogen. This varies directly with the mass flow rate of the hydrogen.

The external heat transfer coefficient can be found from the following equation of the Nusselt Number:

$$
\mathrm{N}_{\mathrm{nu}}=0.021 \mathrm{~N}_{\mathrm{pr}}^{0.6} \mathrm{~N}_{\mathrm{re}}^{0.8}
$$

where:

$\mathrm{N}_{\mathrm{nu}}$ is the Nusselt number

$\mathrm{N}_{\mathrm{pr}}$ is the Prandtl number

and $\mathrm{N}_{\mathrm{re}}$ is the Reynold's number

The Nusselt number is equal to the heat transfer coefficient times the internal diameter of the pipe divided by the conductivity of the hydrogen gas. The Prandtl number for hydrogen is about 0.7 over a wide temperature range. Using this number and solving for the heat transfer coefficient: 


$$
h(t)=[0.01695 \mathrm{k}(\mathrm{t}) / \mathrm{D}][\mathrm{VD} / \mathrm{v}(\mathrm{t}) / \mu(\mathrm{t})] 0.8
$$

where:

$h(t)$ is the external heat transfer coefficient

$D$ is the diameter, $\mathrm{ft}$.

$k(t)$ is the conductivity of the hydrogen gas as a function of temperature

$V$ is the velocity of the hydrogen gas, $\mathrm{ft} / \mathrm{sec}$.

$v(t)$ is the specific volume of the hydrogen gas as a function of temperature, $\mathrm{ft}^{3} / \mathrm{bm}$

$\mu(t)$ is the viscosity of the hydrogen gas as a function of temperature, $1 \mathrm{bm} / \mathrm{ft}$-sec.

The external heat transfer is then equal to the following equation:

$Q=1.8(300-t) / 1 /(2 \pi 0.434 h(t) L)+1 /(2 \pi 0.441(20 L)+\ln (1.016) /(2 \pi k(t) L)$

Equations for the variables that are a function of temperature have been fitted to data using a least squares method. Since units for data varied, equations were fitted to the data as it was and then conversion factors were used in the final equation to get the correct result.

\begin{tabular}{|c|c|c|c|c|c|c|c|}
\hline $\begin{array}{l}\text { ianker } \\
\text { (Dsig) }\end{array}$ & $\begin{array}{l}\text { PorOp } \\
\text { (ps } 9)\end{array}$ & $\begin{array}{l}\text { Mass } \\
\text { Flou } \\
(10 \mathrm{~m} / \mathrm{s})\end{array}$ & $\begin{array}{l}\text { Mass } \\
\text { Flow } \\
(k g / s)\end{array}$ & $\begin{array}{l}\text { Density } \\
\text { (1omerez) }\end{array}$ & $\begin{array}{l}\text { Friezion } \\
\text { Facior }\end{array}$ & $\begin{array}{c}\text { Reynolos } \\
\text { Number }\end{array}$ & $(+2 / s)$ \\
\hline $\begin{array}{l}15.50 \\
16.50 \\
17.50 \\
18.50 \\
19.50 \\
29.58 \\
21.50 \\
22.50 \\
23.50 \\
24.50 \\
25.50 \\
26.58 \\
27.50 \\
28.50 \\
29.50 \\
30.50\end{array}$ & $\begin{array}{l}13.80 \\
14.00 \\
15.00 \\
16.00 \\
17.00 \\
18.08 \\
19.00 \\
20.00 \\
21.00 \\
22.00 \\
23.00 \\
24.00 \\
25.00 \\
26.00 \\
27.00 \\
28.00\end{array}$ & $\begin{array}{l}17.57 \\
18.25 \\
18.98 \\
19.53 \\
20.15 \\
28.74 \\
21.31 \\
21.87 \\
22.41 \\
22.94 \\
23.45 \\
23.95 \\
24.44 \\
24.92 \\
25.39 \\
25.84\end{array}$ & $\begin{array}{l}7.97 \\
8.28 \\
8.57 \\
8.96 \\
9.14 \\
9.41 \\
9.67 \\
9.92 \\
10.17 \\
18.40 \\
10.64 \\
10.87 \\
11.09 \\
11.30 \\
11.52 \\
11.72\end{array}$ & $\begin{array}{l}4.212 \\
4.281 \\
4.190 \\
4.179 \\
4.169 \\
4.158 \\
4.117 \\
4.136 \\
4.126 \\
4.115 \\
4.1104 \\
4.893 \\
4.083 \\
4.072 \\
4.061 \\
4.058\end{array}$ & $\begin{array}{l}0.0889 \\
0.0889 \\
0.0088 \\
0.0988 \\
0.0088 \\
8.0987 \\
0.0887 \\
0.0887 \\
1.0087 \\
0.0086 \\
0.0886 \\
0.0086 \\
0.0886 \\
0.0886 \\
0.0085 \\
0.0885\end{array}$ & $\begin{array}{l}6490,678 \\
6742245 \\
6984411 \\
7218048 \\
7443896 \\
7662590 \\
7874680 \\
8089645 \\
8280987 \\
8475838 \\
8653770 \\
8851080 \\
9031794 \\
9208394 \\
9381010 \\
9549865\end{array}$ & $\begin{array}{l}40.718 \\
42.396 \\
44.832 \\
45.522 \\
47.178 \\
48.582 \\
58.159 \\
51.685 \\
53.021 \\
54.411 \\
55.776 \\
57.118 \\
58.438 \\
59.738 \\
51.919 \\
62.282\end{array}$ \\
\hline
\end{tabular}

TABLE V. Result of calculation using English units. Friction factor fit assumed valid for all Reynold's numbers 


\begin{tabular}{|c|c|c|c|c|c|c|c|}
\hline Pe enker & $\begin{array}{l}\text { Pdrop } \\
\text { (psig) }\end{array}$ & $\begin{array}{c}\text { Mass } \\
\text { Flow } \\
(k g / s)\end{array}$ & $\begin{array}{c}\text { Mass } \\
\text { Flow } \\
(10 m-s)\end{array}$ & $\begin{array}{l}\text { Density } \\
(x g-m 3)\end{array}$ & $\begin{array}{l}\text { Friction } \\
\text { Factor }\end{array}$ & $\begin{array}{c}\text { Reynolas } \\
\text { Number }\end{array}$ & $\begin{array}{c}V e l o c i t y \\
(m / s)\end{array}$ \\
\hline $\begin{array}{l}14.50 \\
15.50 \\
16.50 \\
17.50 \\
18.50 \\
19.50 \\
28.50 \\
21.50 \\
22.58 \\
23.50 \\
24.50 \\
25.50 \\
26.50 \\
27.50 \\
28.50 \\
29.50 \\
30.58 \\
31.50 \\
32.50\end{array}$ & $\begin{array}{l}12.00 \\
13.00 \\
14.08 \\
15.00 \\
16.80 \\
17.08 \\
18.00 \\
19.00 \\
28.08 \\
21.00 \\
22.08 \\
23.08 \\
24.08 \\
25.80 \\
26.00 \\
27.00 \\
28.08 \\
29.08 \\
30.00\end{array}$ & $\begin{array}{l}7.781 \\
8.187 \\
8.420 \\
8.721 \\
9.811 \\
9.292 \\
9.564 \\
9.828 \\
18.884 \\
10.333 \\
10.576 \\
10.812 \\
11.042 \\
11.267 \\
11.486 \\
11.781 \\
11.918 \\
12.116 \\
12.317\end{array}$ & $\begin{array}{l}17.15 \\
17.87 \\
18.56 \\
19.23 \\
19.87 \\
28.49 \\
21.89 \\
21.67 \\
22.23 \\
22.78 \\
23.31 \\
23.84 \\
24.34 \\
24.84 \\
25.32 \\
25.80 \\
26.26 \\
26.71 \\
27.15\end{array}$ & $\begin{array}{l}67.637 \\
67.465 \\
67.293 \\
57.121 \\
66.948 \\
66.776 \\
66.684 \\
66.432 \\
66.259 \\
66.087 \\
65.915 \\
65.743 \\
65.570 \\
65.398 \\
65.226 \\
65.054 \\
64.881 \\
64.789 \\
64.537\end{array}$ & $\begin{array}{l}0.0086 \\
0.0086 \\
0.0886 \\
0.0885 \\
0.0885 \\
0.0085 \\
0.0884 \\
0.0084 \\
0.0884 \\
0.0084 \\
0.0084 \\
0.0083 \\
0.0083 \\
0.0883 \\
0.0083 \\
0.0083 \\
0.0083 \\
0.0082 \\
0.0082\end{array}$ & $\begin{array}{l}8,409,846 \\
8762248 \\
9108562 \\
9426193 \\
9748321 \\
10,043,945 \\
18337924 \\
10622998 \\
10899817 \\
11168948 \\
11430895 \\
11686107 \\
11934983 \\
12177884 \\
12415134 \\
12647830 \\
12873838 \\
13895805 \\
13313,155\end{array}$ & $\begin{array}{l}12.886 \\
12.625 \\
13.146 \\
13.651 \\
14.142 \\
14.621 \\
15.888 \\
15.544 \\
15.990 \\
16.428 \\
16.857 \\
17.279 \\
17.693 \\
18.181 \\
18.582 \\
18.897 \\
19.287 \\
19.672 \\
20.052\end{array}$ \\
\hline
\end{tabular}

TABLE VI. Result when the friction factor is not limited even though fit may not be valid, MKS units.

\begin{tabular}{|c|c|c|c|c|c|c|c|}
\hline$(p=10)$ & $\begin{array}{l}\text { Porop } \\
\text { (polg) }\end{array}$ & $\begin{array}{c}\text { Hass } \\
\text { Flow } \\
(100-8)\end{array}$ & $\begin{array}{l}\text { Mass } \\
\text { Flou } \\
\text { (kgos) }\end{array}$ & $\begin{array}{l}\text { Density } \\
\left(1 \mathrm{bm}+\mathrm{t}_{3}\right)\end{array}$ & $\begin{array}{l}\text { Friceton } \\
\text { Factor }\end{array}$ & $\begin{array}{c}\text { Reynolds } \\
\text { Hubber }\end{array}$ & $\begin{array}{r}\text { veloctiy } \\
\text { (recs) }\end{array}$ \\
\hline $\begin{array}{l}13.50 \\
16.50 \\
17.50 \\
18.50 \\
19.50 \\
20.50 \\
21.50 \\
22.50 \\
23.50 \\
24.50 \\
25.50 \\
26.50 \\
27.50 \\
28.50 \\
29.50 \\
30.50\end{array}$ & $\begin{array}{l}13.08 \\
14.00 \\
15.08 \\
16.08 \\
17.00 \\
18.00 \\
19.00 \\
28.00 \\
21.00 \\
22.08 \\
23.08 \\
24.08 \\
25.00 \\
26.08 \\
27.08 \\
28.00\end{array}$ & $\begin{array}{l}16.72 \\
17.33 \\
17.91 \\
18.48 \\
19.82 \\
19.55 \\
28.06 \\
28.55 \\
21.83 \\
21.58 \\
21.95 \\
22.39 \\
22.83 \\
23.25 \\
23.66 \\
24.06\end{array}$ & $\begin{array}{l}7.58 \\
7.96 \\
8.12 \\
8.38 \\
8.63 \\
8.87 \\
9.10 \\
9.32 \\
9.54 \\
9.75 \\
9.96 \\
10.16 \\
10.35 \\
10.54 \\
10.73 \\
10.91\end{array}$ & $\begin{array}{l}4.212 \\
4.281 \\
4.198 \\
4.179 \\
4.169 \\
4.158 \\
4.147 \\
4.136 \\
4.126 \\
4.115 \\
4.184 \\
4.093 \\
4.083 \\
4.072 \\
4.061 \\
4.058\end{array}$ & $\begin{array}{l}0.0098 \\
0.0098 \\
0.0098 \\
0.0098 \\
0.0098 \\
0.0098 \\
0.0098 \\
0.0098 \\
0.0098 \\
0.0098 \\
0.0098 \\
0.0098 \\
0.0898 \\
0.0098 \\
0.0898 \\
0.0098\end{array}$ & $\begin{array}{l}6,177,996 \\
6483029 \\
6619267 \\
6827572 \\
7828641 \\
7223078 \\
7411485 \\
7594877 \\
7771493 \\
7944084 \\
8111923 \\
3275331 \\
8435877 \\
8590789 \\
8742871 \\
8891510\end{array}$ & $\begin{array}{r}38.746 \\
48.268 \\
41.727 \\
43.151 \\
44.536 \\
45.886 \\
47.285 \\
48.494 \\
49.756 \\
56.994 \\
52.288 \\
53.481 \\
54.574 \\
55.728 \\
56.865 \\
57.985\end{array}$ \\
\hline
\end{tabular}

Table VII: Friction factor limited to values of 0.0098 or larger. In English units. 


\begin{tabular}{|c|c|c|c|c|c|c|c|}
\hline$(p=1 g)$ & $(p \operatorname{ig})$ & $\begin{array}{l}\text { Mass } \\
\text { Flow } \\
(k 0 / s)\end{array}$ & $\begin{array}{c}\text { Mass } \\
\text { F1ou } \\
\text { ( I bmos ) }\end{array}$ & $\begin{array}{l}\text { Density } \\
(k 0 / m 3)\end{array}$ & $\begin{array}{l}\text { Friction } \\
\text { Factor }\end{array}$ & $\begin{array}{c}\text { Reynolds } \\
\text { Number }\end{array}$ & $\begin{array}{c}Y e l o c i t y \\
(n / s)\end{array}$ \\
\hline $\begin{array}{l}14.50 \\
15.50 \\
16.50 \\
17.50 \\
18.50 \\
19.50 \\
20.50 \\
21.50 \\
22.50 \\
23.50 \\
24.50 \\
25.50 \\
26.50 \\
27.50 \\
28.50 \\
29.50 \\
30.50 \\
31.50 \\
32.50\end{array}$ & $\begin{array}{l}12.00 \\
13.00 \\
14.80 \\
15.00 \\
16.80 \\
17.80 \\
18.00 \\
19.80 \\
28.00 \\
21.00 \\
22.00 \\
23.80 \\
24.80 \\
25.80 \\
26.80 \\
27.80 \\
28.00 \\
29.80 \\
30.00\end{array}$ & $\begin{array}{l}7.295 \\
7.583 \\
7.868 \\
8.125 \\
8.381 \\
8.627 \\
8.866 \\
9.897 \\
9.322 \\
9.539 \\
9.751 \\
9.957 \\
10.158 \\
10.354 \\
10.545 \\
10.732 \\
10.914 \\
11.093 \\
11.267\end{array}$ & $\begin{array}{l}16.88 \\
16.72 \\
17.33 \\
17.91 \\
18.48 \\
19.82 \\
19.55 \\
28.06 \\
20.55 \\
21.83 \\
21.58 \\
21.95 \\
22.39 \\
22.83 \\
23.25 \\
23.66 \\
24.86 \\
24.45 \\
24.84\end{array}$ & $\begin{array}{l}67.637 \\
67.465 \\
67.293 \\
67.121 \\
66.948 \\
66.776 \\
66.604 \\
66.432 \\
66.259 \\
66.887 \\
65.915 \\
65.743 \\
65.578 \\
65.398 \\
65.226 \\
65.854 \\
64.881 \\
64.709 \\
64.537\end{array}$ & $\begin{array}{l}0.0098 \\
0.0098 \\
0.0098 \\
0.0098 \\
0.0098 \\
0.0098 \\
0.0098 \\
0.0098 \\
0.0098 \\
0.0098 \\
0.0098 \\
0.0098 \\
0.0098 \\
0.0098 \\
0.0098 \\
0.0098 \\
0.0098 \\
0.0098 \\
0.0098\end{array}$ & $\begin{array}{l}7,885622 \\
8197158 \\
8495727 \\
9782651 \\
9059037 \\
9325821 \\
9583806 \\
9833685 \\
19076959 \\
18311468 \\
18540353 \\
10763154 \\
10988233 \\
11191925 \\
11398528 \\
11680315 \\
11797533 \\
11998488 \\
12179145\end{array}$ & $\begin{array}{l}11.332 \\
11.818 \\
12.271 \\
12.718 \\
13.152 \\
13.575 \\
13.986 \\
14.388 \\
14.781 \\
15.166 \\
15.543 \\
15.913 \\
16.277 \\
16.634 \\
16.986 \\
17.332 \\
17.674 \\
18.611 \\
18.343\end{array}$ \\
\hline
\end{tabular}

TABLE VII: Result when the friction factor is limited to values of 0.0098 or greater, in ivi $\mathrm{KS}$ units.

\begin{tabular}{|c|c|c|c|c|c|c|c|}
\hline Pqanker & $(p=i g)$ & $\begin{array}{l}\text { Mass } \\
\text { Flow } \\
\text { (10mes) }\end{array}$ & $\begin{array}{c}\text { Mass } \\
F \mid \text { ou } \\
\text { (kg/s) }\end{array}$ & $\begin{array}{l}\text { Density } \\
(10 m / r+3)\end{array}$ & $\begin{array}{l}\text { Frietion } \\
\text { Factor }\end{array}$ & $\begin{array}{l}\text { Reynolas } \\
\text { Number }\end{array}$ & $\begin{array}{r}\text { Veloctisy } \\
\text { eftes }\end{array}$ \\
\hline $\begin{array}{l}15.50 \\
16.50 \\
17.50 \\
18.50 \\
19.50 \\
20.58 \\
21.50 \\
22.58 \\
23.58 \\
24.56 \\
25.50 \\
26.58 \\
27.50 \\
28.58 \\
29.58 \\
30.58\end{array}$ & $\begin{array}{l}13.00 \\
14.00 \\
15.80 \\
16.80 \\
17.80 \\
18.08 \\
19.08 \\
28.08 \\
21.08 \\
22.08 \\
23.08 \\
24.08 \\
25.08 \\
26.08 \\
27.80 \\
28.08\end{array}$ & $\begin{array}{l}13.18 \\
13.58 \\
14.84 \\
14.48 \\
14.91 \\
15.32 \\
15.72 \\
16.11 \\
16.48 \\
16.85 \\
17.21 \\
17.55 \\
17.89 \\
18.22 \\
18.54 \\
18.86\end{array}$ & $\begin{array}{l}5.94 \\
6.16 \\
6.37 \\
6.37 \\
6.76 \\
6.95 \\
7.13 \\
7.31 \\
7.48 \\
7.64 \\
7.80 \\
7.96 \\
8.12 \\
8.27 \\
0.41 \\
8.55\end{array}$ & $\begin{array}{l}4.212 \\
4.281 \\
4.198 \\
4.179 \\
4.169 \\
4.158 \\
4.147 \\
4.136 \\
4.126 \\
4.115 \\
4.104 \\
4.093 \\
4.083 \\
4.872 \\
4.061 \\
4.850\end{array}$ & $\begin{array}{l}0.0160 \\
0.0160 \\
0.0160 \\
0.0160 \\
0.0160 \\
0.0160 \\
0.0160 \\
0.0160 \\
0.0160 \\
0.0160 \\
0.0160 \\
0.0160 \\
0.0160 \\
0.0160 \\
0.0160 \\
0.0160\end{array}$ & $\begin{array}{l}4,842323 \\
5818697 \\
5188193 \\
5351463 \\
5509061 \\
5661461 \\
5809872 \\
5952251 \\
6891389 \\
6226523 \\
6358139 \\
6486375 \\
6611428 \\
6733475 \\
6852677 \\
6,969,188\end{array}$ & $\begin{array}{l}38.369 \\
31.556 \\
32.706 \\
33.822 \\
34.987 \\
35.966 \\
36.999 \\
38.919 \\
38.999 \\
39.969 \\
40.921 \\
41.856 \\
42.775 \\
43.680 \\
44.571 \\
45.449\end{array}$ \\
\hline
\end{tabular}

TABLE IX: Friction factor limited to values of 0.016 or larger in English Units. 


\begin{tabular}{|c|c|c|c|c|c|c|c|}
\hline $\begin{array}{c}\text { Pt anker } \\
(p \leq \mid g)\end{array}$ & $(p<10)$ & $\begin{array}{c}\text { Mass } \\
\text { Flow } \\
\text { (kors) }\end{array}$ & $\begin{array}{c}\text { Hass } \\
\text { Fiow } \\
(1 \mathrm{bm} / \mathrm{s})\end{array}$ & $(k g / n 3)$ & $\begin{array}{l}\text { Friction } \\
\text { Factor }\end{array}$ & $\begin{array}{l}\text { Reynolds } \\
\text { Number }\end{array}$ & $(n-5)$ \\
\hline $\begin{array}{l}14.58 \\
15.50 \\
16.58 \\
17.50 \\
10.50 \\
19.50 \\
20.50 \\
21.50 \\
22.50 \\
23.50 \\
24.50 \\
25.58 \\
26.58 \\
27.58 \\
28.58 \\
29.58 \\
30.50 \\
31.50 \\
32.50\end{array}$ & $\begin{array}{l}12.00 \\
13.00 \\
14.00 \\
15.00 \\
16.00 \\
17.00 \\
18.00 \\
19.00 \\
20.00 \\
21.08 \\
22.00 \\
23.00 \\
24.08 \\
25.00 \\
26.00 \\
27.00 \\
28.00 \\
29.00 \\
38.00\end{array}$ & $\begin{array}{l}5.718 \\
5.944 \\
6.168 \\
6.368 \\
6.369 \\
6.762 \\
6.949 \\
7.138 \\
7.306 \\
7.477 \\
7.643 \\
7.804 \\
7.962 \\
8.115 \\
8.265 \\
8.411 \\
8.554 \\
8.694 \\
8.831\end{array}$ & $\begin{array}{l}12.61 \\
13.19 \\
13.58 \\
14.84 \\
14.48 \\
14.91 \\
15.32 \\
15.72 \\
16.11 \\
16.48 \\
16.85 \\
17.21 \\
17.55 \\
17.89 \\
18.22 \\
18.54 \\
18.96 \\
19.17 \\
19.47\end{array}$ & $\begin{array}{l}67.637 \\
67.465 \\
67.293 \\
67.121 \\
66.948 \\
66.776 \\
66.684 \\
66.432 \\
66.259 \\
66.087 \\
65.915 \\
65.743 \\
65.578 \\
65.398 \\
65.226 \\
65.854 \\
64.881 \\
64.799 \\
64.537\end{array}$ & $\begin{array}{l}0.0160 \\
0.0160 \\
0.0160 \\
0.0160 \\
0.0160 \\
0.0160 \\
0.0160 \\
0.0160 \\
0.0160 \\
0.0160 \\
0.0160 \\
0.0160 \\
0.0160 \\
0.0160 \\
0.0160 \\
0.0160 \\
0.0160 \\
0.0160 \\
0.0160\end{array}$ & $\begin{array}{l}6,188,764 \\
6424946 \\
6658965 \\
6883856 \\
7108488 \\
7389594 \\
7511804 \\
7787559 \\
7897632 \\
8882139 \\
8261546 \\
8436178 \\
8696325 \\
8772249 \\
8934185 \\
9892346 \\
9246926 \\
9398182 \\
9546934\end{array}$ & $\begin{array}{l}8.882 \\
9.257 \\
9.618 \\
9.969 \\
10.399 \\
18.640 \\
10.962 \\
11.277 \\
11.385 \\
11.887 \\
12.183 \\
12.473 \\
12.758 \\
13.038 \\
13.314 \\
13.585 \\
13.853 \\
14.117 \\
14.377\end{array}$ \\
\hline
\end{tabular}

TABLE X: Result when the friction factor is limited to values of 0.016 or greater. MKS units. 


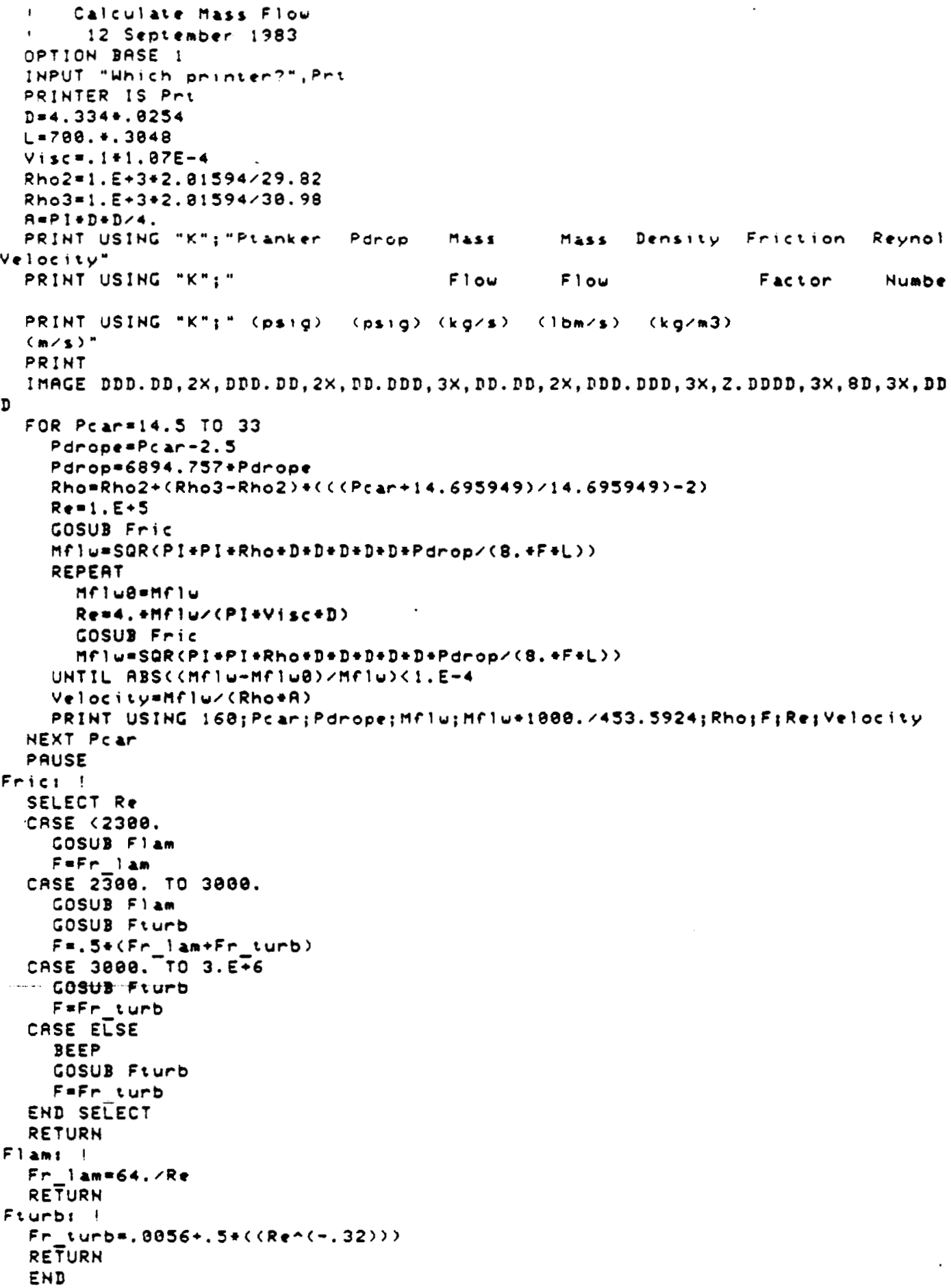

TABLE XI: Computer listing of program to calculate data presented in Tables $V$ through X (MKS Units Version), 


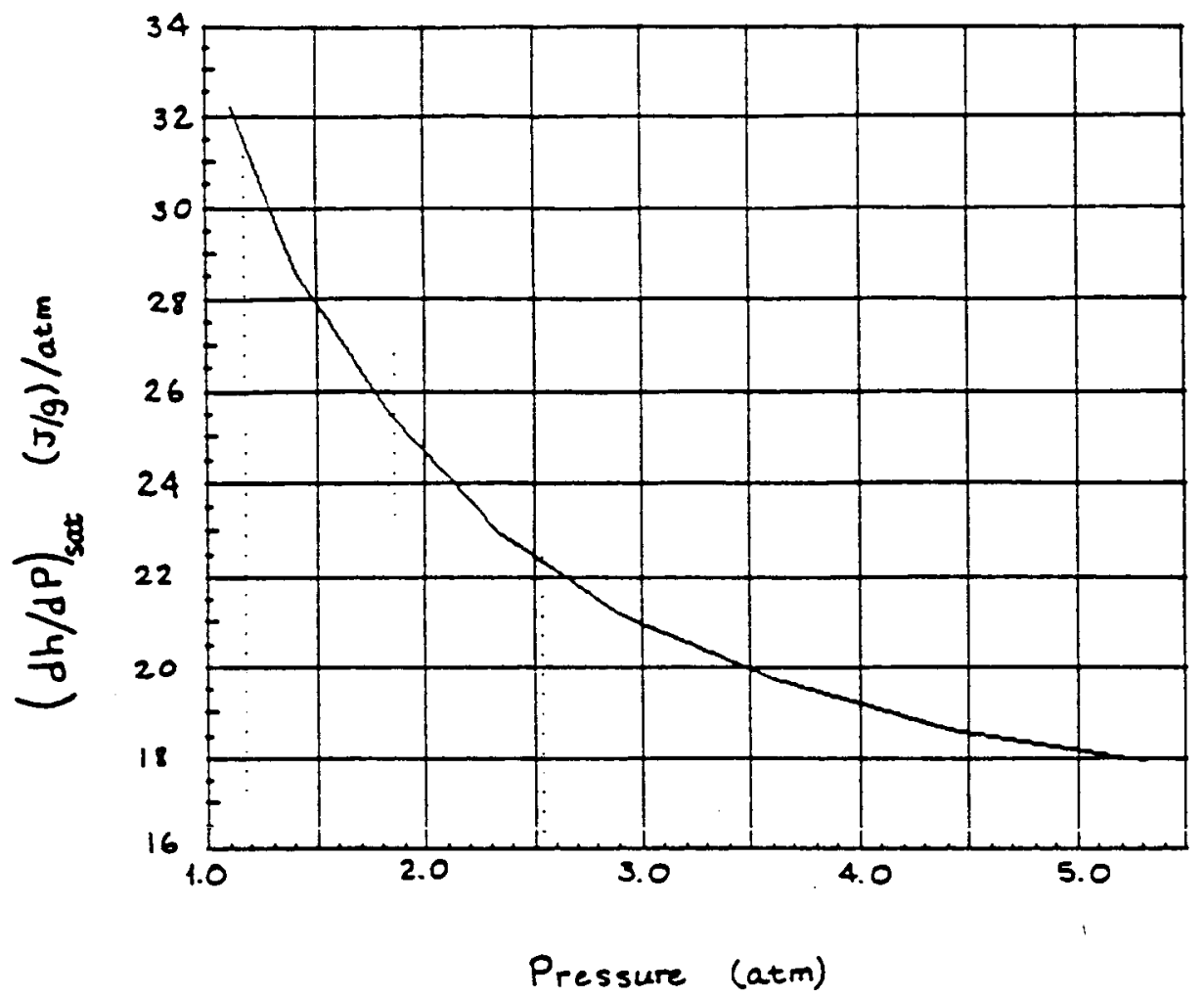

Fig. 1. $\left(\frac{d h}{d P}\right)_{\text {sat }}$ as a function of pressure.

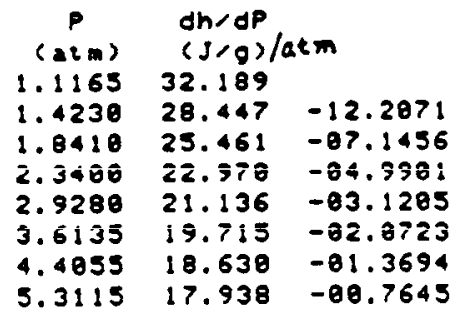

Data Plotted in Fig. 1.

FIGURE 1: Rate of change of enthalpy as a function of pressure differential. 
Finally, the external heat transfer must be equal to the sensible heating of the hydrogen. The equation for the sensible Heat $Q_{S}$ of the hydrogen is:

$$
M_{g} C p(t)(t-30)
$$

where $\mathrm{M}_{\mathrm{g}}$ is the mass flow rate of hydrogen

$C_{p}(t)$ is the heat capacity of the hydrogen gas as a function of temperature

The following table summarizes the results. Most flows will be in the range of 1 to $1.5 \mathrm{lbm} / \mathrm{sec}$. The temperature increase of the hydrogen for various lengths are given in Table XI.

$\begin{array}{lcc}\begin{array}{l}\text { Mass } \\ \text { Flow } \\ \text { Lbm/sec }\end{array} & \begin{array}{c}\text { Distance from } \\ \text { Dewar } \\ \mathrm{Ft} .\end{array} & \begin{array}{c}\text { Temperature } \\ \text { Rise } \\ \text { OK }\end{array} \\ 1.0 & 100 & 15.2 \\ 1.0 & 200 & 33.5 \\ 1.0 & 300 & 51.2 \\ 1.0 & 400 & 67.0 \\ 1.0 & 500 & 79.5 \\ 1.5 & 100 & 11.8 \\ 1.5 & 200 & 24.5 \\ 1.5 & 300 & 38.3 \\ 1.5 & 400 & 52.0 \\ 1.5 & 500 & 63.5\end{array}$

TABLE XII: Temperature increase of vented hydrogen due to external heat transfer from the ambient air. 
The total flow rate of hydrogen vented comes from the boiloff from heating up the sphere, ullage displacement, and flashing. Ullage displacement has not been calculated yet. It may be determined by the mass flow rate of liquid into the dewar and using the density of the liquid, determining the volume displacement rate. Using the density of the vapor leaving the dewar and the volume displacement rate, the mass flow rate of vapor leaving the dewar due to displacement can be calculated and an equivalent SCFM found.

\begin{tabular}{|c|c|c|c|c|}
\hline $\begin{array}{l}\text { Dewar } \mathrm{LH}_{2} \text { Level } \\
\text { Gallons }\end{array}$ & $\begin{array}{l}\text { Sphere } \\
\text { Sensible Heat } \\
\text { Boil-off }\end{array}$ & $\begin{array}{l}\text { SCFM } \times 10^{3} \\
\text { Ullage }\end{array}$ & $\begin{array}{l}\text { SCFM } \times 10^{3} \\
\text { Flashing }\end{array}$ & $\begin{array}{l}\text { Total Boil-off } \\
\text { SCFM10 }\end{array}$ \\
\hline 50,000 & 228 & 1.903 & 5.886 & 7.783 \\
\hline 100,000 & 103 & 2.002 & 6.196 & 8.192 \\
\hline 150,000 & 83 & 2.056 & 6.406 & 8.456 \\
\hline 200,000 & 73 & 2.090 & 6.706 & 8.790 \\
\hline 250,000 & 68 & 2.115 & 6.856 & 8.965 \\
\hline 300,000 & 64 & 2.131 & 7.136 & 9.261 \\
\hline 350,000 & 62 & 2.145 & 7.336 & 9.475 \\
\hline 400,000 & 51 & 2.153 & 7.456 & 9.603 \\
\hline 450,000 & 60 & 2.163 & 7.496 & 9.653 \\
\hline 500,000 & 61 & 2.169 & 7.636 & 9.799 \\
\hline 550,000 & 62 & 2.185 & 7.686 & 9.855 \\
\hline 600,000 & 64 & 2.189 & 7.716 & 9.889 \\
\hline & 68 & 2.183 & 7.886 & 10.063 \\
\hline 700,000 & 73 & 2.187 & 7.896 & 10.077 \\
\hline 750,000 & 83 & 2.191 & 7.756 & 9.941 \\
\hline 800,000 & 103 & 2.193 & 7.606 & 9.793 \\
\hline
\end{tabular}

TABLE XIII: Shows the contribution of each of the terms to the boiloff for a dewar at 2.5 psig and line pressure of $22 . \bar{j}$ psig. 


\section{REFERENCES}

1. ASHRAE Handbook of Fundamentals, 1972 Edition.

2. Cryogenic Systems, Barron, McGraw Hill Series in Mechanical Engineering, 1966, p. 517.

3. Cryogenic Engineering, Scott, Van Nostrand, 1959, p. 306.

4. Convective Heat and Mass Transfer, VeGraw Hill, 1966.

5. Handbook of Chemistry and Physics, 41 st Edition.

6. Fundamentals of Classical Thermodynamics, Van Wylen, Gordon and Sonntag, John Wiley and Sons, Inc.

7. Technology and Use of Liquid Hydrogen, Chapter 11.

8. Experimental Techniques in Low Temperature Physics, White, Guy.K., p. 59.

9. Flow of Fluids through Valves, Fittings and Pipe, Technical Paper. No. 410, Crane Company, pp. A-24 and A-25. 
STANDARD TITLE PAGE

\begin{tabular}{|c|c|}
\hline 2. Government Accession No. & 3. Recipient's Catalog Na. \\
\hline \multirow{2}{*}{$\begin{array}{l}\text { 4. Title and Subtitle } \\
\text { Capture of Liquid Hydrogen } \\
\text { Boiloff with Metal Hydride Absorbers }\end{array}$} & $\begin{array}{l}\text { 5. Report Date } \\
\text { Apr i } 1984\end{array}$ \\
\hline & 6. Performing Organization Code \\
\hline$\ddot{M}$. Author(s) & 8. Performing Organization Report No. \\
\hline \multirow{3}{*}{$\begin{array}{l}\text { 9. Performing Organization Name and Address } \\
\text { Ergenics, Inc. } \\
\text { Wykoff, New Jersey }\end{array}$} & 10. Work Unit No. \\
\hline & $\begin{array}{l}\text { 11. Contract or Grant No. } \\
\text { NAS10-10625 }\end{array}$ \\
\hline & 13. Type of Report and Period Coyered \\
\hline \multirow{2}{*}{$\begin{array}{l}\text { 12. Sponsoring Agency Name and Address } \\
\text { National Aeronautics and Space Administration } \\
\text { John F. Kennedy Space Center, FL }\end{array}$} & \\
\hline & $\begin{array}{c}\text { 14. Sponsoring Agency Code } \\
\text { DD-MED }\end{array}$ \\
\hline
\end{tabular}

15. Abstract

Standard operating procedure at the Kennedy Space Center (KSC) for the Space

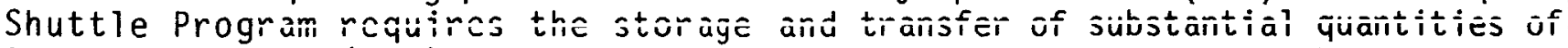
liquid hydrogen $\left(\mathrm{LH}_{2}\right)$. Vaporized liquid, routinely lost during these transfer operations, is vented to the atmosphere or burned in the burn pond, and represents a significant fraction of the total hydrogen-fuel used for each launch. This report described a procedure which uses metal hydrides to capture some of this low pressure (less than $1 \mathrm{psig}$ ) hydrogen for subsequent reliquefaction. Of the five normally occurring sources of boil-off vapor the stream associated with the offloading of liquid tankers during dewar refill was identified as the most cost effective and readily recoverable. The design, fabrication and testing of a proof-of-concept capture device, operating at a rate that is commensurate with the evolution of vapor by the target stream, is described. Liberation of the captures hydrogen gas as pressures greater than 15 psig at normal temperatures (typical liquefier compressor suction pressure) are also demonstrated. A payback time of less than three years is projected.

16. Key Words

Metal Hydrides, Absorption, Poisoning, Boiloff, Isotherm, Kinetics

17. Bibliographic Control

Unclassified
18. Distribution

Unclassified-Unlimited

Subject Category 28 